Distribution Category:

Defense Waste Management

(UC-721)

ANL- $-92 / 26$

ANL-92/26

DE93 006825

ARGONNE NATIONAL LABORATORY

9700 South Cass Avenue

Argonne, IL $60439-4837$

THE USE OF A CENTRIFUGAL CONTACTOR FOR COMPONENT CONCENTRATION BY SOLVENT EXTRACTION

by

R. A. Leonard, D. G. Wygmans, M. J. McElwee, M. O. Wasserman, and G. F. Vandegrift

Chemical Technology Division

July 1992 


\section{TABLE OF CONTENTS}

Page

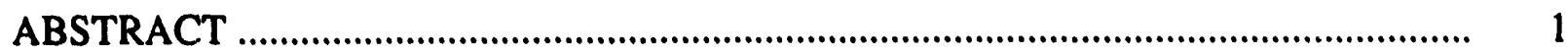

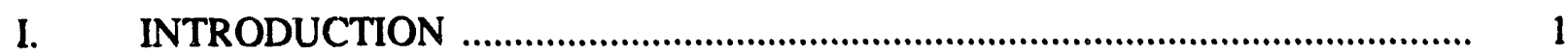

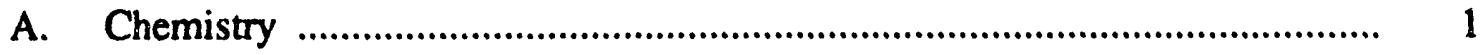

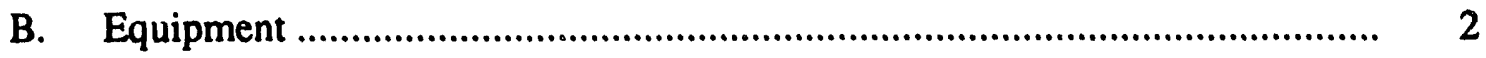

C. Description of the Contactor ............................................................................ 3

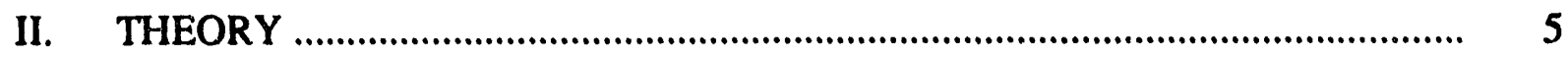

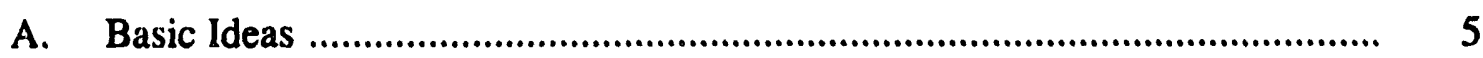

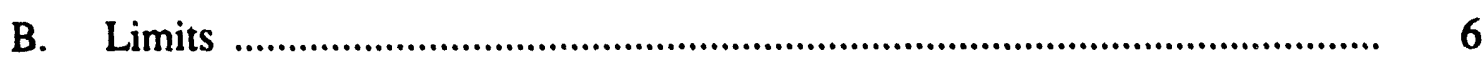

1. Other-Phase Carryover ………………........................................................ 6

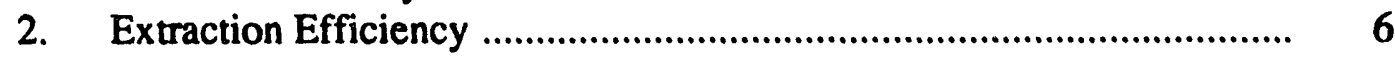

C. Concentrator Design ...................................................................................... 7

1. Basic Configuration ..................................................................... 7

2. Design Variables ............................................................................... 8

3. Model Analysis ....................................................................................... 10

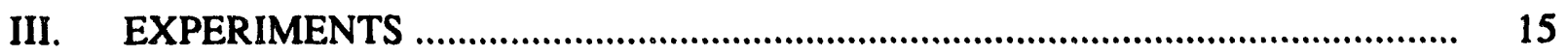

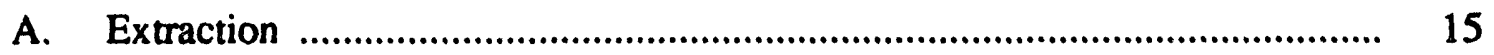

1. Preliminary Considerations .............................................................. 15

2. Concentrator Tests ..................................................................... 18

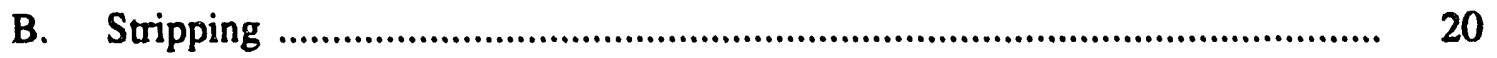

1. Preliminary Considerations ............................................................ 20

2. Concentrator Tests ............................................................................. 25

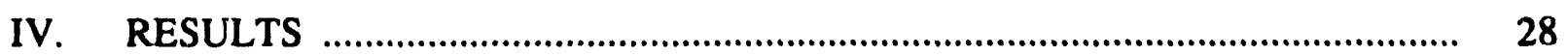

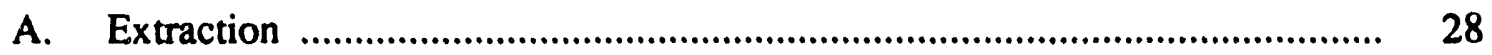

1. Neodymium Concentrations ............................................................. 28

2. Extraction Efficiency ...................................................................... 28

B. Stripping …................................................................................ 32

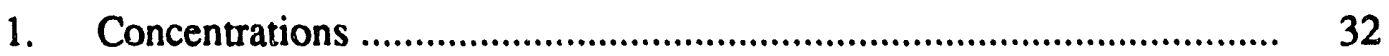

2. Distribution Ratio Values ............................................................. 35

3. Calculated Flow Rates ........................................................................ $\quad 35$

4. Quasi-Steady State .............................................................................. 36 
5. Extraction Efficiencies ..................................................................... $\quad 36$

C. Correlation for Extraction Efficiency ………........................................... 37

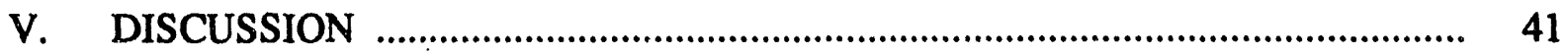

A. Effect of O/A Flow Ratio on Extraction Efficiency ........................................ 41

B. Precipitate Formation ................................................................................ 41

C. Solids Concentrator .................................................................................. 42

D. Additional Notes on Concentrator Design and Operation ............................. 43

E. Extractant Recovery .................................................................................... 43

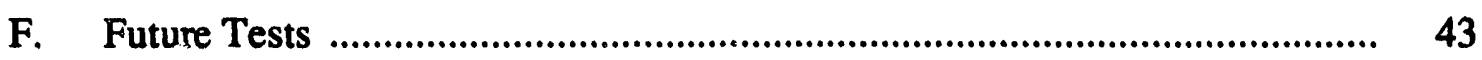

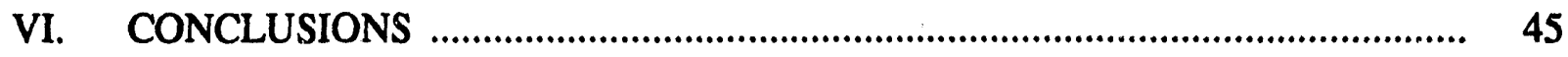

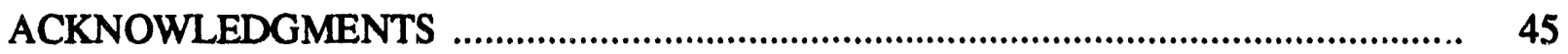

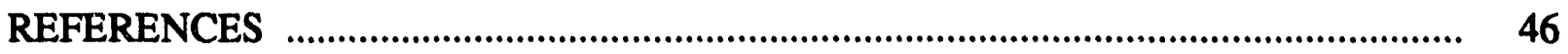

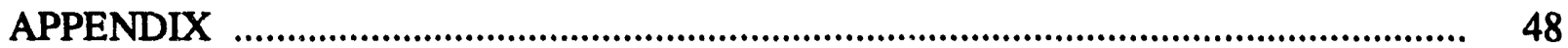




\section{LIST OF FIGURES}

Ne. Title

1. Schematic of an Operating Centrifugal Contactor of the Argonne Design .............. 3

2. Flowsheet for a Concentrator with Eight Contactor Stages ........................................ 8

3. Effect of Organic Recycle on Neodymium Concentration Profiles in the 8-Stage Concentrator

4. Effect of $1 \%$ Other-Phase Carryover on Neodymium Concentration Profiles in the 8-Stage Concentrator

5. Effect of $70 \%$ Extraction Efficiency on Neodymium Concentration Profiles in the 8-Stage Concentrator

6. Effect of 35\% Other-Phase Carryover in the Low Flow Streams on Neodymium Concentration Profiles in the 8-Stage Concentrator

7. Effect of Throughput on the Organic-Phase Volume in One Stage of a 4-cm Contactor at an O/A Flow Ratio of 0.01

8. Flowsheet for Single-Stage Concentrator Tests at O/A of 0.01

9. Flowsheet for Two-Stage Contactor Test

10. Flowsheet for the Two-Stage Concentrator Test with Solvent Recycle

11. Flowsheet for the Two-Stage Concentrator Test without Solvent Recycle ............. 38

12. Overall Correlation of O/A Flow Ratio with Extraction Efficiency ....................... 40

13. Input and Summary Areas of the Two_Stage Worksheet ......................................... 49

14. Calculation Area of the Two_Stage Worksheet ....................................................... 50

15. Flowsheet Area of the Two_Stage Worksheet ...................................................... 51

16. Formulas for Top Part of Stage 1 in the Two_Stage Worksheet ............................ 52

17. Formulas for Bottom Part of Stage 1 in the Two_Stage Worksheet ....................... 53

18. Formulas for Top Part of Stage 2 in the Two_Stage Worksheet .............................. 54

19. Formulas for Bottom Part of Stage 2 in the Two_Stage Worksheet ........................ 55 


\section{LIST OF FIGURES}

No. Title Page

20. Formula for Limit Section of the Two_Stage Worksheet ...................................... 56

21. Formulas for Flowsheet in Two_Stage Worksheet ............................................... 57 


\section{LIST OF TABLES}

Ne.

Title

Page

1. Effect of O/A Flow Ratio on Total Stages Required .............................................. 9

2. Summary of SASSE Model Evaluation .......................................................... 11

3. Summary of Data from Concentrator Tests at an O/A Flow Ratio of $0.01 \ldots \ldots . . . . . . \quad 19$

4. Effect of Throughput on Other-Phase Carryover at O/A Ratios from 0.5 to 2.0 for Remote-Handled 4-cm Contactor ..................................................................... 22

5. Effect of Throughput on Other-Phase Carryover and Phase Volume at an O/A Flow Ratio of 100 for Remote-Handled 4-cm Contactor .......................................... 22

6. Summary of Data Taken during Two-Stage Contactor Test .................................... 26

7. Analytical Results from Concentrator Tests at O/A Flow Ratio of $0.01 \ldots \ldots . . . . . . . . . .29$

8. Extraction Efficiencies for Single-Stage Concentrator Tests at O/A Flow

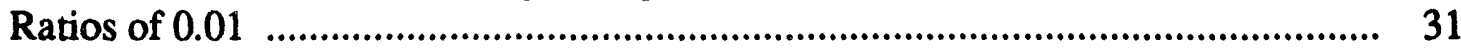

9. Aqueous Feed Compositions for Concentrator Test at O/A of $40 \ldots \ldots \ldots \ldots \ldots \ldots \ldots \ldots . . . . . . . . \quad 32$

10. Neodymium Concentrations in Organic Feed for Concentrator

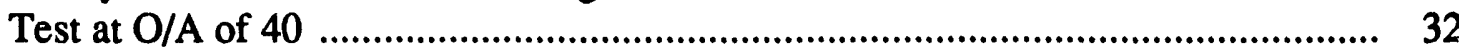

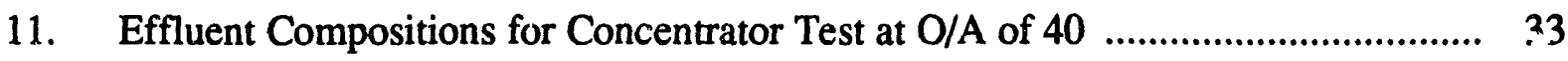

12. Extraction Efficiencies in Stage 1 of the Two-Stage Concentrator Test .................. 37

13. Extraction Efficiencies in Stage 2 of the Two-Stage Concentrator Test .................. 39

14. Summary of Extraction Efficiency Data at Various O/A Flow Ratios ................... 39

15. Names Used in Two_Stage Worksheet Shown with Their Cell Locations ............. 58 


\title{
THE USE OF A CENTRIFUGAL CONTACTOR FOR COMPONENT CONCENTRATION BY SOLVENT EXTRACTION
}

\author{
by
}

\author{
R. A. Leonard, D. G. Wygmans, M. J. McElwee, \\ M. O. Wasserman, and G. F. Vandegrift
}

\begin{abstract}
Theoretical and experimental work was undertaken to explore the use of the Argonne design centrifugl contactor as a concentrating device for metal ions in solutions such as transuranic-containing waste streams and contaminated groundwater. First, the theoretical basis for operating the contactor as a concentrator was developed. Then, the ability of the contactor to act as a concentrating device was experimentally demonstrated with neodymium over a wide range of organic-to-aqueous $(\mathrm{O} / \mathrm{A})$ flow ratios $(0.01$ to 33$)$. These data were also used to derive a correlation for the effect of $\mathrm{O} / \mathrm{A}$ flow ratio on extraction efficiency.
\end{abstract}

\section{INTRODUCTION}

An impressive advantage of the centrifugal contactor, compared with other solventextraction equipment, is its ability to operate at very high and very low organic-to-aqueous $(\mathrm{O} / \mathrm{A})$ flow ratios. If the normally high extraction efficiency of the centrifugal contactor is still high at these extreme O/A flow ratios, then the contactor can be used to concentrate (by factors of 10 to 1000 or more) those metal ions that have a high distribution ratio (D value) during extraction and/or a low $\supset$ value during stripping. For process streams containing such metal ions, the need for downstream processing of one or more effluent streams could be reduced or even eliminated.

There are three general areas where the centrifugal contactor could be very useful as a concentrator. The first area is the concentration of dilute feed streams so that the final process feed has a much smaller volume and process costs are reduced accordingly. The second area is the concentration of process effluents so that the need for further processing, such as concentration by water evaporation, is greatly reduced or eliminated. The third area is the concentration and recovery of contaminants from groundwater. In addition, a contactor concentrator could be used to recover and concentrate any extractant or modifier that is dissolved or entrained in the aqueous effluent (raffinate) if pure diluent is the organic feed. In this way, any impact of residual extractant in the treated waste can be minimized.

\section{A. Chemistry}

Component concentration using solvent extraction requires a favorable $D$ value, which is the concentration of the component in the organic phase divided by its concentration in the aqueous phase after the two phases have been equilibrated. For extraction processes, this means the $\mathrm{D}$ value is high, indicating that the component is concentrated in the organic phase even 
though the O/A flow ratio is low. For stripping processes, it means that the $D$ value is low and the component is concentrated in the aqueous phase even though the O/A flow ratio is high. The ideal situation is to have a high $\mathrm{D}$ value as the component is extracted into the organic phase and a low D value as the component is stripped "backextracted" into the aqueous phase. (The identification of appropriate extracting and stripping agents, which is not discussed in this report, can be found in many places, e.g., [MARCUS, RITCEY, SCHULZ]).

Having a high $\mathrm{D}$ value when extracting a component requires an appropriate solvent. The solvent consists of an extractant and, usually, a diluent. In some special cases, there may also be a modifier. The high $\mathrm{D}$ value is attained mainly by the proper choice of extractant. Other factors, such as the acid concentration and/or the salt concentration, can play a significant role. In the case of a neutral extractant, a lower $\mathrm{D}$ value is obtsined when either or both of these two concentrations is lowered. In most cases, the reduction in $D$ value that such factors as acid and salt bring about is not enough to get a concentrating effect for both extracting and stripping. However, a significant concentrating effect can usually be obtained in at least one of these operations.

Our theory assumes that very high and very low $\mathrm{D}$ values can be obtained, and that the equipment can be operated at essentially any O/A flow ratio. We will show that essentially any O/A flow ratio can be chosen if the centrifugal contactor is used. However, the overall concentrating effect that can be achieved will be limited by the amount that the $\mathrm{D}$ value can be decreased as one goes from the extraction section to the stripping section.

\section{B. Equipment}

While several kinds of equipment can be used to concentrate a component using the very high and very low D values that solvent extraction can provide, a centrifugal contactor designed at Argonne National Laboratory (ANL) is seen to be particularly suitable. Other possibilities include supported liquid menbranes, mixer settlers, spray columns, and pulsed columns.

Supported liquid membranes (SLMs) have the advantage that the organic phase is not normally lost to the aqueous phase except by dissolution. Two drawbacks are a lack of longterm stability for the liquid in the pores of the solid support and the difficulty in carrying out continuous countercurrent multistage operations, which are needed when $D$ values are high enough for extraction but not so high as to give a large concentrating effect in one stage. In particular, for these units to work as concentrators, the $D$ value for the extraction side must be very high $(>1000)$, while that for the strip side must be very low $(<0.001)$ to effectively remove and concentrate a species. Note that the strip-side liquid would be constantly recycled through the SLM module.

Mixer settlers, pulsed columns, and, especially, spray columns require a much larger volume for a given throughput than does the centrifugal contactor. Thus, they require more solvent in inventory and take much longer to reach steady state. In addition, the mixer settler and the pulsed column can handle only a limited range of O/A flow ratios, from about 0.25 to 4 , so that concentrating effects are restricted to about a factor of 16 . Note that for the two types of columns, the continuous phase should be the aqueous phase in the extraction column and the organic phase in the stripping column. 
Thus, because the centrifugal contactor (1) provides easy access to the solvent (i.e., the ratio of the interfacial area to the liquid volume is large), (2) has low liquid holdup for a given throughput, and (3) allows operation at any O/A flow ratio, it is preferred when concentrating a component via solvent extraction. However, while the contactor can be operated easily at any $\mathrm{O} / \mathrm{A}$ flow ratio, no data were available on whether or not the contactor maintains its high extraction efficiency at these very high or low O/A flow ratios. We designed this experimental work to answer this question.

\section{Description of the Contactor}

Figure 1 shows a centrifugal contactor of the Argonne design. In this design, two immiscible liquids flow into the annular mixing zone formed by the spinning rotor and the stationary housing wall. They are quickly dispersed in the turbulent two-phase flow created by the spinning housing wall. The resulting dispersion flows down the mixing zone and enters the centrifugal separating zone of the rotor through an opening in the bottom. Here, the dispersion breaks rapidly under the high centrifugal forces created by the spinning rotor. The separated phases flow over their respective weirs and are thrown from the rotor into collector rings in the housing. Each liquid leaves its collector ring through a tangential exit port. A slinger ring minimizes the amount of the more-dense phase that leaks down into the collector ring for the less-dense phase. Phase separation is generally considered satisfactory if each effluent from a contactor stage contains $<1 \%$ of the other phase.

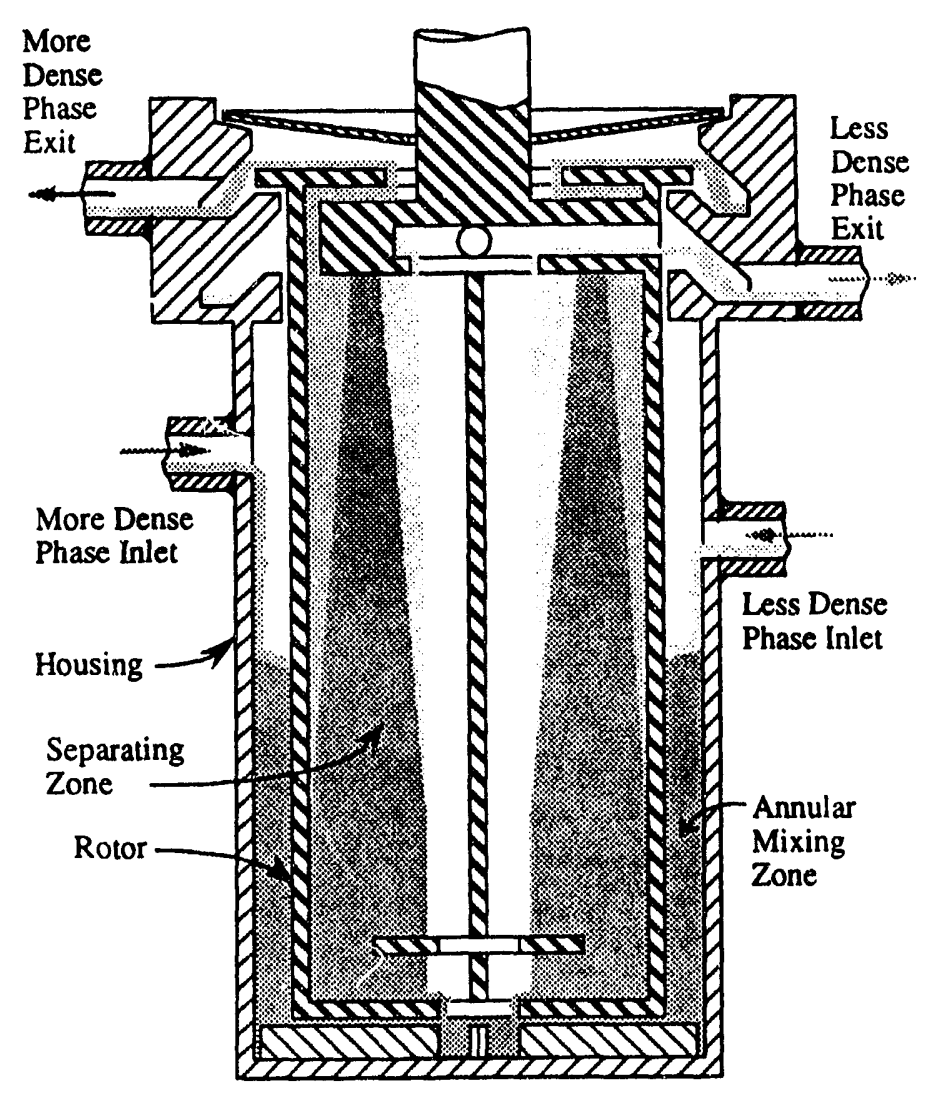

Fig. 1. Schematic of an Operating Centrifugal Contactor of the Argonne Design 
A key feature of contactor operation with respect to very high or very low $\mathrm{O} / \mathrm{A}$ flow ratios is the energy being dissipated in the highly turbulent flow of the mixing zone. This energy insures that intimate mixing of the two phases is attained no matter what the O/A flow ratio. As a result, the extraction efficiency is high, typically greater than $90 \%$ for small $(2-\mathrm{cm})$ contactors where the $\mathrm{O} / \mathrm{A}$ flow ratios range from 0.9 to 2.5 in single-stage operation [LEONARD-1980]. For larger 9- and 25-cm contactors, extraction efficiencies of essentially $100 \%$ were obtained for an O/A flow ratio of 1.0 in single-stage operation [BERNSTEIN, LEONARD-1980]. Based on this work on the extraction efficiency of centrifugal contactors at flow ratios close to 1.0 , it was expected that extraction efficiency would remain high at $\mathrm{O} / \mathrm{A}$ flow ratios far from 1.0. It is this assumption that was tested in the neodymium extraction and stripping tests reported here. Additional information on design and operation of centrifugal contactors is given by Leonard [LEONARD-1988]. 


\section{THEORY}

\section{A. Basic Ideas}

In solvent extraction processes, the distribution coefficient or ratio (D) of each component and the O/A flow ratio $(\mathrm{R})$ for the process or section of the process are required for process analysis. These two quantities form the extraction factor $(E)$ for the component to be extracted, as follows:

$$
\mathrm{E}=\mathrm{RD}
$$

For a given process stage, the extraction factor is the ratio of the moles of a component leaving in the organic phase divided by the moles of this same component leaving in the aqueous phase. If $\mathrm{E}$ is greater than 1.0, the component is being concentrated in the organic phase; if less than 1.0 , in the aquenus phase. A stripping factor (S) can be defined as $1 / E$. When $E$ is high, conditions are favorable for extraction. When $S$ is high, conditions are favorable for stripping.

When a component is being extracted, its extraction factor should be at least greater than 2 and preferably greater than 10 . Since the $D$ value is fixed for a given system, the $R$ value determines the $E$ valuc. $A$ high $R$ (and thus $E$ ) value indicates that extraction will be easy and only a few process stages will be required to achieve a given decontamination factor (D.F.). The D.F. is the concentration of a component in the aqueous feed to the extraction section divided by its concentration in the aqueous raffinate from this section. As a first approximation, the D.F. for an extraction section with $\mathrm{n}$ stages is given by

$$
\text { D.F. }=E^{n}
$$

Thus for a given D.F., a process with an $\mathrm{E}$ of 10 will typically need considerably fewer stages than a process with an $E$ of 2 . On the other hand, a low $R$ value will result in good component concentration in the organic phase. However, the $\mathrm{E}$ value will also be lower so that extraction is harder and more process stages will be required for a given D.F. In designing the extraction section of a concentrator, the $\mathrm{R}$ value chosen is a compromise between a high value for good component extraction with only a few contactor stages and a low value for good component concentration in the organic phase but with more contactor stages.

Conversely, when a component is being stripped, its extraction factor should be less than 0.5 , with 0.1 or lower being preferred. Since the D value is fixed for a given system, the extraction factor is set by the choice of $R$ value. A low $R$ value gives a low $E$ value, so that stripping is easy and only a few process stages are required for a given stripping factor (S.F.). The S.F. is the concentration of a component in the organic feed to a strip section divided by its concentration in the organic raffinate from this section. As a first approximation, the S.F. for a stripping section with $\mathrm{n}$ stages is given by

$$
\text { S.F. }=E^{-n}
$$

Thus, a process with an $\mathrm{E}$ of 0.1 will typically need far fewer stages than a process with an $\mathrm{E}$ of 0.5 for a given S.F. On the other hand, a high $\mathrm{R}$ value gives good component concentration in the aqueous phase. However, the $\mathrm{E}$ value will also be higher, so that : ripping is harder and 
many process stages may be required for a given S.F. In designing the stripping section of a concentrator, the $\mathrm{R}$ value chosen is a compromise between a low value for good component stripping with only a few contactor stages and a high value for good component concentration in the aqueous phase but with more contactor stages.

\section{B. Limits}

Two factors, other-phase carryover and stage efficiency, could limit the effectiveness of the centrifugal contactor as a concentrator. They are discussed in the following sections.

\section{Other-Phase Carryover}

One limit on the basic theory we just described comes from the effect of otherphase carryover. Because of this factor, the actual $D$ value in Eq. 1 must be replaced with an effective $D$ value $\left(D_{\text {eff }}\right)$. Typically, $D_{\text {eff }}$ changes in such a way that the concentrating effect is diminished. When other-phase carryover is low, $D_{\text {eff }}$ is approximated by

$$
D_{\text {eff }}=\frac{D+f_{o}}{1+f_{a} D}
$$

where $f_{a}$ is the fraction of organic phase in the effluent from the aqueous-phase exit and $f_{o}$ is the fraction of aqueous phase in the effluent $f: b)$ inc organic-phase exit [LEONARD-1991]. This equation shows that no matter how high $D$ is in extraction section, $D_{\text {eff }}$ will always be less than $1 / f_{a}$ but essentially unaffected by $f_{o}$. Since $f_{a}$ will be low $(<0.01)$ when the aqueous phase is the predominant phase in the extraction section of a concentrator, the $D$ value must be fairly high before $D_{\text {eff }}$ becomes important. Since $D_{\text {eff }}$ is essentially unaffected by $f_{0}$, the possibility that the low flow of the organic phase might result in high other-phase carryover should be only a minor problem in operating a concentrator.

Conversely, Eq. 4 shows that no matter how low $D$ is in the stripping section, $D_{\text {eff }}$ will always be greater than $f_{o}$ but essentially unaffected by $f_{a}$. Since $f_{o}$ will be low $(<0.01)$ when the organic phase is the predominant phase in the stripping section of a concentrator, the $D$ value must be fairly low before $D_{\text {eff }}$ becomes important. Since $D_{\text {eff }}$ is essentially unaffected by $f_{a}$, the possibility that the low flow of the aqueous phase might result in high other-phase carryover should be only a minor problem in operating a concentrator.

As other-phase carryover increases, Eq. 4 becomes less and less accurate. It should not be used if other-phase carryover is much greater than $1 \%$. Instead, the stage-to-stage concentration pr-files for the various components during concentrator operation should be calculated using hie more general equations presented in [LEONARD-1990]. These equations can be incorporated into a Microsoft Excel worksheet named SASSE (Spreadsheet Algorithm for Stagewise Solvent Extraction), where these stage-to-stage calculations are easily made.

\section{Extraction Efficiency}

In designing a contactor for which the rotor diameter and speed have already been fixed, the annular gap between the spinning rotor and the stationary housing wall that forms the mixing zone must be made small enough so that a good dispersion is formed and 
extraction efficiency is therefore high. However, the gap should not be so small that the twophase dispersion backs up in the mixing zone and overflows into the lower collector ring for the exiting less-dense phase. By optimizing the ann ar gap, the contactor can operate at extraction efficiencies that are greater than $95 \%$ (typically, 98 to 100\%) while maintaining reasonable liquid levels in the annular mixing zone at O/A flow ratios close to 1.0 [BERNSTEIN, LEONARD-1980]. In the tests reported below, the extraction efficiencies were measured over a range of O/A flow ratios from $1 / 100$ to 32 . These tests were made to determine if the extraction efficiency is still high when one phase largely predominates in the annular mixing zone.

One factor that affects extraction efficiency in a stage is the liquid flow. If the flow of one phase is so small that it flows in spurts, the extraction efficiency will be degraded. This can be seen must clearly for the extreme case where there is twice the average flow for the low-flow phase in the mixing zone during half of the time, and no flow during the other half. If the time intervals are relatively long, one half of the high-flow phase will have had almost no contact with the low-flow phase as the high-flow phase passes through the mixing zone of the centrifugal contactor, and the extraction efficiency will be about $50 \%$. This intermittent flow is seen to be a possible problem with smaller contactors, such as the $2-\mathrm{cm}$ contactor that has a nominal througnput of $40 \mathrm{~mL} / \mathrm{min}$ [LEONARD-1980]. In such cases, surface tension forces have a large effect on the liquid flow in the interstage lines. Larger contactors with increased throughpat capacities have larger low-flow stream flow rates for the same O/A flow ratio. When the interstage flow becomes continuous, any degradation of the extraction efficiency in the contactor stage due to this factor should disappear.

\section{Concentrator Design}

Here we present the basic cunfiguration of our concentrator design using a centrifugal contactor as the equipment to carry out this process. The basic design variables, namely, the distribution ratios, the O/A flow ratios, and the number of stages, are evaluated for their effect on concentrator design, and a rule of thumb is presented for estimating an overall concentration factor. Finally, the SASSE worksheet is used to determine the effects of various operational parameters on an eight-stage concentrator. These parameters were extraction efficiency, otherphase carryover, and solvent recycle.

\section{Basic Configuration}

A flowsheet for a typical concentrator is shown in Fig. 2. In the figure, four stages are shown for each of the two sections. With a high extraction factor in the extraction section (i.e., 10 or higher), $90 \%$ of the concentrating effect in the organic phase will be realized with only one stage. The use of additional extraction stages lowers the component concentration in the aqueous raffinate and pushes the concentrating effect even closer to $100 \%$. With lower extraction factors (typically greater than or equal to 2), several stages will be required to realize a concentrating effect of $90 \%$ or higher in the organic phase.

Conversely, with a low extraction factor in the strip section ( 0.1 or lower), $90 \%$ of the concentrating effect in the aqueous phase will be realized with only one stage. The use of additional stripping stages increases the component concentration in the concentrated 


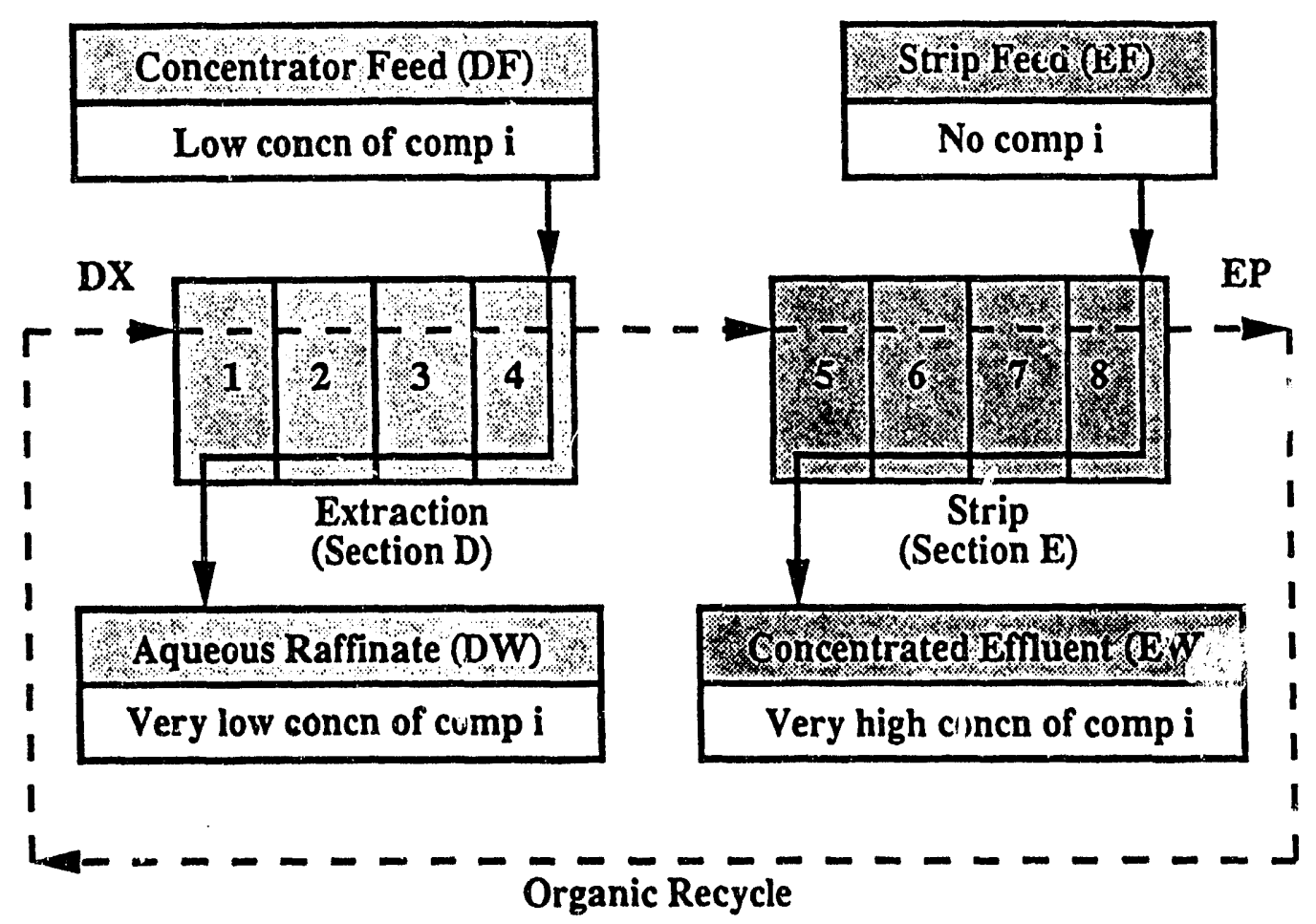

Fig. 2. Flowsheet for a Concentrator with Eight Contactor Stages

aqueous effluent and pushes the concentrating effect even closer to $100 \%$. With higher extraction factors (typically less than or equal to 0.5 ), several stages will be required to realize a concentrating effect of $90 \%$ or higher in the aqueous phase.

In addition to the extraction and strip sections shown in Fig. 2, some processes may have one or more components entrained or partially extracted into the organic phase coming from the extraction section. A scrub section of one or more stages can bc inserted between the extraction and strip sections to remove them, if necessary. Typically, tie aqueous effluent from the scrub section joins with the aqueous feed to form a combined feed for the extraction section and comes out as part of the aqueous raffinate.

A final feature of the concentrator design shown in Fig. 2 is the complete recycle of the organic phase. This feature of the design requires that the extraction and strip sections be balanced. To do this, enough of the concentrated component must be removed from the organic phase (EP) leaving the strip section to achieve the low component concentration desired in the aqueous raffinate (DW) from the extraction section. In some cases, it will be necessary to have a solvent cleanup section after the strip section.

\section{Design Variables}

For a given system where the $\mathrm{D}$ values are fixed by the compositions of the aqueous and organic phases, the main design variables are the O/A flow ratio and the number of stages. Using Eqs. 1 to 3 with $D_{\text {extr }}=100$ and $D_{\text {strip }}=0.01$, the effect of the $O / A$ flow ratio on the total number of stages required is shown in Table 1 for three levels of concentrating effect. 
The low level of concentrating effect uses O/A flow ratios close to $1.0(1 / 2$ and 2$)$ so that both the extraction and stripping factors are high and the total number of stages required is low. The tradeoff is that the overall concentiating factor is low, only 4 for the example shown in Table 1 . The medium level of concentrating effect uses O/A flow ratios somewhat further from 1.0 (1/10 and 10 ) so that both the extraction and stripping factors are lower and the total number of stages required is higher. However, the overall concentrating factor is also higher, 100 for the example shown in Table 1 . The high level of concentrating effect uses O/A flow ratios even further from 1.0 (1/50 and 50) so that both the extraction and stripping factors are only 2.0 and the total number of stages required is much higher. The tradeoff is that the overall concentrating factor is also very high, 2500 for the example shown in Table 1.

Table 1. Effect of O/A Flow Ratio on Total Stages Required

\begin{tabular}{|c|c|c|c|c|c|c|c|c|}
\hline \multirow{3}{*}{$\begin{array}{l}\text { Levels } \\
\text { of } \\
\text { Cinc. } \\
\text { Effect }\end{array}$} & & & \multicolumn{2}{|c|}{ Extraction Factor (E) } & \multirow{3}{*}{$\begin{array}{l}\text { Overall } \\
\text { Conc. } \\
\text { Factor } \\
\text { (O.C.F.) }\end{array}$} & \multirow{3}{*}{$\begin{array}{l}\text { No. Extr. } \\
\text { Stages } \\
\text { Req. for } \\
\text { D.F. of } \\
1.0 \mathrm{E}+6\end{array}$} & \multirow{3}{*}{$\begin{array}{l}\text { No. Strip } \\
\text { Stages } \\
\text { Req. for } \\
\text { S.F. of } \\
1.0 \text { E } 6\end{array}$} & \multirow{3}{*}{$\begin{array}{c}\text { Total } \\
\text { Stages } \\
\text { Reg. }\end{array}$} \\
\hline & \multicolumn{2}{|c|}{ O/A Flow Ratio (R) } & Extraction & Strip & & & & \\
\hline & Extraction & Sarip & $(D=100)$ & $(\mathrm{D}=0.01)$ & & & & \\
\hline Low" & 0.5 & 2 & 50 & 0.02 & 4 & 4 & 4 & 8 \\
\hline Medium ${ }^{b}$ & 01 & 10 & 10 & 0.1 & 100 & 6 & 6 & 12 \\
\hline Highc & 0.02 & 50 & 2 & 0.2 & 2500 & 20 & 20 & 40 \\
\hline
\end{tabular}

"The O/A flow ratios are near 1 so that extraction and stripping factors are high. Thus, the number of stages needed to reach the required D.F. and S.F. is low.

bThe O/A flow ratios are further from 1 so that extraction and stripping are lower. Thus, the number of stages needed to reach the required D.F. and S.F. is higher.

CThe O/A flow ratios are even further from 1 so that extraction and stripping factors are low. Thus, the number of stages needed to reach the required D.F. and S.F. is high.

Note that thc overall concentrating factor (O.C.F.) in Table 1 is the concentration of a component in the aqueous effluent from the strip section $x_{\text {strip }}$ ( $E W$ in Fig. 2) divided by the concentration of the same component in the aqueous feed to the extraction section $x_{\text {feed }}$ (DF in Fig. 2); that is,

$$
\text { O.C.F. }=\frac{x_{\text {strip }}}{x_{\text {feed }}}
$$

In Table 1, O.C.F. is obtained indirectly by assuming that (1) the other-phase carryover is zero, (2) the extraction efficiency is $100 \%$, and (3) there are a sufficient number of extraction and strip stages so that D.F. and S.F. are high (e.g., 106). With these assumptions, which lead to the highest possible level of component recovery, the resulting overall concentration factor (O.C.F.--high recovery) can be written in terms of the $R$ values for the stripping section ( $\left.R_{\text {strip }}\right)$ and the extraction section $\left(R_{\text {feed }}\right)$ as

$$
\text { O.C.F.--high recovery }=\frac{R_{\text {strip }}}{R_{\text {feed }}}
$$


To set a medium level for the concentrating effect shown in Table 1, we balanced the number of stages required with the desired concentrating effect. We chose to relate the O/A flow ratio for a section to the $\mathrm{D}$ value for the key component to be concentrated in that section using

$$
R=\frac{1}{\sqrt{D}}
$$

Substituting this into Eq. 1 gives an extraction factor of

$$
E=\sqrt{D}
$$

With this choice for a balanced design, the overall concentrating factor (D.C.F.--balanced) at conditions of high recovery becomes

$$
\text { O.C.F.--balanced }=\sqrt{\frac{D_{\text {extr }}}{D_{\text {strip }}}}
$$

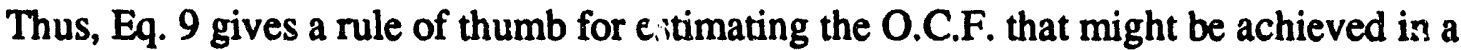
balancad concentrator design for a component that has a $D$ value of $D_{\text {extr }}$ in the extraction section and of $D_{\text {strip }}$ in the strip section.

\section{Model Analysis}

A SASSE worksheet was created as outlined in [LEONARD-1991]. It included (1) the general equations to handie high amounts of other-phase carryover [LEONARD-1991] and (2) the effect of extraction efficiency on the D value for each component at each stage [LEONARD-1987]. Using this worksheet, the neodymium concentration in the aqueous effluent (EW) from the strip section was explored as a function of extraction efficiency, otherphase carryover (both organic phase in the aqueous phase and aqueous phase in the organic phase), and organic-phase recycle.

The sysiem modeled was a neodymium concentrator using the TRUEX (TRansUranic EXtraction) solvent extraction process with eight stages (4 extracting and 4 stripping) set up as shown in Fig. 2. The aqueous DF feed had a neodymium concentration of $7 \times 10^{-7} \mathrm{M} \mathrm{Nd}$ with $2.0 \mathrm{M} \mathrm{NaNO}$ and $0.02 \mathrm{M} \mathrm{HNO}_{3}$ so that $\mathrm{D}_{\mathrm{Nd}}$ in the extraction section would be about 500 when the organic DX feed is the TRUEX-NPH solvent. The solvent is $0.20 \mathrm{M}$ CMPO (octyl(phenyl)-N,N-diisobutylcarbamoylmethylphosphine oxide) and 1.4M TBP (tributyl phosphate) diluted by NPH (normal paraffin hydrocarbon), which is a mixture of $\mathrm{C}_{12^{-}}$ $\mathrm{C}_{14}$ hydrocarbons, mainly normal dodecane. The $\mathrm{O} / \mathrm{A}$ flow ratio in the extraction section was 0.01 , so that each stage had an extraction factor of 5 with respect to neodymium. The loaded solvent enters the stripping section where the neodymium is removed by countercurrent contact with an aqueous solution of $0.1 \mathrm{M} \mathrm{HNO} \mathrm{HN}_{3}$ containing $0.05 \mathrm{M}$ of the complexant HEDPA (1hydroxyethane-1,1-diphosphonic acid) so that $D_{\mathrm{Nd}}$ in the stripping section would be about 0.002 . To achieve these low $D_{\mathrm{Nd}}$ values for good stripping, the complexant concentration should be at least 10 times that of the metal ion. The O/A flow ratio in the stripping section was 100 so that each stage had a stripping factor of 5 with respect to neodymium. For this 
analysis, the base case hid an extraction efficiency of $100 \%, f_{a}$ (the fraction of organic phase in the exiting aqueous phase) and $f_{o}$ (the fraction of aqueous phase in the exiting organic phase) values of $0.005(0.5 \%)$, and no organic recycle.

Results of the model evaluation are listed in Table 2. For this model, Eq. 6 gives an overall concentrating factor of 10,000 when there is no other-phase carryover. Since the base case (case 1) has $0.5 \%$ other-phase carryover, the O.C.F. was found to be lower (6470). Thus, as shown in Table 2 , the concentrated aqueous effluent (EW) for case 1 is $0.00453 \mathrm{M} N d$ rather than $0.007 \mathrm{M} \mathrm{Nd}$. When the organic phase is recycled (case 2), the neodymium concentration in EW increases about $1 \%$, and the neodymium concentration in the aqueous raffinate (DW) increases about $12 \%$. The stage-to-stage concentration profiles for the organic and aqueous phases of these two cases, which are given in Fig. 3, show that the effect of organic recycle is minimal for this design. The one other case with organic phase recycle (case 8) again showed very little effect of this solvent recycle. Organic recycle would become important if there were insufficient stages in the stripping section to adequately remove the concentrated species.

Table 2. Summary of SASSE Model Evaluation

\begin{tabular}{|c|c|c|c|c|c|c|c|c|}
\hline \multirow[b]{3}{*}{ Case } & \multirow{3}{*}{$\begin{array}{l}\text { Fract. } \\
\text { Ext. } \\
\text { Eff. }\end{array}$} & \multicolumn{3}{|c|}{ Other-Phase Carryover } & \multirow{3}{*}{$\begin{array}{c}\text { Org. } \\
\text { Recycle }\end{array}$} & \multirow{2}{*}{\multicolumn{3}{|c|}{ Nd in Effluents, $\mathbf{M}$}} \\
\hline & & Fract. & Fract. & & & & & \\
\hline & & $O$ in $A$ & $A$ in $O$ & Section & & DW & $\mathrm{EW}$ & EP \\
\hline $1^{2}$ & 1.0 & 0.0 .05 & 0.005 & Both & no & $1,15 \mathrm{E}-8$ & $4.53 \mathrm{E}-3$ & $7.58 \mathrm{E}-7$ \\
\hline 2 & 1.0 & 0.005 & 0.005 & Both & yes & $1.30 \mathrm{E}-8$ & 4.57E-3 & 7.64E-7 \\
\hline 3 & 1.0 & 0.001 & 0.001 & Both & no & $2.30 \mathrm{E}-9$ & $6.31 \mathrm{E}-3$ & 2.04E-7 \\
\hline 4 & 1.0 & 0.010 & 0.010 & Both & no & $2.47 \mathrm{E}-8$ & $3.30 \mathrm{E}-3$ & $1.21 \mathrm{E}-6$ \\
\hline 5 & 0.9 & 0.005 & $\begin{array}{c}0.04444 \\
405\end{array}$ & Both & no & $2.62 \mathrm{E}-8$ & $4.41 \mathrm{E}-3$ & $1.16 \mathrm{E}-6$ \\
\hline 6 & 0.8 & 0.005 & 0.005 & Both & no & $4.76 \mathrm{E}-8$ & $4.22 \mathrm{E}-3$ & $1.84 \mathrm{E}-6$ \\
\hline 7 & 0.7 & 0.005 & 0.005 & Both & no & $7.68 \mathrm{E}-8$ & 3.95E-3 & $2.98 E-6$ \\
\hline 8 & 0.7 & 0.005 & 0.005 & Both & yes & 8.23E-8 & $4.11 \mathrm{E}-3$ & $3.10 \mathrm{E}-6$ \\
\hline 9 & 1.0 & $\begin{array}{l}0.005 \\
0.350\end{array}$ & $\begin{array}{l}0.350 \\
0.005\end{array}$ & $\begin{array}{l}\text { Extn. } \\
\text { Strip }\end{array}$ & no & $1.16 \mathrm{E}-8$ & $4.53 \mathrm{E}-3$ & $7.66 \mathrm{E}-7$ \\
\hline
\end{tabular}

Base case.

When other-phase carryover is lowered from its base case value of $0.005(0.5 \%)$ as in case 1 to 0.001 as in case 3 , the overall concentrating factor was found to increase from 6470 to 9010 , very close to the value of 10,000 for no other-phase carryover and many stages in each section (so that D.F. and S.F. are very high). Conversely, when other-phase carryover is increased from its base case value to 0.010 (case 4), the overall concentrating factor decreases from 6470 to 4710 . These results show that concentrator operation is sensitive to small changes in the other-phase carryover that are within the range of normal contactor operation. The stageto-stage concentration profiles for the organic and aqueous phases of cases 1 and 4, which are 
given in Fig. 4, show how increasing other-phase carryover (O.P.C.) affects the neodymium concentration in the various concentrator stages.

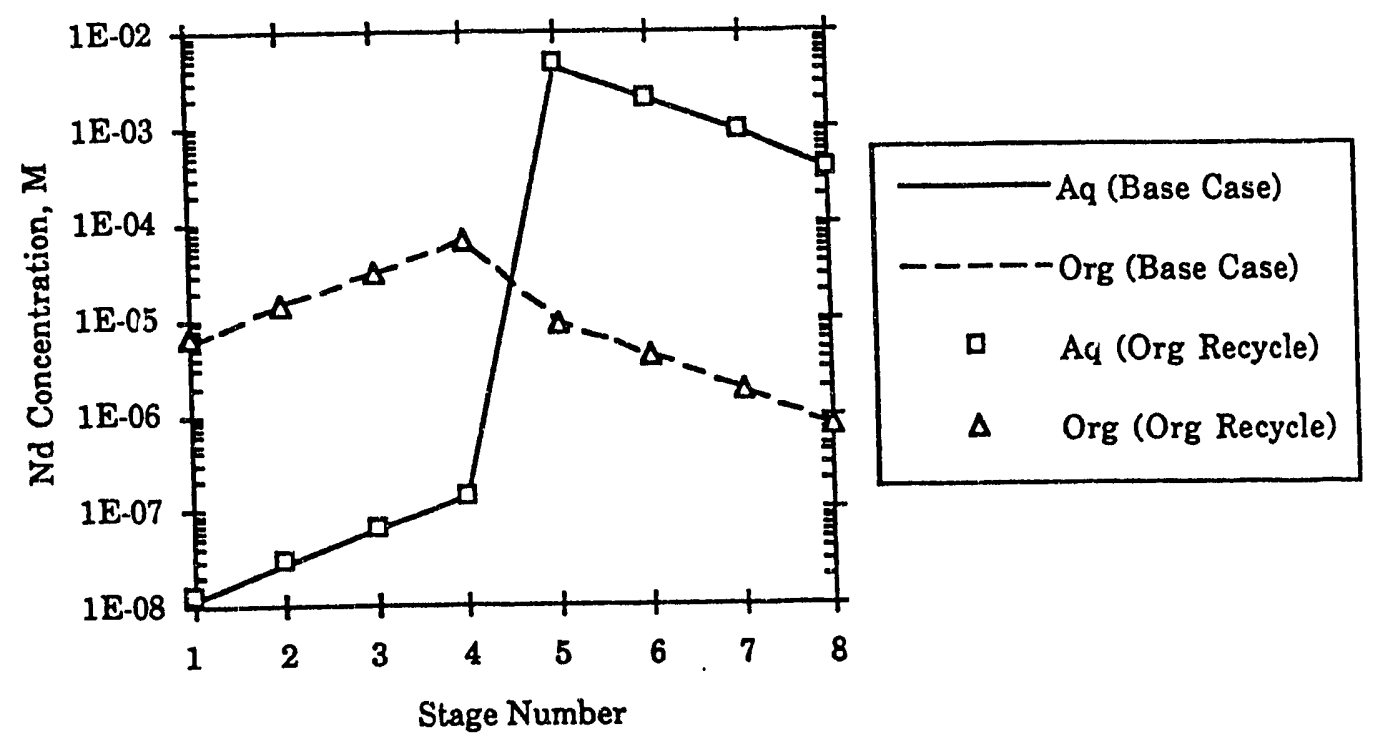

Fig. 3. Effect of Organic Recycle on Neodymium Concentration Profiles in the 8-Stage Concentrator. Comparison of cases 1 and 2.

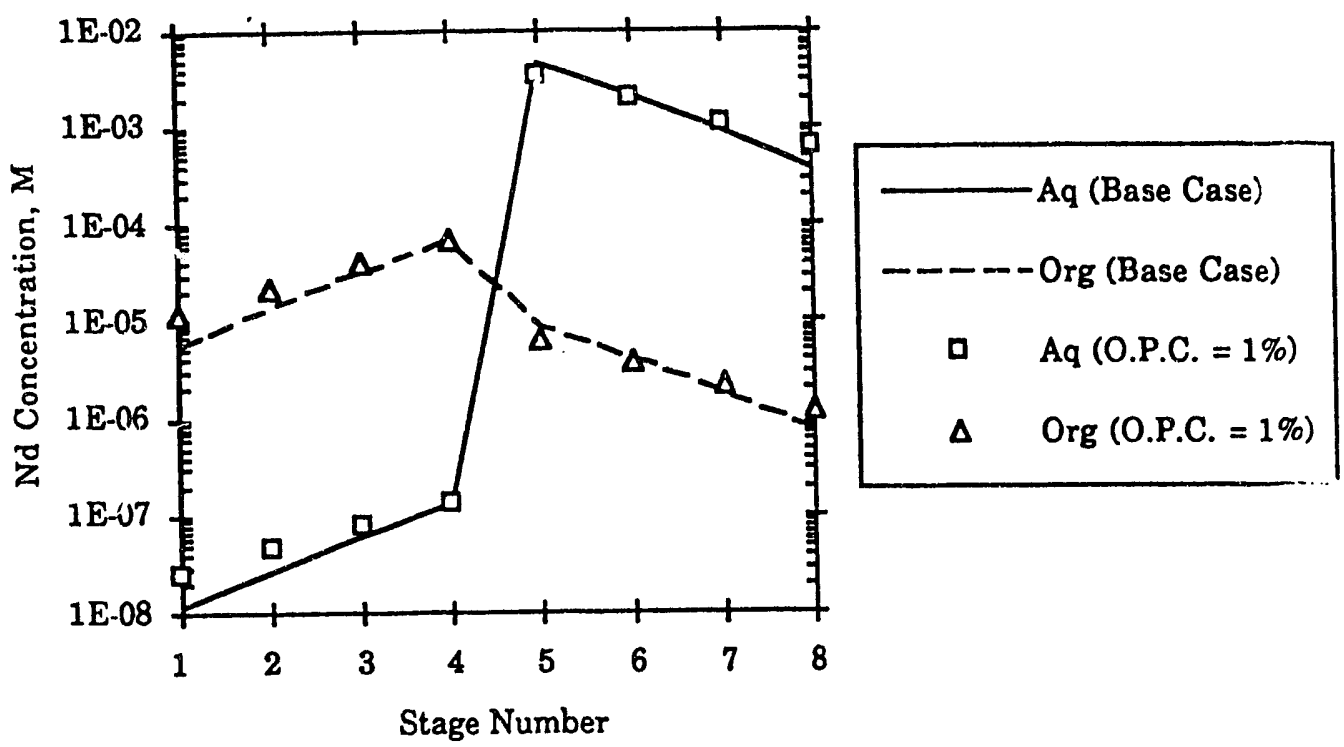

Fig. 4. Effect of $1 \%$ Other-Phase Carryover on Neodymium Concentration Profiles in the 8-Stage Concentrator. Comparison of cases 1 and 4 where the other-phase carryover (O.P.C.) was increased from $0.5 \%$ (base case) to $1 \%$.

As the extraction efficiency drops (cases 5-7), the overall concentrating factor is reduced, as shown by the decrease in the EW values for neodymium. However, even for the worst case modeled (case 7), which has an extraction efficiency of $0.7(70 \%)$, the overall 
concentrating factor is still quite high (5640). These results show that, while concentrator operation is sensitive to changes in the extraction efficiency, it will still work. The stage-tostage concentration profiles for the organic and aqueous phases of cases 1 and 7 , which are given in Fig. 5, show how decreasing extraction efficiency (E.E) affects the neodymium concentration in the various concentrator stages.

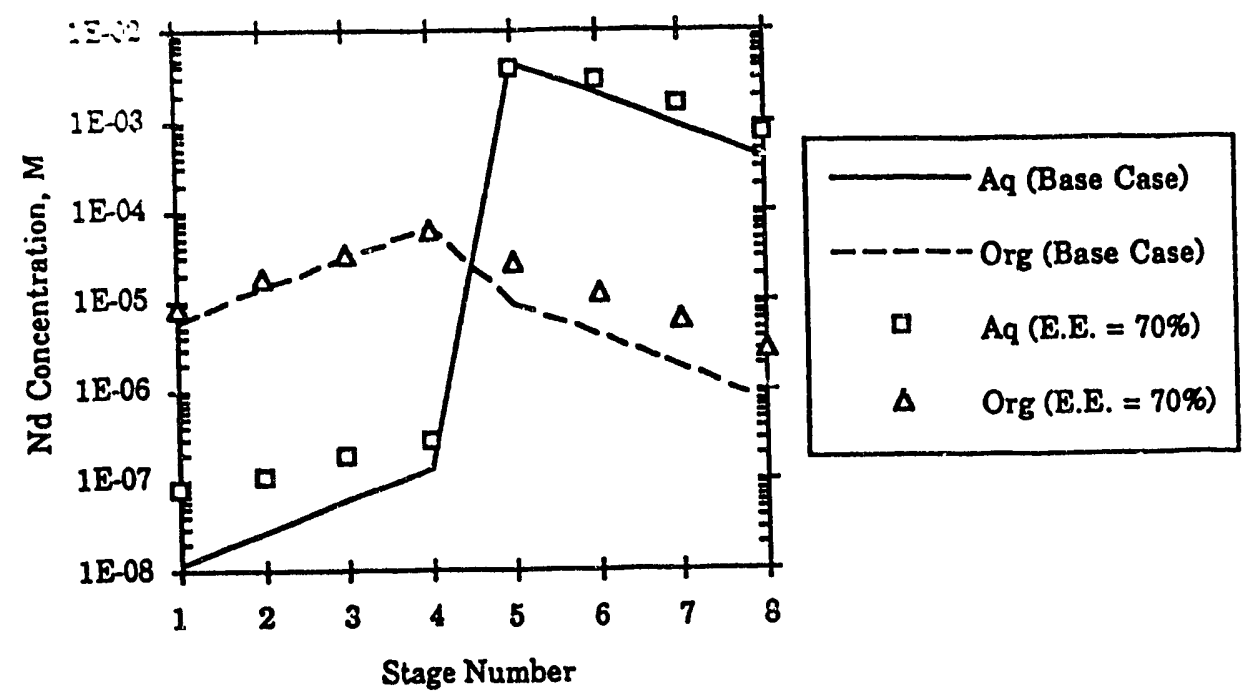

Fig. 5. Effect of $70 \%$ Extraction Efficiency on Neodymium Concentration Profiles in the 8-Stage Concentrator. Comparison of cases 1 and 7 where the extraction efficiency (E.E.) was decreased from $100 \%$ (base case) to $70 \%$.

Finally, when the base case is modified so that there is $35 \%$ other-phase carryover in the low-flow phase (case 9), the overall concentrating factor is unaffected although the neodymium concentration in DW does increase by $1 \%$. This result was expected based on the $\mathrm{D}_{\text {eff }}$ analysis given abovs. The stage-to-stage concentration profiles for the organic and aqueous phases of cases 1 and 9, which are given in Fig. 6, also show that the neodymium concentration in ti.. val ous concentrator stages is not affected by this change. Note that a problem with this case is that the model was not set up to increase $D_{\mathrm{Nd}}$ values if the salt concentration in any strip stage was high. If the other-phase carryover in the organic flow going from the extraction section to the stripping section, for example, $>50 \%$ for an aqueous feed with $2.0 \mathrm{M} \mathrm{NaNO}_{3}$, the high nitrate concentration of this carried-over aqueous phase would increase the nitrate concentration in the first strip stage to $>1.0 \mathrm{M}$. For this strip stage, the $\mathrm{D}_{\mathrm{Nd}}$ value would then be $>1.0$ even with $0.05 \mathrm{M}$ complexant present. The resulting high extraction factor for neodymium in this stage greatly reduces the effectiveness of the whole stripping section. Thus, while one can normally tolerate high other-phase carryover in the low-flow phase, one may not be able to tolerate this behavior when the low-flow phase enters a section where it becomes the high-flow phase.

Overall, this more detailed analysis of concentrator operation shows that, over the range of variables expected for contactor operation, concentrator operation should be reasonably effective. 


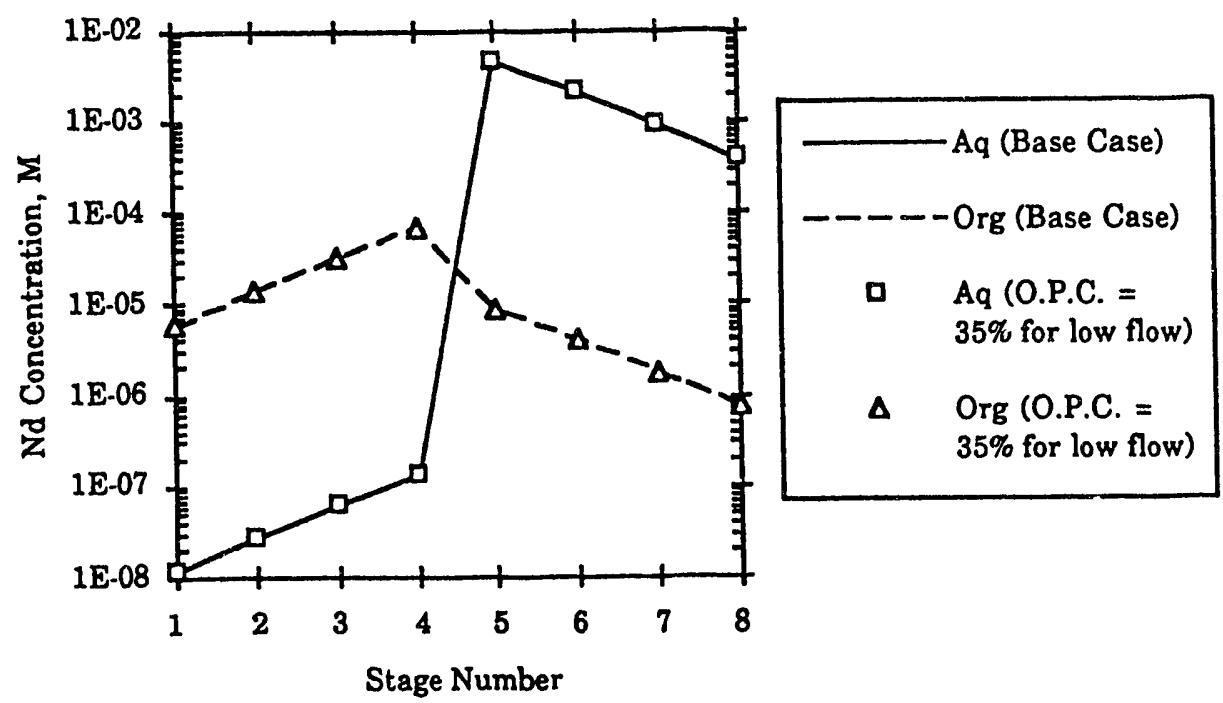

Fig. 6. Effect of 35\% Other-Phase Carryover in the Low Flow Streams on Neodymium Concentration Profiles in the 8-Stage Concentrator. Comparison of cases 1 and 9 where other-phase carryover (O.P.C.) was increased from $0.5 \%$ (base case) to $35 \%$ for the aqueous phase in the strip section and the organic phase in the extraction section. 


\section{EXPERIMENTS}

The purpose of the experimental work was to determine if contactor efficiency remains high at extremely high and extremely low O/A flow ratios. In the first phase of the work, onestage contactor tests were run at very low $\mathrm{O} / \mathrm{A}$ flow ratios, contacting aqueous and organic phases using a very high D value for neodymium. As a result, most of the neodymium was concentrated into the organic effluent. We focused here on finding the efficiency of the contactor as it was extracting at these very low O/A flow ratios. In the second phase of the work, a two-stage contactor test was run with the first stage as an extraction stage and the second as a stripping stage. In the stripping stage, a high $\mathrm{O} / \mathrm{A}$ flow ratio was used with a process having a low $\mathrm{D}$ value for neodymium so that neodymium was effectively concentrated into the aqueous effluent. Here, we focused on the efficiency of the second contactor stage as it stripped neodymium at a very high O/A flow ratio. Taken together, the experimental work evaluates the efficiency of the contactor when it is used as a concentrator at extremes in the O/A flow ratio. All contactor tests were carried out in the remote-handled 4-cm contactor [LEONARD-1988].

The organic phase in these tests contains $0.2 \mathrm{M}$ CMPO and 1.4M TBP with either NPH or $\mathrm{nDD}$ (normal dodecane) as the diluent. These solutions are referred to here as TRUEX-NPH or TRUEX-nDD, respectively. More details on the TRUEX process, which is used to remove long-lived transuranic elements from nuclear wastes, are available elsewhere [CHIARIZIA, HORWITZ, LEONARD-1985, VANDEGRiFT]. While the nom nal concentration of the TRUEX-NPH was $0.2 \mathrm{M}$ CMPO and 1.4M TBP, density me asurernents indicated that this solution, which had been in use for some time, had lost sore NPH. As a result, the actual CMPO concentration may have been as much as $25 \%$ greater than the nominal CMPO concentration. Since $D_{N d}$ has a third power dependence on the CMPO concentration, the $D_{N d}$ value could be high by a factor of two. Thus, it is not surprising that the experimental $D_{\mathrm{Nd}}$ value for the extraction tests was found to be about 500 , while the value calculated using the Generic TRUEX Model (GTM) correlation, which is based on a CMPO concentration of $0.2 \mathrm{M}$, was found to be 239 .

\section{A. Extraction}

In two series of tests, neodymium was extracted from an aqueous phase into an organic phase at very low $\mathrm{O} / \mathrm{A}$ ratios (about 0.01 ) in a process with a $\mathrm{D}_{\mathrm{Nd}}$ value of about 500 . Thus, since the overall extraction factor was about 5 , the neodymium was concentrated in the organic phase.

\section{Preliminary Considerations}

To determine the concentrations and volumes of the feed solutions needed for the tests, we had to know the residence time required to reach steady state. In addition, the feed concentration had to be chosen low enough so that the solvent would not become loaded with neodymium and high enough so that the neodymium could be analytically detected. 


\section{a. Residence Time}

As a rule of thumb, three residence times are required for a process to reach equilibrium inside a centrifugal contactor. When the two phises have different residence times, the phase with the longer residence time is used. For these tests at very low O/A flow ratios, the residence time for the organic phase was much longer than that for the aqueous phase, so the organic-phase residence time was used. To insure that steady state would be reached, the concentrator tests were run for up to six organic-phase residence times; aqueous raffinate (DW) and loaded solvent (DP) samples were taken at each residence time starting with the third one. This first sample, which was typically taken between 3 and 4 residence times, is called the third-residence-time sample. If the concentration of neodymium in DW does not vary with time, the process has reached steady state. To estimate the residence time for the organic phase in the rotor, and thus the amount of solution needed for the concentrator tests, preliminary tests were made to determine the volume of the organic phase inside the contactor as a function of the total throughput at an $\mathrm{O} / \mathrm{A}$ of 0.01 . In these measurements, aqueous-phase $\left(0.01 \mathrm{M} \mathrm{HNO}_{3}\right)$ flow is established with no organic phase in the contactor. Once the organicphase (TRUEX-NPH) flow is started, the residence time for the organic phase is taken to be the time between the first entry of the organic phase into the contactor and its first exit from the contactor. The flow rate of the organic effluent was also measured. From these measurements, we calculated the volume of organic phase in the contactor stage. The results, given in Fig. 7, show how organic-phase volume decreases as the total throughput increases.

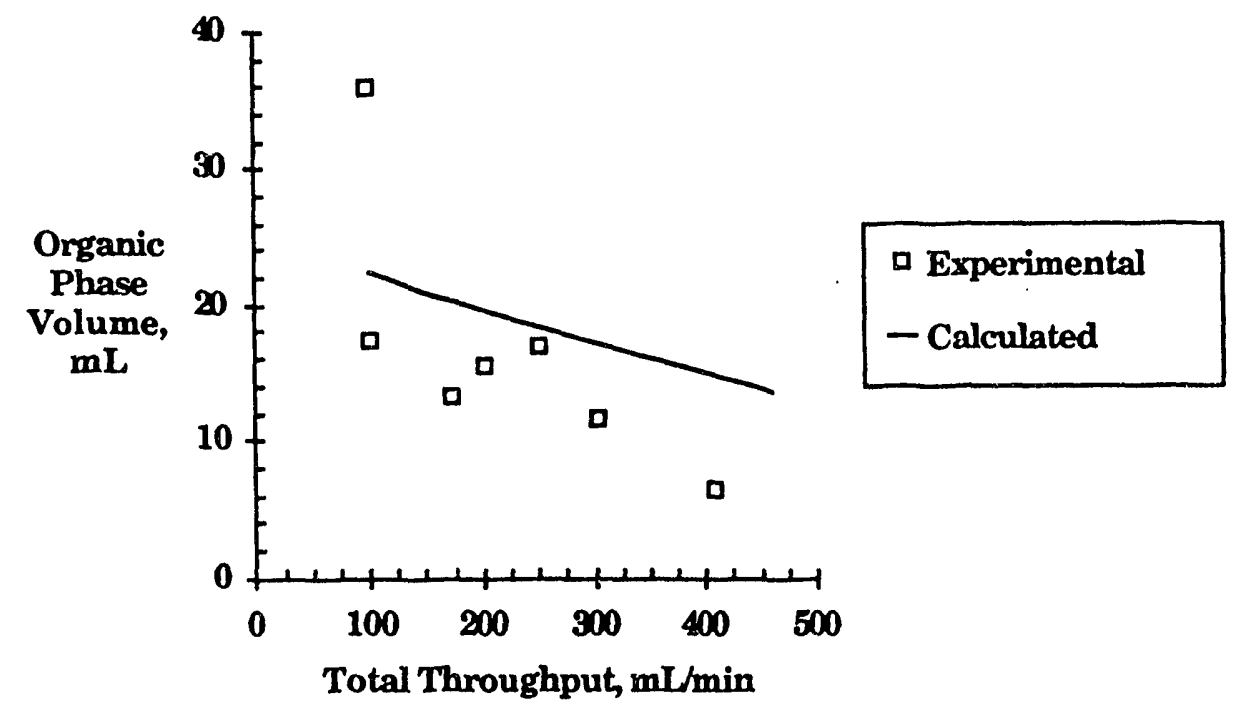

Fig. 7. Effect of Throughput on the Organic-Phase Volume in One Stage of a 4-cm Contactor at an O/A Flow Ratio of 0.01 . The organic and aqueous phases were TRUEX-NPH and $0.01 \mathrm{M} \mathrm{HNO}_{3}$, respectively.

An analysis of a 4-cm contactor stage for an O/A flow ratio of 0.01 shows that most of the organic-phase volume is inside the rotor. First, the total liquid volume inside the rotor at a total flow rate of $400 \mathrm{~mL} / \mathrm{min}$ and an $\mathrm{O} / \mathrm{A}$ flow ratio of 0.01 is about 
$75 \mathrm{~mL}$, while that in the mixing zone around the rotor is about $30 \mathrm{~mL}$. Then, since the $\mathrm{O} / \mathrm{A}$ volume ratio in the mixing zone is the same as the $\mathrm{O} / \mathrm{A}$ flow ratio, the volume of organic phase in the mixing zone is about $0.3 \mathrm{~mL}$. Thus, the experimental volumes for the organic phase in Fig. 7 are essentially the organic-phase volumes in the rotor. The organic-phase volume in the rotor was calculated as a function of the total throughput at an O/A flow ratio of 0.01 . These results, plotted in Fig. 7, also show a decrease of organic-phase volume with increasing total throughput. Note that the experimental data are typically lower than the calculated curve. One experimental value (at a total throughput of $100 \mathrm{~mL} / \mathrm{min}$ ) is considerably higher than the calculated value. It is most likely an error, which reflects the difficulty in telling exactly when the liquid enters the mixing zone at very low flow rates.

The work shown in Fig. 7 used a $0.01 \mathrm{M} \mathrm{HNO}_{3}$ aqueous solution and TRUEX-NPH. When a concentrated salt solution $\left(2.0 \mathrm{M} \mathrm{NaNO} / 3 / 0.02 \mathrm{MNO}_{3}\right)$ with a density of $1101 \mathrm{~g} / \mathrm{L}$ is used in place of the dilute nitric acid solution that has a density of $997 \mathrm{~g} / \mathrm{L}$, the calculated volume for the organic phase in Fig. 7 is decreased by about $7 \mathrm{~mL}$. Thus, the calculated curve shown in Fig. 7 is an upper bound for the volume of organic phase in the contactor stage and is used to determine the residence time of the organic phase in the stage. This insures that the residence times, used to estimate the approach to steady state, error on the side of being too long.

\section{b. Eeed Concentration}

To determine an appropriate neodymium concentration in the aqueous feed solution, two factors were considered. The first factor was that the TRUEX solvent, into which the neodymium was to be extracted, has a limit to the amount of metal ions it can complex. It takes approximately three moles of CMPO (the extractant in the TRUEX solvent) to complex one mole of neodymium. Since the TRUEX solvent has a CMPO concentration of $02 \mathrm{M}$, the theoretical loading of neodymium in the TRUEX solvent is $0.067 \mathrm{M}$. However, when the TRUEX solvent becomes heavily loaded with metal ions, a second organic phase will form. To avoid this, the neodymium in the TRUEX solvent was limited to $10 \%$ of the theoretical loading limit, that is, to $0.0067 \mathrm{M}$.

The second factor in choosing an appropriate neodymium feed concentration is that it must be high enough so that the neodymium concentration of the various samples can be determined. Except as noted, the analytical procedure used to measure neodymium was inductively coupled plasma/atomic emission spectrometry (ICP/AES), which has a detection limit of $3.6 \times 10^{-7} \mathrm{M}$ for neodymium. For the measurement of neodymium concentrations to within $+10 \%$ of their true value, the neodymium concentration of the solution should be three times the detection limit. In addition, the ICP/AES procedure requires that the total dissolved solids not exceed $20 \mathrm{mg} / \mathrm{mL}$. Thus, when a salt concentration of $2.0 \mathrm{M} \mathrm{NaNO}$ was used in the aqueous feed with $0.02 \mathrm{M} \mathrm{HNO}_{3}$, it had to be diluted 4 to 1 before samples could be analyzed. This dilution set the minimum level at $5 \times 10^{-6} \mathrm{M}$ for measuring neodymium concentrations with $\pm 10 \%$ accuracy. Note that ICP/AES can be used only for the aqueous phase; all organic-phase concentrations were determined indirectly by measuring the neodymium concentration in an aqueous phase that had been used to strip the neodymium from the organic phase. 
Based on an O/A flow ratio of 0.01 and a maximum allowable organic phase concentration of $7 \times 10^{-3} \mathrm{M}$, we chose $7 \times 10^{-5} \mathrm{M}$ for the neodymium concentration in the aqueous feed. Thus, even if all the neodymium were to go into the organic phase, the maximum concentration would not exceed the limit we set for that phase. Since the value for $\mathrm{D}_{\mathrm{Nd}}$ will be less than 1000 , as discussed above, a material balance on the neodymiumi shows that its concentration in the aqueous raffinate should be above the minimum neodymium concentration that we can measure using ICP/AES with $\pm 10 \%$ accuracy $\left(5 \times 10^{-6} \mathrm{M}\right)$. Thus, the aqueous feed concentration of $7 \times 10^{-5} \mathrm{M}$ Nd is low enough to prevent third-phase formation due to solvent loading, yet high enough to be analyzed for its neodymium concentration.

\section{Concentrator Tests}

\section{a. Test Runs}

As we stated, two series of extraction tests at O/A flow ratios or 0.01 were run with various throughputs within each series to see if extraction efficiency was affected by throughput. For these tests, one stage of the 4-cm contactor designed for remote-handled operation was used with appropriate FMI (Oyster Bay, NY 11771) pumps providing the influent flow rates. The contactor rotor had an upper-weir diameter of $18.14 \mathrm{~mm}$ (0.714 in.). Based on the preliminary considerations that we presented above, neodymium was extracted from a $0.02 \mathrm{M} \mathrm{HNO} / 2.0 \mathrm{M} \mathrm{NaNO}$ solution into the TRUEX-nDD solvent at approximate total throughputs of 200,300 , and $400 \mathrm{~mL} / \mathrm{min}$ using the flowsheet shown in Fig. 8.

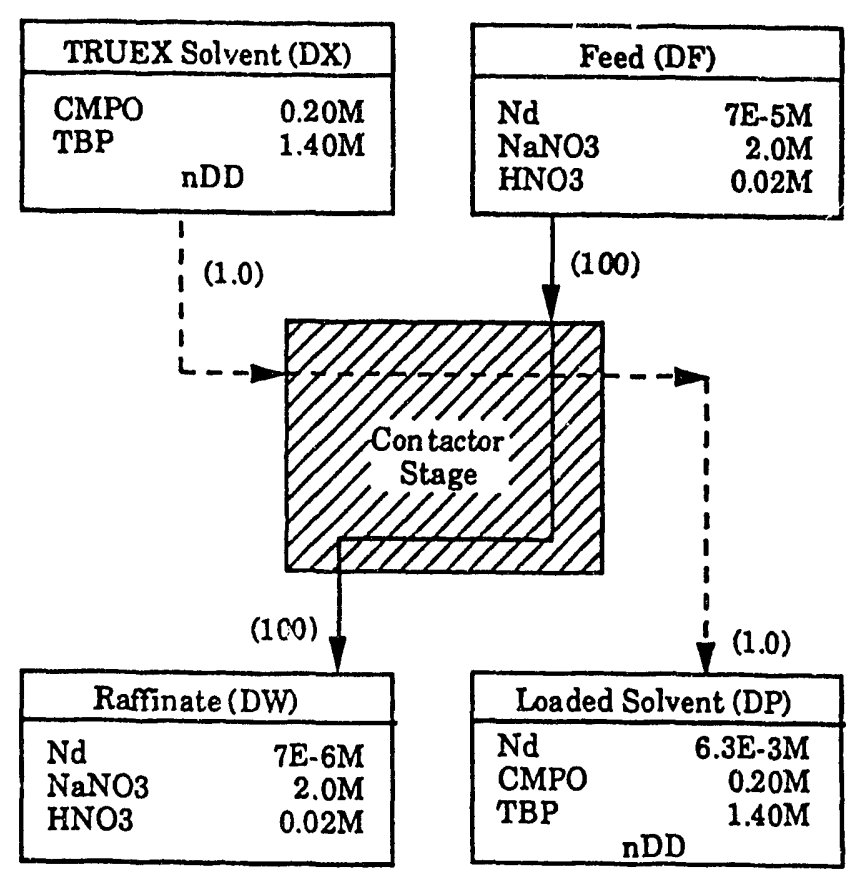

Fig. 8. Flowsheet for Single-Stage Concentrator Tests at O/A of 0.01. Effluent concentrations are shown for the case where the extraction efficiency is $100 \%$ and $D_{\mathrm{Nd}}$ is assumed to be 900 . Relative flow rates are shown in parentheses. 
The first series of tests (tests 1,2 , and 3, at total throughputs of about 200,400 , and $300 \mathrm{~mL} / \mathrm{min}$, respectively) was planned to run for seven organic-phase residence times each, with aqueous- and organic-effluent samples (DW and DP, respectively) taken at the end of organic-phase residence times 3,4,5, and 6. For each test, the DF feed was sampled and its temperature measured just before and just after the run. The DW samples were collected in a graduated cylinder for one minute. After each DW sample was taken, its volume was noted, its temperature measured, and a portion was set aside for ICP/AES analysis. For the DP samples, all the organic effluent for one residence time was collected in a tared Teflon bottle. Because the actual residence times for the organic phase were slightly longer than had been calculated from the preliminary tests, insufficient aqueous feed was available to continue to 7 residence times in test 3 . That test ran for 5.5 residence times.

After all tests were run, the DW flow rates were calculated from the sample voiumes and sample times, the DP sample bottles were weighed, and the DP mass flow rate was calculated. The density of the organic phase (DX) was then used to convert the mass flow rate to the volume flow rate. These data are summarized in Table 3.

Table 3. Summary of Data from Concentrator Tests at an O/A Flow Katio of 0.01

\begin{tabular}{cccccc}
\hline \multirow{2}{*}{$\begin{array}{c}\text { Test } \\
\text { No. }\end{array}$} & \begin{tabular}{c} 
Overage Flow Rate \\
\cline { 2 - 3 } $\mathrm{mL} / \mathrm{min}$
\end{tabular} & $\begin{array}{c}\text { Aqueous, } \\
\mathrm{mL} / \mathrm{min}\end{array}$ & $\begin{array}{c}\text { Total } \\
\text { Throughput, } \\
\mathrm{mL} / \mathrm{min}\end{array}$ & $\begin{array}{c}\text { O/A } \\
\text { Flow } \\
\text { Ratio }\end{array}$ & $\begin{array}{c}\text { Organic-Phase } \\
\text { Residence Time, } \\
\mathrm{min}\end{array}$ \\
\hline 1 & 2.19 & 192 & 194 & 0.0114 & 7.00 \\
2 & 3.53 & 402 & 406 & 0.0088 & 2.85 \\
3 & 3.04 & 304 & 307 & 0.0100 & 3.95 \\
4 & 1.95 & 196 & 198 & 0.0099 & 8.28 \\
5 & 3.72 & 395 & 399 & 0.0094 & 3.12 \\
6 & 2.82 & 301 & 304 & 0.0094 & 3.73 \\
\hline
\end{tabular}

Results for the first series of tests showed that the neodymium concentration in the aqueous feed solution had slowly increased with time. Therefore, when the second set of three cests was run, a motorized stirrer was used to mix the aqueous feed in its 25- $\mathrm{L}$ carboy instead of the manual mixing techniques used in the first series. In addition, each test ran for a shorter time to avoid running out of aqueous feed. The $200-\mathrm{mL} / \mathrm{min}$ test (test 4) ran for a total of 5 organic-phase residence times, with aqueous and organic effluent samples (DW and DP, respectively) taken starting at $2.5,3.2,3.8$, and 4.4 residence times. The $400-\mathrm{mL} / \mathrm{min}$ test (test 5) ran for a total of 6.5 residence times, with DW and DP samples taken starting at 3.0, 3.8, 4.5, and 5.3 residence times. The $300-\mathrm{mL} / \mathrm{min}$ test (test 6 ) ran for a total of 6.4 organic-phase residence times, with DW and DP samples taken starting at 3.0,4.1, 4.9, and 5.6 residence times. The residence times for the organic phase are reported in Table 3 . These residence times were determined by the time it took the organic phase to go through the contactor on startup with the aqueous phase flow fully established.

\section{b. Phase Equilibration}

Portions of the DW and DP samples taken during the final residence time of each concentrator test were mixed and allowed to reach equilibrium at the same temperature 
and the same O/A ratio at which they were contacted. This was done to determine the actual $\mathrm{D}_{\mathrm{Nd}}$ value for each test. For each equilibration, a measured aqueous-phase (DW) volume was placed in the equilibrating container; then the organic phase (DP) was added to the container while its weight was measured. For each test, this mixture was allowed to equilibrate in a constant-temperature bath for one hour. Then the mixture was vigorously shaken for 15 seconds and returned to the bath for three minutes. After the shaking/equilibrating cycle was repeated for a total of four times, the two phases were separated using a separatory funnel.

For two equilibrations, an aqueous sample was taken after four cycles and the remaining solutions were put through four more cycles. This way, we could determine whether or not the four shaking/equilibrating cycles were sufficient to allow the neodymium in the two phases to reach equilibrium. Analysis of the aqueous samples from these extended tests showed that equilibrium had indeed been reached.

\section{c. Neodymium Concentration in the Organic Phase}

An attempt was made to strip the neodymium from the organic phase (DP) samples through contact with an aqueous solution containing $0.05 \mathrm{M}$ HEDPA in $0.1 \mathrm{M}$ $\mathrm{HNO}_{3}$. This was done to determine the neodymium concentration in these samples so that a mass-balance check could be made for the neodymium. The analytical results for the neodymium concentrations in these organic samples did not match mass balance predictions. After much work, we finally determined that a precipitate of a neodymium salt of HEDPA was formed in the aqueous phase during and after the contact of the HEDPA solution with the DP samples. The existence of this precipitate interfered with the analysis of neodymium in the organic phase. Because of this problem, organic-phase concentrations were determined from mass balances using aqueous-phase concentrations.

\section{B. Stripping}

A two-stage contactor test was done to measure the extraction (stripping) efficiency when neodymium is stripped from the organic phase at very high O/A flow ratios. The flowsheet for this test is shown in Fig. 9. In the first stage, neodymium was loaded into the organic phase from an aqueous phase at normal O/A flow ratios, that is, at an O/A flow ratio close to 1.0. In the second stage, the concentrating stage, the neodymium was stripped from the organic phase into another aqueous phase at a high O/A flow ratio. The $\mathrm{D}$ value for neodymium in the second stage was low because of the HEDPA complexant in the aqueous feed to stage 2 . As a result, the neodymium was concentrated in the aqueous effluent from the second stage.

\section{Preliminary Considerations}

Besides the considerations of solvent loading, ICP/AES detection limits, and residence time discussed above for the extraction tests, several other factors were considered in planning this test.

\section{a. Other-Phase Carryover}

Since the O/A flow ratio in stage 2 of this test is high, a small fraction of other-phase carryover in the organic effluent from stage 1 (the organic influent to stage 2) will 
make a large difference in it. To be sure that the other-phase carryover in the organic effluent from stage 1 is low $(<1 \%)$, a series of tests was run in stage 1 with an aqueous solution $(0.01 \mathrm{M}$ $\mathrm{HNO}_{3}$ ) and an organic solvent (TRUEX-NPH). The results of the test, listed in Table 4, show how O/A flow ratio and total throughput affect other-phase carryover. Basically, in the O/A flow range from 0.5 to 2.0 , the other-phase carryover should be $<0.3 \%$ if the total throughput is less than or equal to $600 \mathrm{~mL} / \mathrm{min}$.

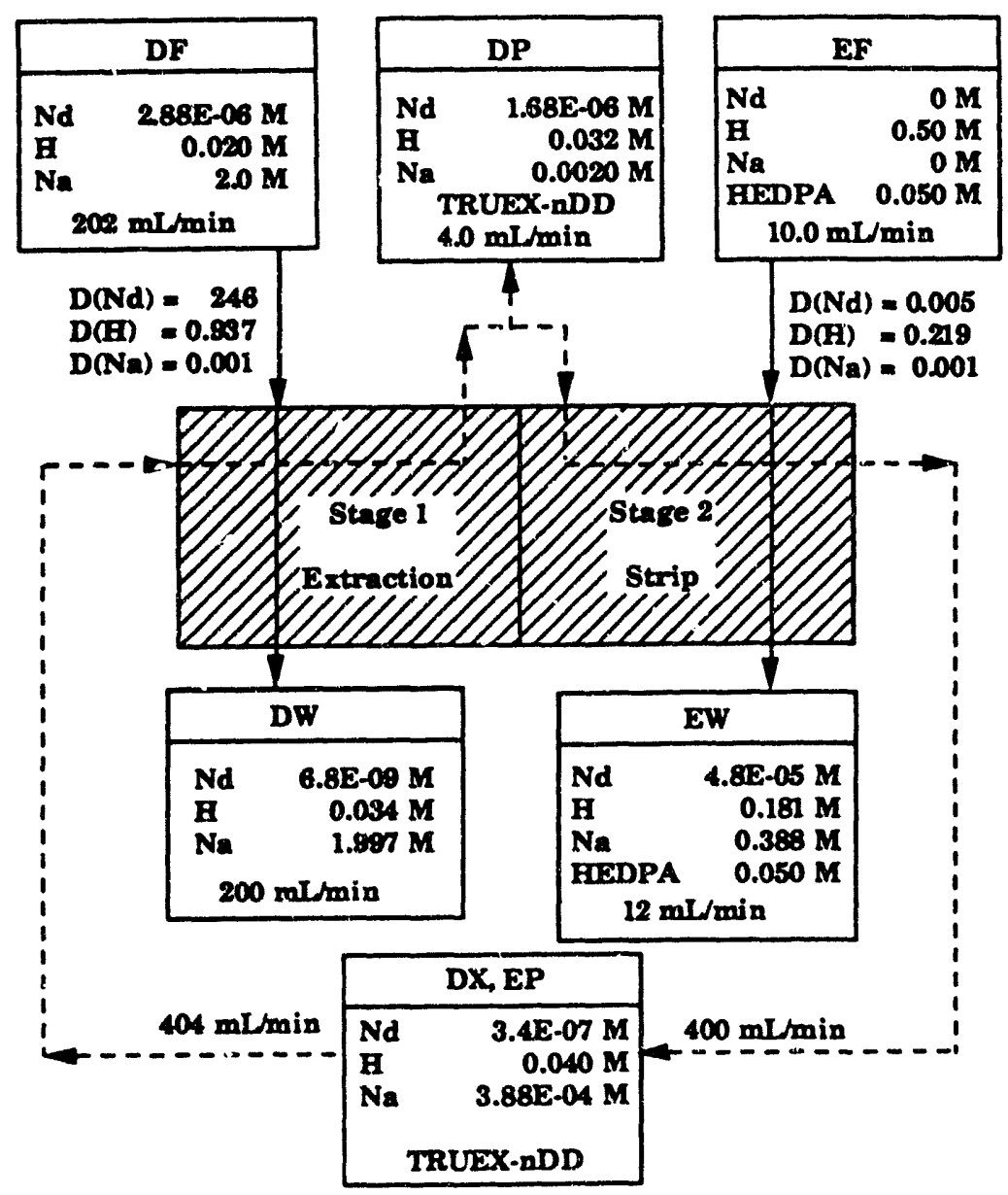

Fig. 9. Flowsheet for Two-Stage Contactor Test. Effluent concentrations are for the case where the extraction efficiency is $100 \%$, the D values for stages 1 and 2 are as shown, and the aqueous-phase carryover from stage 1 to stage 2 is $0.5 \%$.

The other-phase carryover was also measured at a high O/A flow ratio (100) to determine lise amount of aqueous phase in the organic phase for high flow ratios. If it is high, the aqueous effluent could disappear entirely since the aqueous flow rate is low relative to the organic flow rate. The results, given in Table 5, show that it is very low $(<0.1 \%)$. Note that the amount of organic phase in the aqueous phase is greater than $1 \%$ for total throughputs greater than $200 \mathrm{~mL} / \mathrm{min}$. Since this is high other-phase carryover in the low-flow phase, it can be tolerated, as the concentrator theory above shows it will have only a minimal effect on concentrator operation. Note also that $O$ in $A$ for a given flow rate is greatest for rotor 1 . This is not unexpected as the more-dense-phase weir of the stage 1 rotor has a larger diameter than that of the other three stages, $18.14 \mathrm{vs.} 18.01 \mathrm{~mm}(0.714 \mathrm{vs} .0 .709 \mathrm{in}$.). In the actual 
concentrator test, the O/A flow ratio was 33, not 100 . Thus, the other-phase carryover for the test will be between the results in Tables 4 and 5, but they shouic be closer to the results in Table 5.

Table 4. Effect of Throughput on Other-Phase Carryover at O/A Ratios from 0.5 to 2.0 for Remote-Handled 4-cm Contactor

\begin{tabular}{|c|c|c|c|c|c|c|}
\hline \multirow{2}{*}{$\begin{array}{l}\text { Nominal } \\
\text { O/A }\end{array}$} & \multicolumn{3}{|c|}{ Flow Rates, $\mathrm{mL} / \mathrm{min}$} & \multirow{2}{*}{$\begin{array}{c}\text { Actual } \\
\text { O/A }\end{array}$} & \multicolumn{2}{|c|}{$\begin{array}{l}\text { Other-Phase } \\
\text { Carryover, \% }\end{array}$} \\
\hline & Organic & Aqueous & Total & & $O$ in $A$ & $A$ in $O$ \\
\hline \multirow[t]{4}{*}{0.5} & 98.4 & 201.3 & 300 & 0.49 & 0.04 & 0.02 \\
\hline & 151.2 & 302.3 & 454 & 0.50 & 0.06 & 0.13 \\
\hline & 201.0 & 400.3 & 601 & 0.50 & 0.06 & 0.20 \\
\hline & 252.6 & 496.5 & 749 & $0.5 !$ & 0.04 & 11.72 \\
\hline \multirow[t]{4}{*}{1} & 196.4 & 197.4 & 394 & 0.99 & 0.08 & 0.02 \\
\hline & 298.3 & 303.2 & 602 & 0.98 & 0.27 & 0.11 \\
\hline & 387.4 & 400.0 & 787 & 0.97 & 0.50 & 1.91 \\
\hline & 501.1 & 500.2 & 1001 & 1.00 & 0.04 & 6.19 \\
\hline \multirow[t]{4}{*}{2} & 201.4 & 97.8 & 299 & 2.06 & 0.15 & 0.06 \\
\hline & 298.5 & 148.7 & 447 & 2.01 & 0.05 & 0.23 \\
\hline & 392.4 & 201.4 & 594 & 1.95 & 0.10 & 0.11 \\
\hline & 493.2 & 244.6 & 738 & 2.02 & 0.57 & 0.62 \\
\hline
\end{tabular}

Table 5. Effect of Throughput on Other-Phase Carryover and Phase Volume at an O/A Flow Ratio of 100 for Remote-Handled 4-cm Contactor

\begin{tabular}{|c|c|c|c|c|c|c|c|c|}
\hline \multirow[b]{2}{*}{ Stage } & \multicolumn{3}{|c|}{ Flow Rate, $\mathrm{mL} / \mathrm{min}$} & \multirow{2}{*}{$\begin{array}{l}\text { Actual } \\
\text { O/A }\end{array}$} & \multicolumn{2}{|c|}{$\begin{array}{l}\text { Other-Phase } \\
\text { Carryover, \% }\end{array}$} & \multicolumn{2}{|c|}{$\begin{array}{l}\text { Phase Volume } \\
\text { in Rotor, } \mathrm{mL}\end{array}$} \\
\hline & Ag. & Org. & Total & & $\overline{O \text { in } A}$ & $A$ in $O$ & Ag. & Org \\
\hline \multirow[t]{4}{*}{1} & 1.02 & 99.6 & 100.6 & 97.6 & 1.0 & $<0.1^{b}$ & 35.6 & 36.3 \\
\hline & 2.04 & 196.5 & 198.5 & 96.3 & 1.1 & $<0.1^{b}$ & 35.5 & 36.5 \\
\hline & 3.04 & 301.2 & 304 & 99.1 & 6.6 & $<0.1^{b}$ & 33.9 & 38.9 \\
\hline & 4.05 & 402 & 406 & 99.3 & 6.2 & $<0.1^{b}$ & 34.0 & 37.5 \\
\hline 2 & 2.70 & 298.5 & 301 & 110.6 & 2.9 & $<0.1^{b}$ & 31.8 & 41.2 \\
\hline $3^{c}$ & 2.85 & 298.9 & 302 & 104.9 & 1.3 & $<0.1^{b}$ & 44.3 & 25.2 \\
\hline $4^{c}$ & 3.06 & 302.7 & 306 & 98.9 & 4.8 & $<0.1^{b}$ & 40.5 & 29.6 \\
\hline
\end{tabular}

The phase volume in the rotor is determined by draining the contents of the contactor rotor into a beaker, separating the organic and aqueous phases using a separatory funnel, and measuring their respective volumes.

bThere was no observable aqueous phase in the organic phase ( $\mathrm{A}$ in $\mathrm{O}$ ) exiting the contactor.

Therefore, the amount of $A$ in $O$ is less than $0.1 \%$.

'The stage was not used in the concentrator tests reported here. It is included to show the variability of other-phase carryover and phase volume from stage to stage. 
In these tests, the other-phase carryover was measured as follows. For the more-dense-phase eff'uent ( $O$ in $A)$, the liquid is collected in a graduated cylinder. If the other-phase carryover is high, the volume of the less-dense phase can be read directly. If the olume is small, the top portion of the liquid is poured into a smaller graduated cylinder or centrifuge tube so that it can be read more accurately. A separatory funnel can also be used to make this separation. For the less-dense-phase effluent ( $A$ in $O$ ), the liquid is also collected in a graduated cylinder. If the other-phase carryover is very high, the volume of the more-dense phase is read directly. If the more-dense-phase volume is small, the top portion of liquid is poured off and the bottom portion is put into a smaller graduated cylinder. If the amount of the more dense phase is very small, a centrifuge tube for which the volume in the tapered tip has been calibrated should be used. In this way, other-phase carryover can be measured down to about $0.1 \%$. If phase separation is slow, the liquid sample should be centrifuged before the volume measurements are made.

\section{b. Residence Time}

For this stripping test, the longest residence time is that of the aqueous phase in stage 2. The volume of the aqueous phase in the rotor was measured at no-flow conditions for an $\mathrm{Q}$ ! A flow ratio of 100 . The results, given in Table 5, show that wis volume is between 32 and $44 \mathrm{~mL}$. This volume should not change much at an O/A flow ratio of 33 . In calculating the residence time of the aqueous phase in stage 2 , a volume of $40 \mathrm{~mL}$ was used. With an aqueous feed of $10 \mathrm{~mL} / \mathrm{min}$ to stage 2 , the residence time of the aqueous phase becomes 4 minutes. Thus, the run time was set at 28 minutes so that samples could be taken up through six residence times. The other effluents, which have much shorter residence times in the contactor, should reach steady-state concentrations much sooner.

\section{c. O/A Flow Ratios}

The O/A flow ratio for the stripping stage (stage 2) was chosen so that the extraction (stripping) efficiency could be measured accurately. To do this, the stripping factor should be greater than or equal to 5 . Based on solvent stripping tests with an HEDPA solution, it appeared that $D_{N d}$ would be about 0.005 in stage 2 . Thus, an O/A flow ratio of 40 was chosen for stage 2 . Since the flow of aqueous feed (EF) to stage 2 should be as high as possible to keep residence times and solution volumes reasonable, a value of $10 \mathrm{~mL} / \mathrm{min}$ was chosen for the EF flow. This sets the organic flow rate at $400 \mathrm{~mL} / \mathrm{min}$.

Since the total flow in stage 1 should not exceed $600 \mathrm{~mL} / \mathrm{min}$, the aqueous flow to that stage should not exceed $200 \mathrm{~mL} / \mathrm{min}$. The high $(200 \mathrm{~mL} / \mathrm{min})$ value for the aqueous flow to stage 1 was used so that the extraction factor would be high. In this way, essentially all the neodymium in the aqueous feed was transferred to the organic phase. This set the O/A flow in stage 1 to 2.0 and allowed us to focus our attention on stage 2.

\section{d. Precipitation of Neodymium Salt of HEDPA}

We needed to avoid the precipitation of the neodymium salt of HEDPA in stage 2. This problem had been encountered in the extraction tests while stripping neodymium from the TRUEX-nDD solvent. The white precipitate was observed in a small volume of aqueous phase at the bottom of a container holding TRUEX-nDD solvent that had 
been discarded after the concentrator tests at an O/A flow ratio of 0.01 . Neodymium had been stripped from this solvent after the tests by using HEDPA solution, and we suspected that the aqueous phase was residual HEDPA solution. We removed $1 \mathrm{~mL}$ of this aqueous phase plus precipitate and found that it dissolved in $20 \mathrm{~mL}$ of $0.5 \mathrm{M}$ nitric acid solution. An ICP/AES analysis showed that the solution contained neodymium $\left(8.4 \times 10^{-4} \mathrm{M}\right)$ and sodium $(0.015 \mathrm{M})$. Since this TRUEX solvent had been through the HEDPA stripping procedure, the amount of neodymium found was surprisingly high; the white precipitate was consequently assumed to be a neodymium salt of HEDPA.

To test this hypothesis, a batch test was made prior to the stripping run at an O/A flow ratio of 40 . First, an aqueous solution containing $3.5 \times 10^{-5} \mathrm{M} \mathrm{Nd}, 0.02 \mathrm{M} \mathrm{HNO}$, and 2.0 M NaNO 3 was mixed well at an O/A of 1.0 with TRUEX-nDD that had been stripped of neodymium from the first two series of concentrator tests. The two phases were then separated and the organic phase was mixed well with an aqueous solution of $0.5 \mathrm{M} \mathrm{HNO}_{3}$ and $0.05 \mathrm{M}$ HEDPA at an O/A of 40 . After about 15 minutes, a large amount of white precipitate was seen in the aqueous phase. Small amounts of the HEDPA solution were added successively to these two phases, which were mixed well and allowed to stand for about ten minutes. The precipitate completely dissolved at an O/A of about 1.67.

To eliminate the possibility that the precipitate was caused by sodium instead of neodymium, an aqueous solution of $2.0 \mathrm{M} \mathrm{NaNO}$ and $0.02 \mathrm{M} \mathrm{HNO}$ was contacted with clean TRUEX-nDD at an O/A of 1.0, after which the TRUEX solution was contacted with the HEDPA solution at an O/A of 40 and allowed to sit for 30 minutes. No precipitate was observed. This confirmed that the precipitate was a neodymium salt of HEDPA.

Since a neodymium precipitate formed at an O/A ratio of 1.0 and was dissolved at an O/A of 1.67 , the saturation concentration for the neodymium salt in the $0.5 \mathrm{M}$ $\mathrm{HNO}_{3} / 0.05 \mathrm{M}$ HEDPA solution was calculated to be about $5.8 \times 10^{-5} \mathrm{M}$. This saturation concentration was verified by additional batch tests with aqueous solutions of various neodymium concentrations. The results confirmed this value for the saturation concentration of the neodymium salt of HEDPA. Based on this solubility and the need to get neodymium concentrations high enough to be analyzed, the neodymium concentration in the aqueous feed to stage 1 was set at $2.88 \times 10^{-6} \mathrm{M}$. Given the O/A flow ratios stated above along with the $D_{\mathrm{Nd}}$ values shown in Fig. 9 for stages 1 and 2, this feed concentration should give a neodymium concentration in the HEDPA stripping solution that is saturated with the neodymium salt of HEDPA.

\section{e. Interstage Sampling Tube}

To obtain organic effluent from stage 1 (DP), the U-shaped interstage tube used to carry the organic phase from stage 1 to stage 2 was modified to include a tee in the middle of the $U$. This tee, which was perpendicular to the $U$ and extended down from it, was connected to a positive-displacement metering pump set at $4 \mathrm{~mL} / \mathrm{min}$. Because the volume of liquid in the pump and sampling line was $21 \mathrm{~mL}$, the lag between the time when the DP solution left stage 1 and the time when it was sampled was 5.25 minutes. Based on a residence time of 4 minutes for the test, this time lag amounts to 1.3 residence times. 


\section{Concentrator Tests}

Based on these preliminary considerations, the flowsheet in Fig. 9 was designei for the two-stage contactor. The effluent concentrations shown are based on $100 \%$ extraction efficiency, $0.5 \% \mathrm{~A}$ in $\mathrm{O}$ to stage 2 , and the $\mathrm{D}$ values as shown.

\section{a. Batch Pretest}

To verify that a neodymium salt would not precipitate during the HEDPA stripping of the organic solvent in stage 2, a trial run was made using batch contacts. The test solutions were contacted in a centrifuge tube at the same O/A ratios planned for the contactor test. After the initial extraction contact, the phases were separated, and the organic phase was contacted with the EF feed to the stripping stage and allowed to stand over a weekend. At the end of that time, no precipitation was seen. Although this batch test did not account for the extra neodymium which would enter into the extraction stage because the organic phase is recycled, Fig. 9 shows that this recycle adds less than 10\% more neodymium. Therefore, no precipitation of the neodymium salt of HEDPA should occur during the test.

\section{b. TestRun}

The flowsheet shown in Fig. 9 was run using two stages of a 4-cm contactor designed for remote handling. The flow rates were attained using FMI positivedisplacement pumps. A common container for the organic feed (DX) and organic raffinate (EP) allows for full organic recycle. The container, a 1.2-L crystallization dish with a height of $75 \mathrm{~mm}$ and a diameter of $150 \mathrm{~mm}$, was placed on a magnetic stirrer that kept the solution well mixed. Approximately $1.1 \mathrm{~L}$ of solvent was in the container at the start of the test. Before the tests started, $40 \mathrm{~mL}$ of a $0.02 \mathrm{M} \mathrm{HNO}_{3}$ solution with $2.0 \mathrm{M} \mathrm{NaNO} \mathrm{Nas}_{3}$ woured into stage 1 so that no organic phase would go out the aqueous exit port. At the same time, $40 \mathrm{~mL}$ of the EF solution was added to stage 2 . Also, three DF samples were taken.

As mentioned above, the residence cime for the system was taken to be 4.0 minutes based on the aqueous phase flowing through stage 2 . Starting at $3,4,5$, and 6 residence times, three operations were carried out. (1) The stage- 1 organic effluent (DP) and stage- 2 aqueous effluent (EW) sample bottles were put in place. (2) The stage-1 aqueouseffluent (DW) and stage-2 organic-effluent (EP) flow rate samples were taken. (3) A stage-1 organic feed (DX) sample was taken. The order and details of these operations are outlined below.

The DP and EW samples were taken by collecting the total volume of effluent for one residence time starting at 3,4,5 and 6 residence times. These samples were taken in tared bottles. After the test was over, the bottles were weighed and the mass flow rates were calculated. Solution densities were sed to convert these mass flow rates to volumetric flow rates.

As soon as the sampling bottles for DP and EW were in place, the flow rates of the DW and EP streams were measured by taking one-minute samples in graduated cylinders. Immediately after these flow rates were measured, a sample was taken from the DX feed container. The volumes of the DW and EP samples were then noted, the temperature of 
each solution was measured, and a small volume of each sample was set aside for chemical analysis. After the test, three additional DF samples were taken. The contactors were then drained and flushed out with $0.1 \mathrm{M} \mathrm{HNO}_{3}$. The data taken during the test are summarized in Table 6 with standard deviations shown for the average flow rates.

Table 6. Summary of Data Taken during Two-Stage Contactor Test

\begin{tabular}{ccccc}
\hline Stage & $\begin{array}{c}\text { Effluent } \\
\text { Stream }\end{array}$ & $\begin{array}{c}\text { Average } \\
\text { Flow Rate, } \\
\mathrm{mL} / \mathrm{min}\end{array}$ & $\begin{array}{c}\text { Average } \\
\text { Temp., } \\
{ }^{\circ} \mathrm{C}\end{array}$ & $\begin{array}{c}\text { Average } \\
\text { Flow } \\
\text { Ratio }\end{array}$ \\
\hline 1 & & & & 2.71 \\
& DW & $144.5 \pm 1.7$ & 23.8 & \\
2 & DP & $3.53 \pm 0.02$ & -- & 32.8 \\
& & & & \\
& EW & $11.85 \pm 0.30$ & -- & \\
\hline
\end{tabular}

With standard deviation.

\section{c. Phase Equilibrations}

In both the extraction and stripping stages, the appropriate $D_{\mathrm{Nd}}$ value was determined by equilibrating portions of the organic and aqueous effluents from the stage at the test temperature. For stage 1, two DP samples were combined to get enough organic phase for an O/A volume ratio of 0.5 when contacted with a portion of the DW sample. For stage 2, DX was contacted with EW at an O/A volume ratio of 3.0. The DX sample was chosen for the organic phase instead of EP since there was more of that sample available. Because the neodymium concentrations of both phases were to be analyzed after they were equilibrated, there was no attempt made to keep the same O/A ratio used in the test or to use samples taken at the same residence time.

For each equilibration, the two phases were placed in a centrifuge tube and equilibrated in a constant temperature bath for one hour. Then the tube was shaken vigorously for 20 seconds and returned to the bath for three minutes. This shaking/equilibrating cycle was repeated seven times, after which the aqueous phase was drawn off using a pipet and was prepared for analysis.

\section{d. Sample Preparation}

Except for DW samples, the analyses for neodymium were done by ICP/AES, which has a detection limit of $3.6 \times 10^{-8} \mathrm{M}$ where sodium salts are $0.4 \mathrm{M}$ or less. Because the predicted neodymium concentration in the DW samples was so low, isotope dilution mass spectrometry (IDMS), which has a detection limit of $7 \times 10^{-9} \mathrm{M}$, was used. However, sample preparation was the same for either method.

The neodymium had to be stripped out of all the organic samples with HEDPA solution, since both ICP/AES and IDMS procedures require the samples to be in the aqueous phase. Of the aqueous samples, only the EW samples could be analyzed in their 
original form. For the others, the DW samples, the neodymium had to be extracted and then stripped to remove the sodium prior to IDMS analysis. In selecting the O/A volume ratios to use in these extracting and stripping preparations, the following factors had to be considered: (1) the neodymium detection limit of the analytical procedure, (2) the concentration at which neodymium forms a precipitate in the HEDPA stripping solution, (3) the minimum volume of aqueous phase needed for analysis, and (4) the available sample volume. The O/A volume ratio, therefore, varied considerably from sample to sample.

Each of the aqueous DW samples, including the equilibrated samples, was contacted once in a centrifuge tube with the TRUEX-nDD solvent. The neodymium was recovered from the solvent by stripping with an HEDPA solution, actually f esh EF solution. The aqueous phase from this stripping operation was sent out for IDMS analysis. The last two DW samples taken during the test, along with the DW sample from equilibration, were prepared for IDMS analysis.

Each organic sample taken during the test was contacted once with fresh EF solution to strip out the neodymium. After separation, the neodymium concentration of the aqueous phase was analyzed by ICP/AES.

Because there was only one contact in each extraction and/or strip operation, it is possible that a small amount of neodymium was not extracted or stripped during the operation. However, from past experience, the $D_{N d}$ for the stripping procedure should have been about 0.005 , and the $D_{\mathrm{Nd}}$ for the extraction process should have been about 500 .

Therefore, the neodymium lost by contacting the samples only once at $\mathrm{O} / \mathrm{A}$ volume ratios close to 1.0 should be $0.5 \%$ or less. 


\section{RESULTS}

Results for contactor efficiency during extraction show how it can be affected by low O/A flow ratios. Results for contactor efficiency during stripping show how it can be affected by high O/A flow ratios. These contactor efficiencies, also called extraction efficiencies, are then combined to derive an overall correlation with the O/A flow ratio.

\section{A. Extraction}

\section{Neodymium Concentrations}

Measured neodymium concentrations are given in Table 7 for the aqueous samples from each extraction test along with the calculated neodymium concentrations in the DP samples and the calculated D values. As the data show, the neodymium concentration in the DF feed varied throughout the first series of tests (tests 1 to 3 ). This variation is attributed to inadequate mixing of the DF feed solution. A corresponding increase with time of the neodymium concentration in the DW raffinate can also be seen in this table. Thus, the system was not quite at steady state, making the error associated with DF at a specific organic-phase residence time somewhat larger than it would otherwise have been. Because of the way the DF feed was prepared, its average neodymium concentration was $8.62 \times 10^{-5} \mathrm{M}$ rather than the $7.0 \mathrm{x}$ $10^{-5} \mathrm{M}$ value planned. Thus, the higher concentrations seen in Table 7 for the first series of tests were not unexpected. The measured neodymium concentrations and $\mathrm{D}_{\mathrm{Nd}}$ values were used to get the stage extraction efficiencies reported here.

In the second series of tests (tests 4 to 6), the neodymium concentration in the DF feed appeared to increase with time during test 4 even though a motor-driven mechanical stirrer was used to mix the feed in its 25-L carboy. During tests 5 and 6 , which continued to feed from the same carboy, the neodymium concentration in the DF feed was effectively constant. However, like the DW raffinate in tests 1 to 3 , the concentration of neodymium in the DW raffinate for tests 4 to 6 rose, leveled off, and then fell over the period of the three tests.

\section{Extraction Efficiency}

To obtain the extraction efficiency, we first calculated the neodymium concentration in the organic phase from the measured values for the neodymium concentration in the aqueous phase and the O/A flow ratio (R). Then, we calculated the $D$ value for neodymium from the equilibrated neodymium concentration in the aqueous phase. Finally, we combined neodymium concentrations with the $R$ and $D$ values to get the extraction efficiency with respect to the aqueous phase.

Neodymium concentrations are given in Table 7 for $(1)$ the aqueous feed, $x_{D F}$, (2) the aqueous raffinate, $x_{D W}$, and (3) the equilibrated aqueous raffinate, $x_{D W}$ eq. These values, along with the O/A flow ratios given in Table 3, were used to calculate the neodymium concentration in the organic phase effluent, $y_{D P}$, and the $D$ value for each test. The $y_{D P}$ values in Table 7 were calculated from the material balance about the contactor stage, which has the form 


$$
y_{D P}=\frac{x_{D F}-x_{D W}}{R}+y_{D X}
$$

Table 7. Analytical Results from Concentrator Tests at O/A Flow Ratio of 0.01

Organic-

\begin{tabular}{|c|c|c|c|c|c|c|c|}
\hline \multirow[b]{2}{*}{$\begin{array}{l}\text { Test } \\
\text { No. }\end{array}$} & \multirow{2}{*}{$\begin{array}{l}\text { Organic- } \\
\text { Phase } \\
\text { Residence } \\
\text { Time }\end{array}$} & \multicolumn{4}{|c|}{ Nd Concentration in Feeds and Effluents, $\underline{M}$} & \multirow[b]{2}{*}{$\begin{array}{c}\text { Calc. } \\
\text { D Value }\end{array}$} & \multirow[b]{2}{*}{ Notes } \\
\hline & & DF & DW & $\begin{array}{c}\text { Equil. } \\
\text { DW: }\end{array}$ & $\begin{array}{c}\text { Calc. } \\
\text { DP }\end{array}$ & & \\
\hline \multirow[t]{6}{*}{1} & 0 & $6.10 \mathrm{E}-05$ & & & & & \\
\hline & 3 & & 1.48E-05 & & & & \\
\hline & 4 & & $1.60 \mathrm{E}-05$ & & & & \\
\hline & 5 & & $1.40 \mathrm{E}-05$ & & & & \\
\hline & 6 & $7.94 \mathrm{E}-05^{\mathrm{b}}$ & $1.71 \mathrm{E}-05$ & 8.80E-06 & 5.47E-03 & 703 & c \\
\hline & 7 & $8.25 \mathrm{E}-05$ & & & & & \\
\hline \multirow[t]{6}{*}{2} & 0 & 8.53E-05 & & & & & \\
\hline & 3 & & 3.36E-05 & & & & \\
\hline & 4 & & 3.23E-05 & & & & \\
\hline & 5 & & 3.61E-05 & & & & \\
\hline & 6 & $9.18 \mathrm{E}-05^{b}$ & $3.21 E-05$ & $1.48 \mathrm{E}-05$ & $6.80 \mathrm{E}-03$ & 591 & $c, d$ \\
\hline & 7 & $9.29 \mathrm{E}-05$ & & & & & \\
\hline \multirow[t]{4}{*}{3} & 0 & $9.22 \mathrm{E}-05$ & & & & & \\
\hline & 3 & & & & & & $\mathbf{e}$ \\
\hline & 4 & $9.34 \mathrm{E}-05^{\mathrm{b}}$ & 1.97E-05 & $1.76 \mathrm{E}-05$ & 7.38E-03 & 431 & $c, f$ \\
\hline & 4.5 & $9.36 \mathrm{E}-05$ & & & & & \\
\hline \multirow[t]{6}{*}{4} & 0 & 3.99E-05 & & & & & \\
\hline & 2.5 & & $1.77 \mathrm{E}-05$ & & & & \\
\hline & 3.2 & & $1.78 \mathrm{E}-05$ & & & & \\
\hline & 3.8 & & & & & & e \\
\hline & 4.4 & $6.29 \mathrm{E}-05^{\mathrm{b}}$ & $2.14 \mathrm{E}-05$ & $1.19 \mathrm{E}-05$ & 4.18E-03 & 433 & c \\
\hline & 5.1 & $6.66 \mathrm{E}-05$ & & & & & \\
\hline \multirow[t]{6}{*}{5} & 0.0 & $6.59 \mathrm{E}-05$ & & & & & \\
\hline & 3.0 & & 2.36E-05 & & & & \\
\hline & 4.1 & & 2.37E-05 & & & & \\
\hline & 4.9 & & $2.30 \mathrm{E}-05$ & & & & \\
\hline & 5.6 & $6.53 \mathrm{E}-05^{b}$ & $2.41 \mathrm{E}-05$ & 7.45E-06 & 4.37E-03 & 823 & c \\
\hline & 6.4 & $6.52 \mathrm{E}-05$ & & & & & \\
\hline \multirow[t]{6}{*}{6} & 0.0 & $6.59 \mathrm{E}-05$ & & & & & \\
\hline & 3.0 & & $2.44 \mathrm{E}-05$ & & & & \\
\hline & 3.8 & & 2.21E-05 & & & & \\
\hline & 4.5 & & 2.18E-05 & & & & \\
\hline & 5.3 & $6.55 \mathrm{E}-05^{\mathrm{b}}$ & 1.77E-05 & $9.91 \mathrm{E}-06$ & $5.11 E-03$ & 599 & c, $g$ \\
\hline & 6.0 & $6.55 \mathrm{E}-05$ & & & & & \\
\hline
\end{tabular}

"From batch measurements using an O/A volume that matches the O/A flow ratio.

bInterpolated value.

cThis line used to calculate extraction efficiency by method II.

${ }^{\mathrm{d} D W}$ equilibrated at $\mathrm{O} / \mathrm{A}=0.0092$.

eDW sample lost.

${ }^{f}$ Averge $D$ value for the first series is $570 \pm 140$.

BAverge D value for the second series is $620 \pm 200$. 
Since there was no neodymium in the organic (DX) feed (i.e., $\mathrm{y}_{D X}=0$ ), Eq. 10 becomes

$$
y_{D P}=\frac{x_{D F}-x_{D W}}{R}
$$

To get the $\mathrm{D}$ value for neodymium, first note that the $\mathrm{D}$ value is defined as the equilibrated organic phase with a concentration of $y_{D P_{-} \text {eq }}$ divided by the equilibrated aqueous phase; that is,

$$
D=\frac{y_{\text {DP_eq }}}{x_{\text {DW_eq }}}
$$

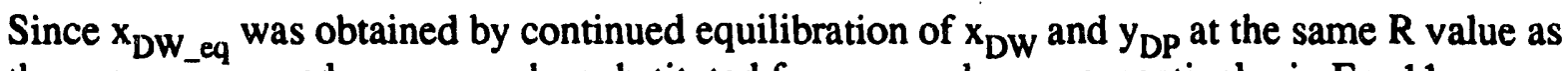
the run, $x_{D W}$ eq and $y_{D P_{-e q}}$ can be substituted for $x_{D W}$ and $y_{D P}$, respectively, in Eq. 11. Substituting the results into Eq. 12 gives

$$
D=\frac{1}{R}\left(\frac{x_{D F}}{x_{D W_{e q}}}-1\right)+\frac{y_{D X}}{x_{D W_{-} e q}}
$$

Again, since there was no neodymium in the organic (DX) feed, that is, $y_{D X}$ is zero, Eq. 13 becomes

$$
\mathrm{D}=\frac{1}{\mathrm{R}}\left(\frac{\mathrm{x}_{\mathrm{DF}}}{\mathrm{x}_{\mathrm{DW}_{-} \text {eq }}}-1\right)
$$

This expression was used to get the calculated D values shown in Table 7. As noted in Table 7, the standard deviation for the $D$ values for all tests is large, $\pm 28 \%$. It reflects the various errors in the experimental process, including those in the neodymium concentration measurements at low concentrations of neodymium in high concentrations of $\mathrm{NaNO}_{3}$, the variations in the neodymium concentration with time, and the errors in getting the same $\mathrm{O} / \mathrm{A}$ volume ratio for equilibration of the aqueous (DW) effluent with the organic (DP) effluent.

Using these neodymium concentrations and $D$ values, the fractional extraction efficiency was calculated by dividing the amount of neodymium in the aqueous phase that was extracted into the organic phase by the amount of neodymium that would have been extracted if the two phases had reached equilibrium as follows: 


$$
F_{e}=\frac{x_{D F}-x_{D W}}{x_{D F}-x_{D W_{-}}}
$$

The results are listed in Table 8 for methods I and II. In method I, the average D value for each test series was used to calculate $\mathrm{x}_{\mathrm{DW}_{-} \text {eq }}$ using. Eq. 13 rearranged as

$$
x_{D W_{-} e q}=\frac{x_{D F}+R y_{D X}}{1+R D}
$$

Again, since there was no neodymium in the organic (DX) feed, that is, $y_{D X}$ is zero, Eq. 16 becomes

$$
x_{D W_{-} e q}=\frac{x_{\text {PF }}}{1+R D}
$$

Because the mixing problem in the first test series may have caused the loading of the organic solvent and, therefore, the $D_{N d}$ values to vary, the $D$ values for the two series of tests were treated separately. In method II, the measured value for $\mathrm{x}_{\mathrm{DW} \text { eq }}$ for each run was substituted directly into Eq. 15. The extraction efficiencies were about the same for both methods. Their values for second test series were lower than those for the first series, but, given the variation between individual values, these differences were not statistically significant. Nevertheless, the extraction efficiencies for these very low $\mathrm{O} / \mathrm{A}$ flow ratios $(0.01)$ are somewhat less than the

\begin{tabular}{|c|c|c|c|c|}
\hline \multicolumn{3}{|c|}{ Nominal } & \multicolumn{2}{|c|}{ Fractional Extraction Efficiency } \\
\hline Series & $\begin{array}{l}\text { Flow Rate, } \\
\mathrm{mL} / \mathrm{min}\end{array}$ & $\begin{array}{c}\text { Test } \\
\text { Number }\end{array}$ & $\begin{array}{c}\text { Method I } \\
\text { (Average D Value) }\end{array}$ & $\begin{array}{c}\text { Method II } \\
\text { (Equilibrated DW Sampless }\end{array}$ \\
\hline \multirow[t]{4}{*}{ First } & 200 & 1 & 0.905 & 0.883 \\
\hline & 300 & 3 & 0.927 & 0.973 \\
\hline & 400 & 2 & 0.779 & 0.776 \\
\hline & & & $0.870 \pm 0.080^{a}$ & $0.877 \pm 0.099^{4}$ \\
\hline \multirow[t]{4}{*}{ Second } & 200 & 4 & 0.768 & 0.814 \\
\hline & 300 & 6 & 0.856 & 0.860 \\
\hline & 400 & 5 & 0.740 & 0.713 \\
\hline & & & $0.788 \pm 0.061^{\mathrm{a}}$ & $0.796 \pm 0.076^{A}$ \\
\hline
\end{tabular}
greater-than-95\% value observed for O/A ratios close to 1.0. (See Sec. II.B.2 above.)

Table 8. Extraction Efficiencies for Single-Stage Concentrator Tests at O/A Flow Ratios of 0.01

average value with standard deviation. 


\section{B. Stripping}

\section{Concentrations}

Aqueous feed compositions for the two-stage stripping test are given in Table 9. These concentrations include both as-prepared and ineasured values. Neodymium concentrations in the organic feed (DX) are given in Table 10 as a function of the residence time ( $\left.t_{\mathrm{T}}\right)$ into the test. Neodymium concentrations in the aqueous effluents as well as the organic effluent (EP) are given in Table 11 as a function of residence time $\left(t_{T}\right)$. The results in Tables 10 and 11 show that the two-stage stripping test had not reached steady-state operation after 6.6 residence times. Note, for example, that the neodymium concentration in the organic (DX) feed was still decreasing when the test was over.

Table 9. Aqueous Feed Compositions for Concentrator Test at $\mathrm{O} / \mathrm{A}$ of 40

\begin{tabular}{|c|c|c|c|c|c|}
\hline \multirow[b]{3}{*}{ Component } & \multicolumn{4}{|c|}{ Component Concentration, $\mathbf{M}$} & \multirow[b]{3}{*}{ Notes } \\
\hline & \multicolumn{2}{|c|}{ Aqueous Extraction Feed (DF) } & \multicolumn{2}{|c|}{ Aqueous Strip Feed (EF) } & \\
\hline & As Prepared & As Measured & As Prepared & As Measured & \\
\hline $\mathrm{H}$ & 0.02 & 0.016 & 0.5 & 0.61 & $\mathbf{a}$ \\
\hline Nd & $3.42 \mathrm{E}-06$ & $2.08 \mathrm{E}-06$ & 0.0 & -- & b \\
\hline $\mathrm{Na}$ & 2.0 & 1.925 & 0.0 & -- & c \\
\hline HEDPA & 0.0 & -. & 0.05 & .- & d \\
\hline
\end{tabular}

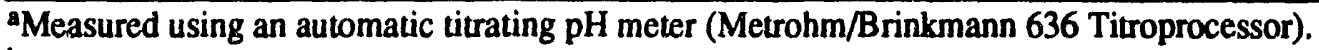

bMeasured value was suspect because ICP/AES error is high when the Nd concentration is low and the Na concentration is high. Because of this, the as-prepared Nd concentration was used in all calculations. As stated in the text, the planned Nd concentration in the DF feed was $2.88 \times 10^{-6} \mathrm{M}$. However, because of pipeting errors that were later identified and corrected, the as-prepared value (shown in this row) was higher.

cMeasured value from ICP/AES analysis. Error is $\pm 5 \%$.

${ }^{\mathrm{d}}$ HEDPA concentrations were not measured.

Table 10. Neodymium Concentrations in Organic Feed for Concentrator Test at O/A of 40

\begin{tabular}{ccc}
\hline $\begin{array}{c}\text { Residence } \\
\text { Time into Test }\end{array}$ & Method Used & Nd in \\
to Obtain Nd & Organic (DX) Feed, M \\
\hline 3.5 & Measured & $4.80 \mathrm{E}-05^{\mathrm{a}}$ \\
4.5 & Measured & $3.40 \mathrm{E}-05^{\mathrm{a}}$ \\
5.6 & Measured & $2.80 \mathrm{E}-05^{\mathrm{a}}$ \\
6.6 & Measured & $1.13 \mathrm{E}-05^{\mathrm{a}}$ \\
$\infty$ & Calculated & $6.3 \mathrm{E}-06^{\mathrm{b}}$ \\
\hline
\end{tabular}

arganic sample was taken from the stirred DX,EP beaker. Using some of the EF solution, the $\mathrm{Nd}$ was stripped from the organic phase. The resulting aqueous phase was analyzed for Nd using ICP/AES.

${ }^{b}$ Assumes steady-state operation with solvent recycle and extraction efficiencies as shown in Fig. 10. 
Table 11. Effluent Compositions for Concentrator Test at $\mathrm{O} / \mathrm{A}$ of 40

\begin{tabular}{|c|c|c|c|c|c|c|c|}
\hline \multirow[b]{2}{*}{ Comp. } & \multirow{2}{*}{$\begin{array}{c}\text { Res. } \\
\text { Time into } \\
\text { Test }^{\mathrm{a}}\end{array}$} & \multirow{2}{*}{$\begin{array}{l}\text { Method Used } \\
\text { to Obtain } \\
\text { Concn }\end{array}$} & \multicolumn{4}{|c|}{ Component Concentration, $\mathbf{M}$} & \multirow[b]{2}{*}{ Notes } \\
\hline & & & DW & $\mathrm{DP}$ & EW & EP & \\
\hline \multirow[t]{2}{*}{$\mathbf{H}$} & 6.6 & Measured & 0.040 & -- & 0.28 & -. & b \\
\hline & & Calculated & 0.038 & -- & 0.191 & -. & c \\
\hline \multirow[t]{7}{*}{ Nd } & 3.5 & Measured & -- & $5.46 \mathrm{E}-05$ & $1.24 \mathrm{E}-04$ & $3.09 \mathrm{E}-05$ & d \\
\hline & 4.5 & Measured & -- & $4.98 \mathrm{E}-05$ & $1.20 \mathrm{E}-04$ & 2.31E-04 & d \\
\hline & & Calculated & 4.5E-07e & $3.5 \mathrm{E}-05^{f}$ & $1.85 E-048$ & 2.95E-05 h & i \\
\hline & 5.6 & Measured & $3.24 \mathrm{E}-07^{\mathrm{j}}$ & 3.87E-05 & $7.60 \mathrm{E}-05$ & 2.05E-05 & d \\
\hline & 6.6 & Measured & $2.99 \mathrm{E}-07^{j}$ & $3.29 \mathrm{E}-05$ & 8.80E-05 & 1.82E-05 & d \\
\hline & $\infty$ & Calculated & 1.72E-07 & 5.9E-06 & 3.3E-05 & 4.9E-06 & $\mathbf{k}$ \\
\hline & Equil. & Measured & $4.41 \mathrm{E}-07^{\mathrm{j}}$ & 4.47E-05 & $1.49 \mathrm{E}-04$ & $1.81 \mathrm{E}-05$ & d, 1 \\
\hline \multirow[t]{6}{*}{$\mathbf{N a}$} & 3.5 & Measured & -- & $-\infty$ & 0.448 & -. & d \\
\hline & 4.5 & Measured & -- & -- & 0.439 & -- & d \\
\hline & 5.6 & Measured &.- & -- & 0.431 & - & d \\
\hline & 6.6 & Measured & -. & -- & 0.428 & -- & d \\
\hline & $\infty$ & Calculated & -- & -- & 0.437 & -- & $\mathbf{m}$ \\
\hline & Equil. & Measured & $\cdots$ & -- & 0.435 & - & $d, 1$ \\
\hline
\end{tabular}

${ }^{\mathrm{a}}$ Except as noted.

${ }^{b}$ Measured using an automatic $\mathrm{pH}$ meter.

'Assumes extraction efficiency is $100 \%$ at steady state with solvent recycle as shown in Fig. 10.

dExcept as noted, measured values are from ICP/AES analysis of the aqueous phase. For organic samples, the Nd was stripped from the organic phase using some of the EF solution and the resulting aqueous phase was analyzed.

eResidence time for this calculated value is close to 4.5 residence times

fActual residence time for this calculated value would be close to 6.3. It takes 1.3 residence times for the DP sample to emerge from the sampling systern and 1.0 residence times to collect it.

8 Actual residence time for this calculated value would be close to 6.0. It takes 1.0 residence times for the EW sample to emerge from the contactor stage and 1.0 residence times to collect the sample.

h Actual residence time for this calculated value would be close to 4.6. It takes about 0.1 residence time for the EP solvent to emerge from stage 2 after it has entered stage 1 as the DX solvent.

iValues shown here are results of calculations given in Fig. 11. Details of the Excel worksheet used to do this calculation are given in the Appendix. It assumes that (1) DX has the concentration measured 4.5 res idence times into the run, (2) the organic feed is not recycled with respect to the $\mathrm{Nd}$, and (3) the stage efficiencies are as shown in the figure.

jMass spectrometric isotope dilution analysis used for this sample.

kAssumes steady-state operation with solvent recycle for extraction efficiencies shown on Fig. 10.

'Concentrations when the two phases from each stage were equilibrated. Since the O/A flow ratios were not the same as those used in the test, these values should only be used to get the $D$ value for $N d$ in the respective stages.

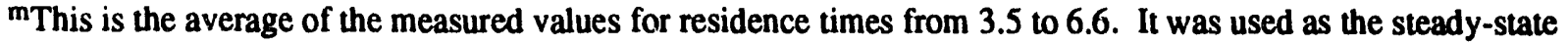
value at full solvent recycle and $100 \%$ extraction efficiency to calculate the amount of aqueous phase in organic phase going from stage 1 to stage 2 shown in Fig. 10.

To determine what the steady-state concentrations would have been, an Excel worksheet named Two_Stage was set up. If (organic) recycle is specified in the worksheet, iteration proceeds to steady-state operation and the flowsheet shown in Fig. 10 is obtained. This flowsheet is a part of the Two_Stage worksheet. In this worksheet, the extraction 
User Input Area for Flows (All valwes in this area are entered by the user)

$\mathrm{qDW}(\mathrm{mL} / \mathrm{min})=144.5 \quad \mathrm{qDP}(\mathrm{mL} / \mathrm{min})=3.53 \quad$ Aq. phase in org. phase from stage $1=0.614 \%$

qEP $(\mathrm{mL} / \mathrm{min})=388.3 \quad$ qEW $(\mathrm{mL} / \mathrm{min})=11.85$

Calculational Area (Only underlined oalwes are entered by user)

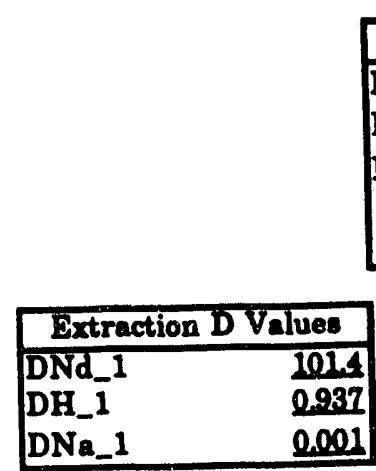

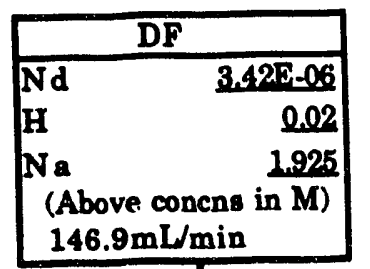

\begin{tabular}{|lr|}
\hline \multicolumn{2}{|c|}{ DP } \\
\hline $\mathrm{Nd}$ & $7.55 \mathrm{E}-06$ \\
$\mathrm{H}$ & 0.035 \\
$\mathrm{Na}$ & $1.92 \mathrm{E}-03$ \\
(Above concns in $\mathrm{M}$ ) \\
3.53 $\mathrm{mL} / \mathrm{min}$
\end{tabular}
$3.53 \mathrm{~mL} / \mathrm{min}$

\begin{tabular}{|lr|}
\hline \multicolumn{2}{|c|}{ EF } \\
\hline $\mathrm{Nd}$ & 0 \\
$\mathrm{H}$ & 0.5 \\
$\mathrm{Na}$ & 0 \\
(Above concns in $\mathrm{M})$ \\
\multicolumn{2}{|c|}{$9.5 \mathrm{~mL} / \mathrm{min}$} \\
\hline
\end{tabular}

Extraction Efficiency (stage 1) = 0.967

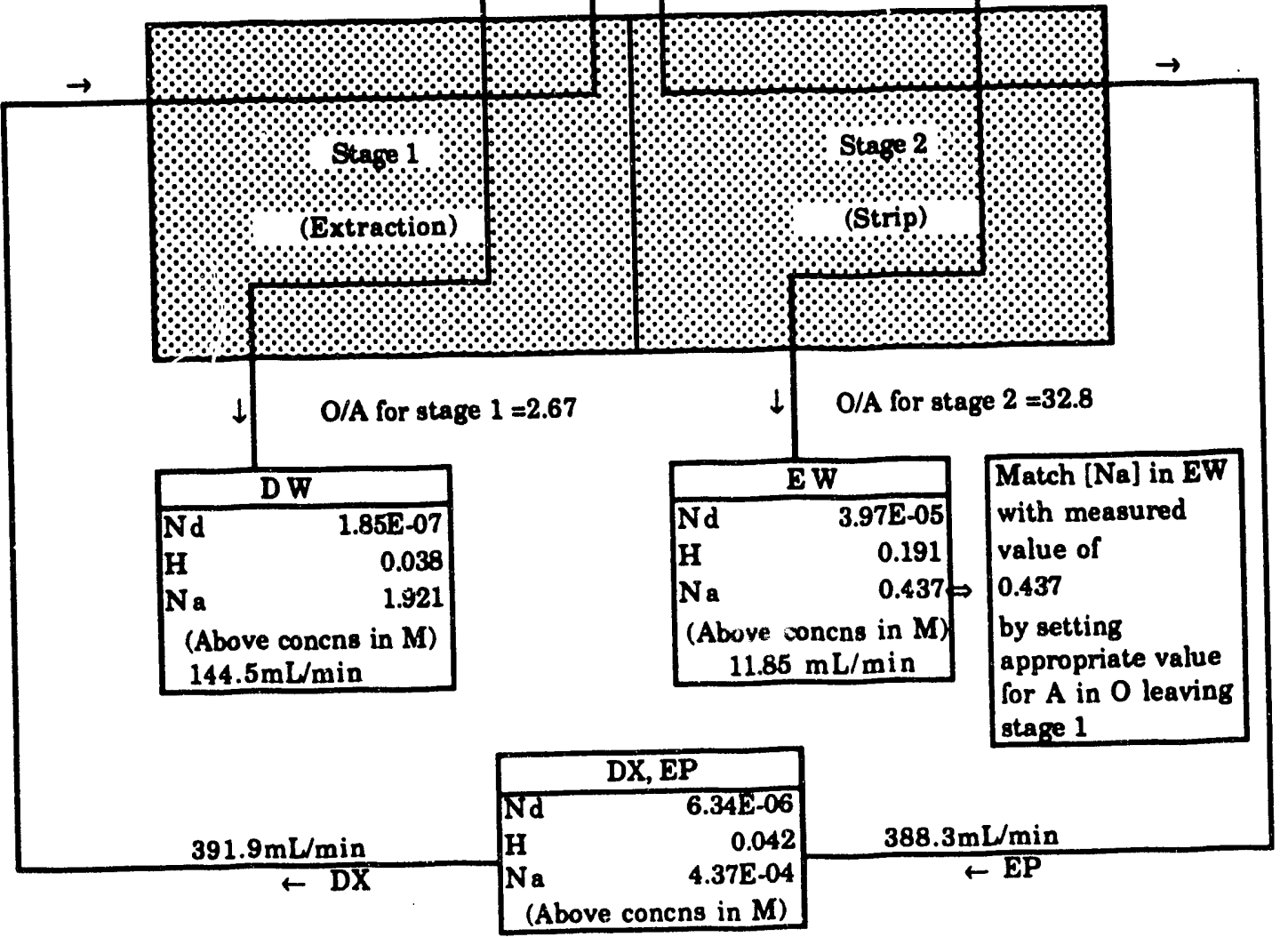

Recycle_Nd yes If "no", use [Nd] in DX given below. If "yes", see DX, EP box above. [Nd] in DX if "no" recycle $\overline{3.40 E-05}$

Fig. 10. Flowsheet for the Two-Stage Concentrator Test with Solvent Recycle

efficiency for $\mathrm{H}$ and $\mathrm{Na}$ is assumed to be $100 \%$, the value for neodymium is as specified in the worksheet. Note that $\mathrm{D}$ values have to be supplied by the user for $\mathrm{H}, \mathrm{Na}$, and $\mathrm{Nd}$ in both stages. Further information on the Two_Stage worksheet is given in the Appendix. 
Thus, at steady state with full organic recycle, the neodymium concentration in the DX feed should have gone down to $6.3 \times 10^{-6} \mathrm{M}$ (see Fig. 10), less than half of what it was when the test ended. The initial concentration of neodymium in the DX feed was not measured, but the results in Table 10 suggest that this concentration was above $4.8 \times 10^{-5} \mathrm{M}$, possibly by a factor of 2 to 4 . In Table 11, one can see that the neodymium concentrations of the DW, DP, and EP effluents are still decreasing to their steady-state values after 6.6 residence times. (The fact that the neodymium concentrations in EW are not also decreasing will be discussed later.) Based on the steady-state residence times with full solvent recycle shown in Fig. 10 and listed in Table 11 as calculated neodymium concentrations for a residence time of infinity, it appears that the neodymium concentrations in the various effluents would have to drop by an additional factor of 2 to 5 before steady-state operation would be reached.

As shown in Table 11, the $\mathrm{H}$ and $\mathrm{Na}$ concentrations readily reached steady state. The measured and calculated steady-state concentrations for $\mathrm{H}$ are essentially the same after 6.6 residence times into the run. The measured $\mathrm{Na}$ concentrations are essentially the same after 3.5 residence times into the run and agree with the equilibrated $\mathrm{Na}$ concentration. The reason for this difference between $\mathrm{Nd}$ and $\mathrm{H}$ and $\mathrm{Na}$ is shown by their $\mathrm{D}$ values. The $\mathrm{D}$ values for neodymium are such that (1) essentially all the Nd goes into the organic phase in stage 1 and (2) only $60 \%$ of the Nd is removed from the organic phase on any given pass of the organic phase through stage 2. Because of their D values, any excess ' ' in the recycled organic phase is removed in stage 1 , and $\mathrm{Na}$ is removed easily from both stages.

\section{Distribution Ratio Values}

The $\mathrm{D}$ values used to get the calculated coric trations given in Table 11 are shown in Fig. 10. The $D_{\mathrm{Nd}}$ values for stages 1 and 2 were determined using the rieasured equilibration concentrations for DP with DW and EP wirh EW, respectively, shown in Table 11. The $D_{H}$ values were estimated using the Generic TRUEX Model that was developed at ANL. Note that the GTM does not include any effect for the HEDPA that is in stage 2. The $D_{\mathrm{Na}}$ values re low and were first estimated to be 0.001 . Al such low $D_{\mathrm{Na}}$ váiues, other-phase carryover becomes important in determining the amount of $\mathrm{Na}$ in the aqueous effluent from stage 2. Next, we discuss how this fact is used to calculate the amount of aqueous phase in the organic phase going from stage 1 to stage 2.

\section{Calculated Elow Rates}

The four flow rates measured during this test are given in Table 6 and shown in the User Input Area of Fig. 10. From the measured organic flow rates for DP and EP, the organic flow rate for DX is calculated directly and the result is shown on the flowshret. Using the measured aqueous flow rates for DW and EW, as well as the Na concentration in EW, the aqueous flow rates for $\mathrm{DF}$ and $\mathrm{EF}$ are calculated along with the amount of aqueous phase in the organic phase from stage 1 going to stage 2 , or $f_{o, 1}$. The trial-and-error solution was set up in the Two_Step worksheet. The amount of $\mathrm{f}_{\mathrm{o}, 1}$ was varieul until the calculated $\mathrm{Na}$ concentration in EW matched the measured value. These results are also shown in Fig. 10.

Note that because $0.614 \%$ of the organic phase going to stage 2 was aqueous phase carried over from stage 1 , the actual flow ratio in stage 2 was 32.8 rither than the planned value of 40 . This fraction of other-phase carryover, while within the design limits for the 
4-cm contactor, is more than twice that predicted by the pretests used to estimate this value.

\section{Quasi-Steady State}

When extraction efficiencies were calculated for stage 2 in the two-stage concentrator test, it was assumed that the two-stage concentrator was at a quasi-steady state condition. To test this assumption for necdymium, the Two_Step worksheet was used with no solvent recycle, with the stage efficiencies as determined in the next section, and with the measured [Nd] value for $t_{\zeta}$ of 4.5. The calculated neodymium concentrations in the various effluents, shown in Fig. 11 and Table 11, are generally within a factor of two of the measured values, which are also shown in Table 11.

For the DW effluent, the calculated $[N d]$ value of $4.5 \times 10^{-7} \mathrm{M}$ is somewhat higher than the extrapolated measured value of $3.5 \times 10^{-7} \mathrm{M}$ (extrapolated back from measured DW values at $t_{T}$ 's of 5.6 and 6.6).

For the DP effluent, the calculated [Nd] value of $3.5 \times 10^{-5} \mathrm{M}$ is somewhat lower than the measured value of $5.0 \times 10^{-5} \mathrm{M}$ for this $t_{\mathrm{T}}$. However, as the time lag for the DP effluent is about two $\zeta_{\zeta}$ 's, the more appropriate measured value would be $3.3 \times 10^{-5} \mathrm{M}$ (from $t_{T}$ of 6.6 ), which agrees well with the calculated value.

For the EW effluent, the calculated neodymium concentration of $1.85 \times 10^{-4} \mathrm{M}$ is somewhat higher than the measured value of $1.20 \times 10^{-4} \mathrm{M}$ for this residence time. However, as the time lag for the EW effluent is about $0.5 \mathrm{t}_{\mathrm{T}}$, the more appropriate measured value would be $9.8 \times 10^{-5} \mathrm{M}$, which deviates even more from the calculated value. Note that for the $\mathrm{EW}$ effluents, the neodymium concentrations are all above the $5.8 \times 10^{-5} \mathrm{M}$ limit set to prevent the for.ation of a neodymium salt precipitate with the aqueous-phase complexant, HEDPA. This maj be the canse of the erratic values for the neodymium concentration in EW, the only case where the [Nd] does not clearly drop as $t_{t}$ increases.

For the EP effluent, the calculated [Nd] value of $2.95 \times 10^{-5} \mathrm{M}$ is somewhat higher than the measured value of $2.3 \times 10^{-5} \mathrm{M}$. Since there is a time lag of only $0.1 \mathrm{t}$, this difference appears to be ieal. The slightly higher value of the calculated neodymium concentration shows the same trend that was seen for the DW and DP results.

\section{Extraction Efficiencies}

The extraction efficiencies for the stripping test were calculated in the same manner as for the extraction tests, that is, the ancunt of neodymium in the aqueous phase that was extracted (or stripped from the organic phase) is divided by the amount of neodymium in the aqueous phase that would have been extracted (or stripped from the organic phase) if the organic and aqueous phases had reached equilibrium (100\% extraction efficiency). Since YDX is no longer zero, Eqs. 10,12,13,15, and 16 are used. When using these equations as generic equations for any stage, $x_{D F}$ is the neodymium concentration in the aqueous phase (or phases) entering a stage, $x_{D X}$ is the concentration in the aqueous phase leaving a stage, $y_{D X}$ is the neodymium concentration in the organic phase entering a stage, $x_{D P}$ is the concentration in the organic phase leaving a stage, $D$ is the distribution ratio in the stage, and $R$ is the O/A flow ratio in the stage. 
For stage 1, fractional extraction efficiencies were calculated from Eqs. 15 and 16, using flow rates and concentrations in Tables 6,9,10, and 11 for residence times of 5.6 and 6.6. As expected, the results show that the extraction efficiency is greater than $95 \%$ for the Argonne centrifugal contactor when $\mathrm{O} / \mathrm{A}$ flow ratios are close to 1.0 (see Table 12). This extraction efficiency is relatively insensitive to changes in $x_{D F}$ because $D$ is high and $R$ is close to 1.0. Thus, if $x_{D F}$ had been the measured value of $2.08 \times 10^{-6} \mathrm{M}$, the average value for the fractional extraction efficiency shown in Table 12 would have been only slightly lower, i.e., $0.942 \pm 0.049$.

Table 12. Extraction Efficiencies in Stage 1 of the Two-Stage Concentrator Test

\begin{tabular}{cc}
\hline & Fractional \\
$\begin{array}{c}\text { Approx. Residence } \\
\text { Time into Test }\end{array}$ & $\begin{array}{c}\text { Extraction } \\
\text { Efficiency }\end{array}$ \\
\hline 5.6 & 0.996 \\
6.6 & 0.938 \\
& $0.967 \pm 0.0292$ \\
\hline
\end{tabular}

Standard deviation is shown for the average value.

For stage 2, the extraction efficiency is harder to determine because of the failure of the system to reach a true steady state and the uncertainty in some of the neodymium concentrations, especially the EW values. For this stage, the Two_Stage worksheet was used as shown in Fig. 11 with no solvent recycle, that is, we assumed quasi-steady state conditions in the two-stage contactor. Trial-and-error entries of the extraction efficiency for stage 2 were used to get the best fit for a specific effluent stream from stage 2 at a specific residence time. The results of these calculations, summarized in Table 13, show some degradation of the extraction efficiency at this high (33) O/A flow ratio. This degradation of extraction efficiency is similar to that seen at low $(0.01) \mathrm{O} / \mathrm{A}$ flow ratios.

\section{Correlation for Extraction Efficiency}

In this work, the ability of the ANL centrifugal contactor to act as a concentrating device was tested at very high and very low O/A flow ratios ( 33 and 0.01 ). The results are summarized in Table 14 and plotted in Fig. 12. It appears that contactor operation at these extreme O/A flow ratios ( $R$ ) is accompanied by some loss in the fractional extraction efficiency $\left(F_{\mathrm{e}}\right)$. This efficiency, which is $>95 \%$ for $\mathrm{O} / \mathrm{A}$ ratios close to 1.0 , drops down to about $80 \%$ for these extreme ratios. This drop in $\mathrm{F}_{\mathrm{e}}$ as $\mathrm{R}$ moves away from 1.0 (100\%) was correlated using an equation of the form

$$
F_{e, R}=F_{e, 1}\left(1-a\left|\log _{10} R\right|\right)
$$

where $a$ is the correlation constant, $F_{e, R}$ is the value of $F_{e}$ at an $O / A$ flow ratio of $R$, and $F_{e, l}$ is the value of $F_{e}$ when $R$ is 1.0. The value of $F_{e}$ when $R$ is 1.0 was estimated to be 0.986 from earlier measurements using uranium where the O/A flow ratios ranged from 0.5 to 2.5 [BERNSTEIN, CLARK, LEONARD-1980]. The constant a was then chosen so that the 
correlation goes through all the 1-a error bars and distributes the data points evenly above and below the curve. A value of 0.09 was found to work well. Thus, Eq. 18 becomes

$$
F_{c}=0.986\left(1-0.09\left|\log _{10} R\right|\right)
$$

which gives the correlation used in Fig. 12.

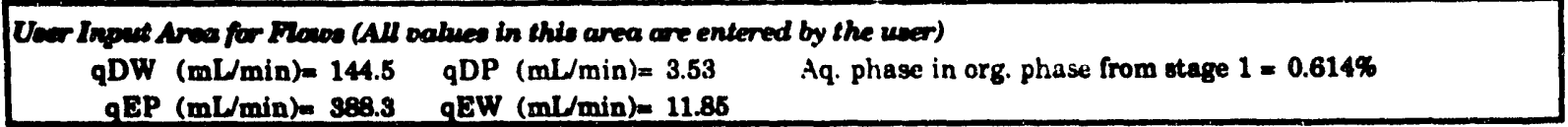
Calcalotional Aroe (Only underined volues are entered by waer)

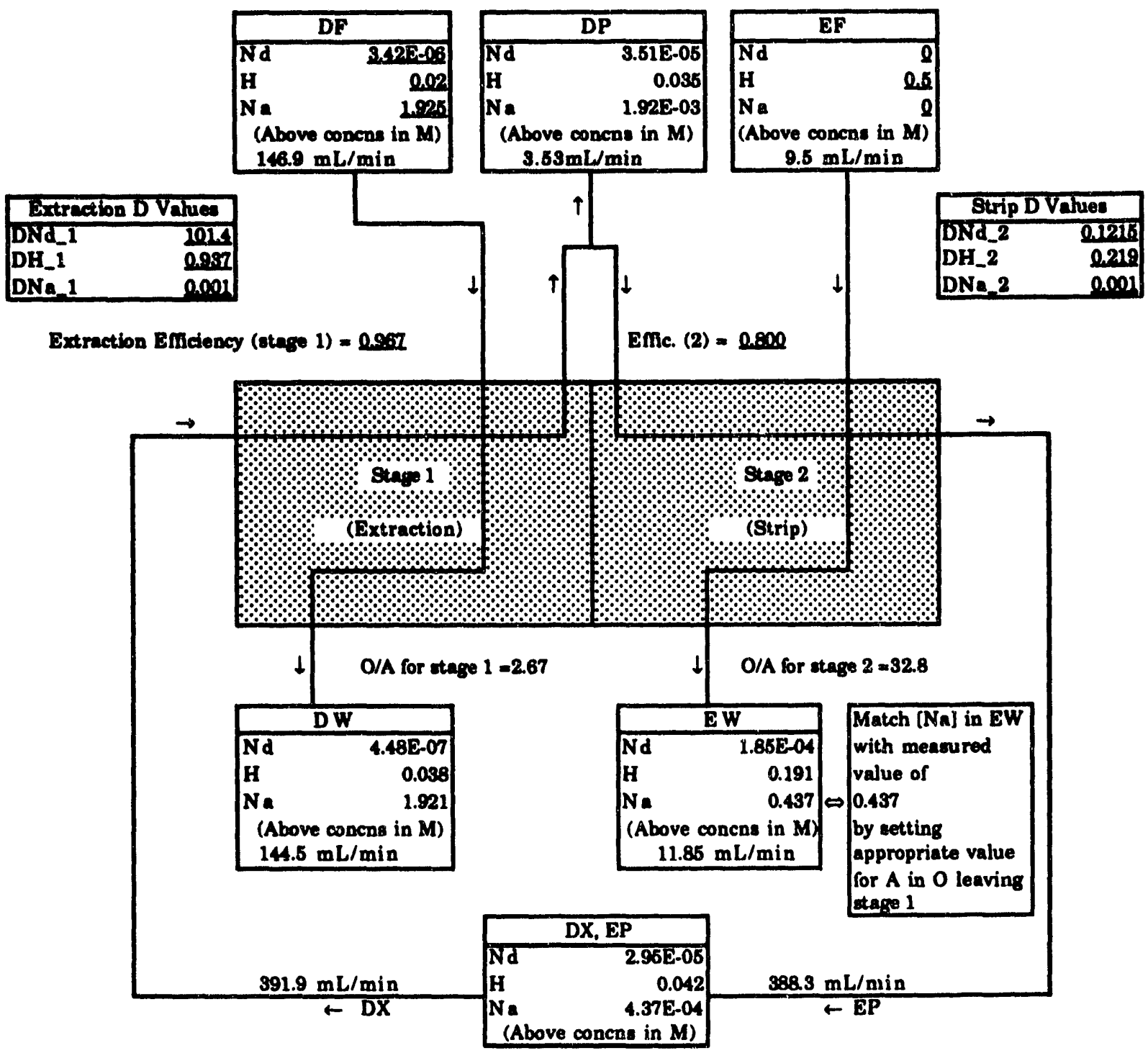

Recycle_Nd $\frac{\text { no }}{3.40 \mathrm{E}-05}$ If "no", use [Nd] in DX given below. If "yes", see DX, EP box above.
[Nd] in DX if "no" recycle

Fig. 11. Flowsheet for the Two-Stage Concentrator Test without Solvent Recycle. For this quasi-steady state flowsheet, the neodymium concentration in DX is $3.4 \times 10^{-5} \mathrm{M}$, which corresponds to a residence time of 4.5. 
Table 13. Extraction Efficiencies in Stage 2 of the Two-Stage Concentrator Test

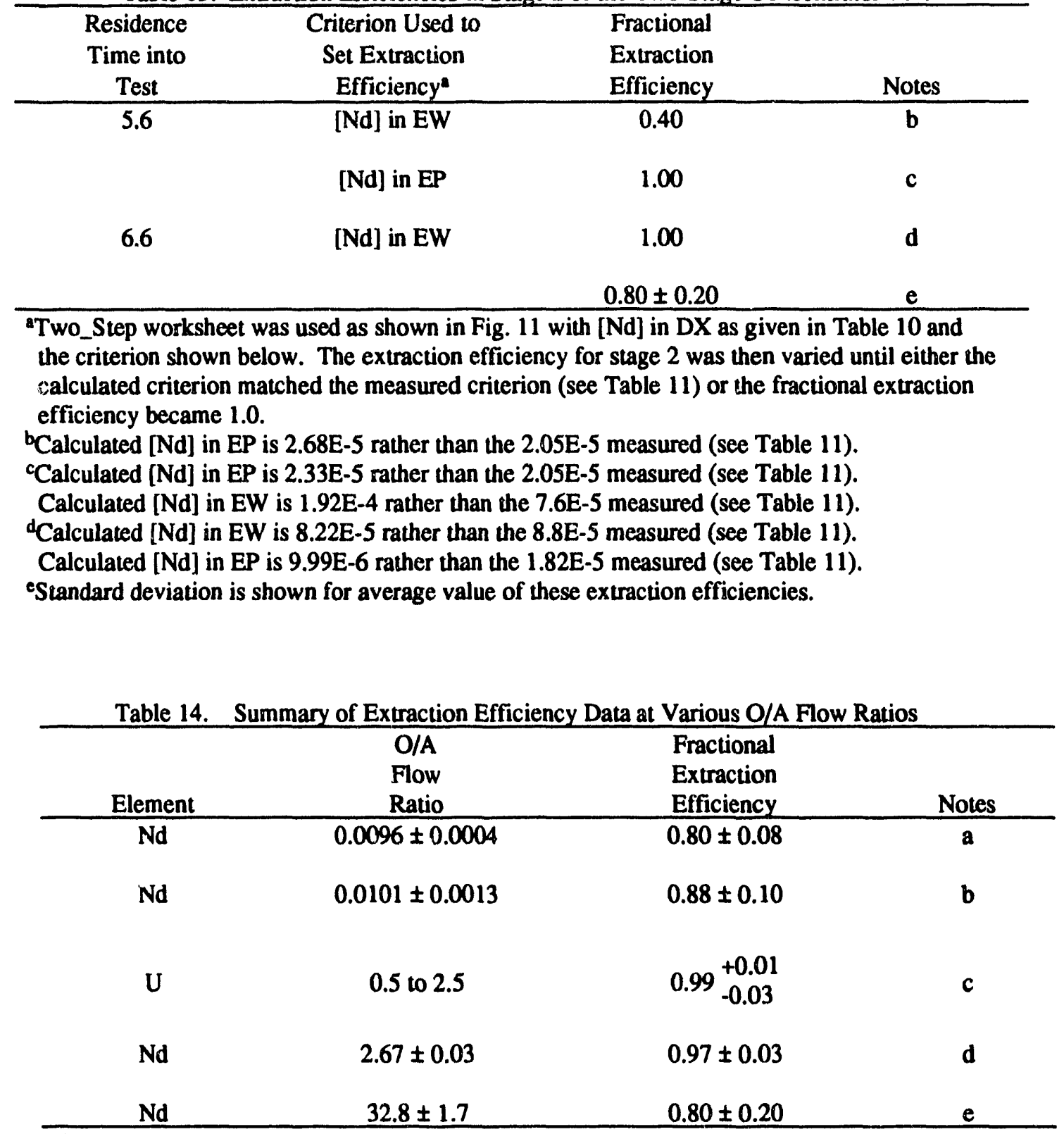

Composite of the three tests in the second test series at $\mathrm{O} / \mathrm{A}=0.01$.

${ }^{b}$ Composite of the three tests in the first test series at $\mathrm{O} / \mathrm{A}=0.01$.

'Extraction efficiency and error range were estimated from earlier measurements as discussed in the text. Most of these extraction efficiency measurements were made at an O/A of 1.0.

${ }^{d}$ Composite of two tests carried out while loading the solvent with neodymium for the high O/A flow ratio tests.

eComposite of two stripping iests. 


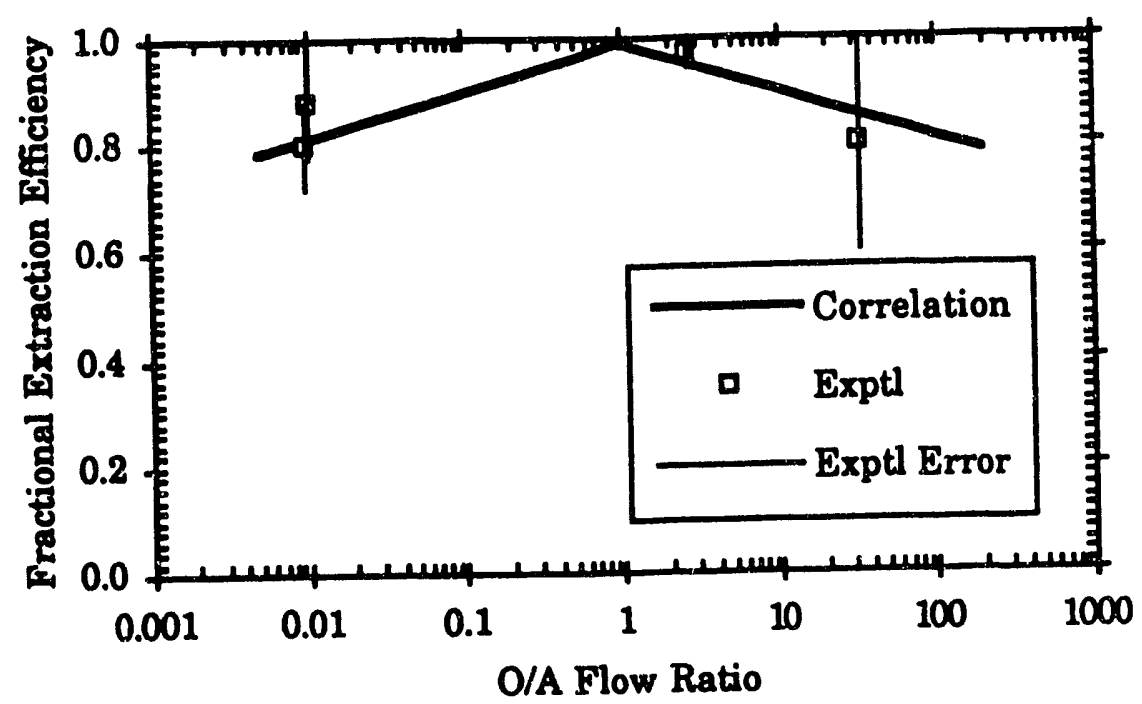

Fig. 12. Overall Correlation of O/A Flow Ratio with Extraction Efficiency 


\section{DISCUSSION}

\section{A. Effect of O/A Flow Ratio on Extraction Efficiency}

The results of our tests with the 4-cm contactor show that the extraction efficiency decreases when the O/A flow ratio is very high or very low. However, the decrease in extraction efficiency is relatively small, so that when evaluated using the results in the section on concentrator theory, concentrator operation in centrifugal contactors will still be quite good. As shown in Table 2 and Fig. 5, a concentrator is quite effective even when extraction efficiency is only $70 \%$, one of the lowest extraction efficiencies that we measured. Typically for this case, additional contactor stages would be required to meet a specific process goal. In some cases, an O/A flow ratio with a slightly less favorable concentrating effect might also be required. Note that based on the results in Table 8, there appears to be no strong dependence of extraction efficiency on the total flow rate through the contactor.

Using the 4-cm contactor to evaluate the contactor as a concentrator represents a balance between the various factors that become important as contactor size changes. Because the contactor was relatively small, it had the drawback of low flow rates. For example, at an O/A flow ratio of 0.01 , when the total flow was a maximum of $404 \mathrm{~mL} / \mathrm{min}$, the flow of the organic phase was a maximum of $4 \mathrm{~mL} / \mathrm{min}$. Thus, the organic phase entered the contactor in droplets controlled by the surface tension of the liquid in the feed line. This periodic and somewhat erratic flow rate can downgrade the extraction efficiency. However, the small size of the contactor also has two benefits. First, the volumes of liquid required are reasonable for a laboratory-scale test. Second, the contactor gives a worst-case value for any $F_{\mathrm{e}}$ that might be observed in an actual process plant. For the larger contactors in the plant, the low-flow phase would have a higher absolute flow, so its flow should be continuous. When this is the case, contactor operation could show an extraction efficiency higher than that given by Eq. 19. Thus, the use of Eq. 19 to determine the effect of the O/A flow ratio on extraction efficiency should result in a conservative process design, that is, in a design that has more stages than necessary and so will work even better than specified by the design criteria.

A way to improve extraction efficiency in a contactor stage would be to recycle the lowflow phase at each stage so that the actual O/A flow ratio in the stage is close to $100 \%$. If the low-flow phase is then pumped on to the next stage at the appropriate low flow rate, the overall $\mathrm{O} / \mathrm{A}$ flow ratio can be maintained at the desired very high or very low flow ratio. When this type of operation is carried out, the $\mathrm{F}_{\mathrm{e}}$ value for the stage should be close to $1.0(100 \%)$.

\section{B. Precipitate Formation}

We had to be careful when using HEDPA to strip neodymium from the organic phase to avoid forming a solid neodymium salt of HEDPA. As noted above, when we stripped neodymium from the organic phase using a solution of $0.05 \mathrm{M} \mathrm{HEDPA}_{\mathrm{A}}$ and $0.5 \mathrm{M} \mathrm{HNO}_{3}$, the solid neodymium salt of HEDPA formed if the neodymium concentration exceeded $5.8 \mathrm{x}$ $10^{-5} \mathrm{M}$.

The solubility of the neodymium salt of HEDPA was not determined for the extraction tests. In these tests, a solution consisting of $0.05 \underline{\mathrm{M}} \mathrm{HEDPA}$ and $0.1 \underline{\mathrm{M}} \mathrm{HNO}_{3}$, a low-acid HEDPA solution, was used to recover neodymium from the organic phase. Measured $D_{\mathrm{Nd}}$ 
values for this solution were $0.0051 \pm 0.0021$ for 10 samples in the first test series and 0.0057 \pm 0.0015 for the 10 samples in the second test series. An eleventh sample in the second test series gave a $D_{N d}$ value of 0.16 , a value much closer to that actually observed during the stripping test. In these tests with this low-acid HEDPA solution, the neodymium concentration in the aqueous phase after equilibration with the loaded organic phase was about $0.0020 \mathrm{M}$ $(0.0028 \mathrm{M}$ maximum) for the first test series and $0012 \mathrm{M}(0.0015 \mathrm{M}$ maximum) for the second test series. Thus, based on the $5.8 \times 10^{-5} \mathrm{M}$ solubility limit for Nd in $0.05 \mathrm{M}$ HEDPA with $0.5 \mathrm{M}$ $\mathrm{HNO}_{3}$, the low-acid HEDPA stripping after the extraction tests could also have been carried out above the solubility limit for neodymium. The solubility limit for this low-acid HEDPA solution was never determined, but white particles of the neodymium salt of HEDPA were found in organic phase after it had been stripped of neodymium using this solution. Because of this, only the aqueous phase concentrations were used to calculate extraction efficiency from the tests at the very low O/A flow ratios.

In general, if a component has a very high $D$ value when it is extracted, a very low $D$ value on stripping is unusual unless an aqueous-phase complexant can be found to bring the component back into the aqueous phase. When using a complexant, one has to evaluate (1) its contribution to the final aqueous composition and (2) the possibility that the complexant might form a solid precipitate with the component being stripped. Such a precipitate may not be bad if it can be recovered (e.g., by filtration) in such a way that the component concentration is reduced.

\section{Solids Concentrator}

Even though precipitate formation was a problem in the work reported here, it could be a boon to some processes where the amount of metal to be removed is very small. In that case, the aqueous strip solution could be completely recycled for each strip stage. A complexant would be used to precipitate the solid, which would be either (1) trapped in the rotor or (2) recycled with the aqueous complexant solution. Thus, the contactor would function as a solids concentrator.

After the first strip stage (i.e., the strip stage that first is exposed to the organic phase to be stripped) becomes loaded with particles, its rotor would be removed for cleaning. The second-stage rotor would be moved to the first stage, the third-stage rotor to the second stage, and so forth. Finally, the last stage would be given a clean rotor. In a similar fashion, the recycled stripping solution from the second stage would be moved to the first stage, the thirdstage stripping solution would be moved to the second stage, etc. Finally, the depleted stripping solution from the first stage would be recharged with the complexant, filtered to remove any precipitate, and returned to the last stage. Such a process would achieve the ultimate in concentration of the metal component, going from a very dilute concentration to a solid that is the metal salt of the complexant. Note that to make this process work, one would need to develop a contactor that can be cleaned easily and quickly, especially if the process is done in a glovebox or a fully remote facility. Another potential problem is the extraction of the complexant into the organic phase. Even if the amount of complexant extracted were low, its depletion could be of concern because of (1) complexant makeup costs and (2) complexant contamination of other effluents. 


\section{Additional Notes on Concentrator Design and Operation}

The basics of concentrator design and operation have been discussed in the section on concentrator theory. However, one practical matter is not discussed there, that is, the long time resyired to start up a concentrator. If the $\mathrm{O} / \mathrm{A}$ flow ratio is very high in the extraction section, tiven the centrifugal contactors for the stripping section should be smaller than those for the extraction section to reduce startup time. To have the concentrator working right from the outset, the low-flow phases should be introduced at a high flow on startup so that they fill properly all the concentrator stages. If this is done, the concentrator will be fully functional even though it is still in a startup mode. Each of the stages could then be put in the stripping section on full aqueous-phase recycle until the desired concentrating effect is reached. This would speed up the approach to steady state and insure that when the initial aqueous concentrate comes out, it is close to its steady-state concentration.

A second practical matter to consider in the design of a flowsheet for the concentrator is the solubility of the aqueous-phase complexant in the organic phase. Many complexants, such as $\mathrm{HF}$ and $\mathrm{H}_{2} \mathrm{C}_{2} \mathrm{O}_{4}$, have $\mathrm{D}$ values close to 1.0 so that a significant amount of the complexant can be carried out of the strip section in the organic phase. When this is the case, the complexant strip section should be designed to minimize this loss by feeding most of the complexant to the first strip stage.

\section{E. Extractant Recovery}

A special use of the concentrator would be to recover extractant from an aqueous effluent. This might be done because of the toxicity or high cost of the extractant. An organic diluent such as NPH, which has a low aqueous-phase solubility [YAWS], could be used as the organic phase in the extracting section of a concentrator to remove and concentrate the extractant. For this case, the stripping section of the concentrator would be replaced by a distillation column. This column would further concentrate the extractant in the NPH so that it could be recycled directly to the main process. The other column effluent would be the pure $\mathrm{NPH}$ that would be recycled as the organic feed to the extracting section of the concentrator. Because of the concentrating potential for such an extracting section, the size of the distillation column and the energy required would be relatively small.

\section{F. Euture Tests}

As noted above, the stripping test was at a quasi-steady state with respect to neodymium. By using the concentrations at specific residence times, a fair approximation to steady-state operation was realized so that it was possible to get a reasonable value for extraction efficiency. In future tests, this problem could be avoided by having a lower initial neodymium concentration in the organic solvent. This concentration should be less than that expected for the EP effluent at steady-state conditions. A higher initial neodymium concentration in DX would not have been so bad if neodymium had been more effectively removed at stage 2 . Based on some preliminary work, we had expected that the $D_{\mathrm{Nd}}$ value to be much lower than the value that we actually found $(0.005 \mathrm{vs.} 0.12)$. This higher-than-expected $D_{\mathrm{Nd}}$ value also resulted in the neodymium concentration in the EW samples being above the $5.8 \times 10^{-5} \mathrm{M}$ limit that we had established to prevent precipitation of the neodymium salt of HEDPA. Thus, any future test should be such that this concentration limit is not exceeded 
when $0.05 \mathrm{M}$ HEDPA is present. We recommend staying below the $5.8 \times 10^{-5} \mathrm{M}$ limit by a factor of 10 or more. In addition, similar tests should be carried out with radionuclides so that concentrations could be measured directly in both the organic and aqueous phases. 


\section{CONCLUSIONS}

The ability of the ANL centrifugal contactor to act as a concentrating device for solvent extraction processes was demonstrated over a wide range of O/A flow ratios, from 0.01 to 33 . Over this range, we found that extraction efficiency in the contactor stays high enough that good concentrator operation can be realized. A correlation was developed for the effect of the $\mathrm{O} / \mathrm{A}$ flow ratio on the extraction efficiency.

We developed a theoretical model to facilitate the design of contactors operating as concentrators. Calculations with this model showed that such a concentrating process can tolerate significant ot r-phase carryover in the low-flow phase. As a rule of thumb, the overall concentrating factor for a balanced design is given by $\sqrt{\frac{D_{\text {extr }}}{D_{\text {strip }}}}$ for a component that has a distribution coefficient of $D_{\text {extr }}$ in the extraction section and $D_{\text {strip }}$ in the strip section.

The concentrator can be applied to dilute feed streams so that the final process feed has a much smaller volume and process costs are reduced accordingly. It can also be applied to the concentration of process effluents so that the need for further processing, such as concentration by water evaporation, is greatly reduced or eliminated. It can also be used to concentrate and recover contaminants from groundwater. Finally, the contactor concentrator can be used to recover extractants and other organics from aqueous effluents.

\section{ACKNOWLEDGMENTS}

The funding for the TRUEX Technology-Base Development Program is being provided by the Waste Research and Development Division, Office of Defense Waste and Transportation Management, DOE-HQ. In past years, this program has been funded by the Defense HighLevel Waste Technology Program, DOE-Richland, and by the Materials Processing Division, Office for Nuclear Materials, DOE-HQ.

The authors wish to acknowledge the efforts of E. A. Huff, who did the ICP/AES analyses, A. M. Essling and E. G. Rauh, who did the MSID analyses, and Jennifer Tomczuk, a summer student from the University of Chicago, who did many of the $\mathrm{pH}$ measurements. 


\section{REFERENCES}

\section{BERNSTEIN}

G. J. Bernstein, D. E. Grosvenor, J. F. Lenc, and N. M. Levitz, "A High-Capacity Annular Centrifugal Contactor," Nucl. Technol. 20, 200-202 (1973).

\section{CHIARIZIA}

R. Chiarizia and E. P. Horwitz, "Secondary Cleanup of TRUEX Process Solvent," Solvent Extr. Ion Exch. 8, 907-941 (1990).

\section{CLARK}

A. T. Clark, Performance of a 10-inch Centrifugal Contactor, Savannah River Laboratory Report DP-752 (1962).

HORWITZ

E. P. Horwitz, D. G. Kalina, H. Diamond, G. F. Vandegrift, and W. W. Schulz, "The TRUEX Process--A Process for the Extraction of the Transuranium Elements from Nitric Acid Wastes Utilizing Modified PUREX Solvent," Solvent Extr. Ion Exch. 3, 75-109 (1985).

LEONARD-1980

R. A. Leonard, G. J. Bernstein, A. A. Ziegler, and R. H. Pelto, "Annular Centrifugal Contactors for Solvent Extraction," Sep. Sci. Technol. 15, 925-943 (1980).

LEONARD-1985

R. A. Leonard, G. F. Vandegrift, D. G. Kalina, D. F. Fischer, R. W. Bane, L. Burris, E. P. Horwitz, R. Chiarizia, and H. Diamond, The Extraction and Recovery of Plutonium and Americium from Nitric Acid Waste Solutions by the TRUEX Process-Containing Development Studies, Argonne National Laboratory Report ANL-85-45 (1985).

LEONARD-1987

R. A. Leonard, "Use of Electronic Worksheets for Calculation of Stagewise Solvent Extraction Processes," Sep. Sci. Technol. 22, 535-556 (1987).

LEONARD-1988

R. A. Leonard, "Recent Advances in Centrifugal Contactor Design," Sep. Sci. Technol. 23, 1473-1487 (1988). 
LEONARD- 1990

R. A. Leonard, M. C. Regalbuto, D. B. Chamberlain, and G. F. Vandegrift, "A New Model for Solvent Extraction in Columns," Sep. Sci. Technol. 25, 1689-1707 (1990).

MARCUS

Y. Marcus and A. S. Kertes, Ion Exchange and Solvent Extraction of Metal Complexes, Wiley-Interscience, New York (1969).

\section{RITCEY}

G. M. Ritcey and A. W. Ashbrook, Solvent Extraction: Principles and Applications to Process Metallurgy, Part I, Elsevier, Amsterdam (1984).

\section{SCHULZ}

W. W. Schulz, The Chemistry of Americium, U.S. Energy Research and Development Administration Report TID-26971 (1976).

\section{VANDEGRIFT}

G. F. Vandegrift, R. A. Leonard, M. J. Steindler, E. P. Horwitz, L. J. Basile, H. Diamond, D. G. Kalina, and L. Kaplan, Transuranic Decontamination of Nitric Acid Solutions by the TRUEX Solvent Extraction Process--Preliminary Development Studies, Argonne National Laboratory Report ANL-84-45 (1984).

\section{YAWS}

C. L. Yaws, H.-C. Yang, J. R. Hopper, and K. C. Hansen, "232 Hydrocarbons: Water Solubility Data," Chem. Eng. 90 (4), 177-182; (5), 8 (1990). 


\section{APPENDIX}

\section{DETAILS OF THE Two_Stage WORKSHEET}

The Excel worksheet, called Two_Stage, was used in this report to generate Figs. 10 and 11. The complete worksheet, which was set up in Fig. 10, is shown here with values displayed in Figs. 13-15. Areas of the worksheet that have formulas are printed out with formulas displayed in Figs. 16-21. In all cases, the cells were made wide enough to display the entire formula. Note that some formulas use names to reference various cells or cell groups. The names used in the Two_Stage worksheet and the cells they refer to are listed in Table 15. 


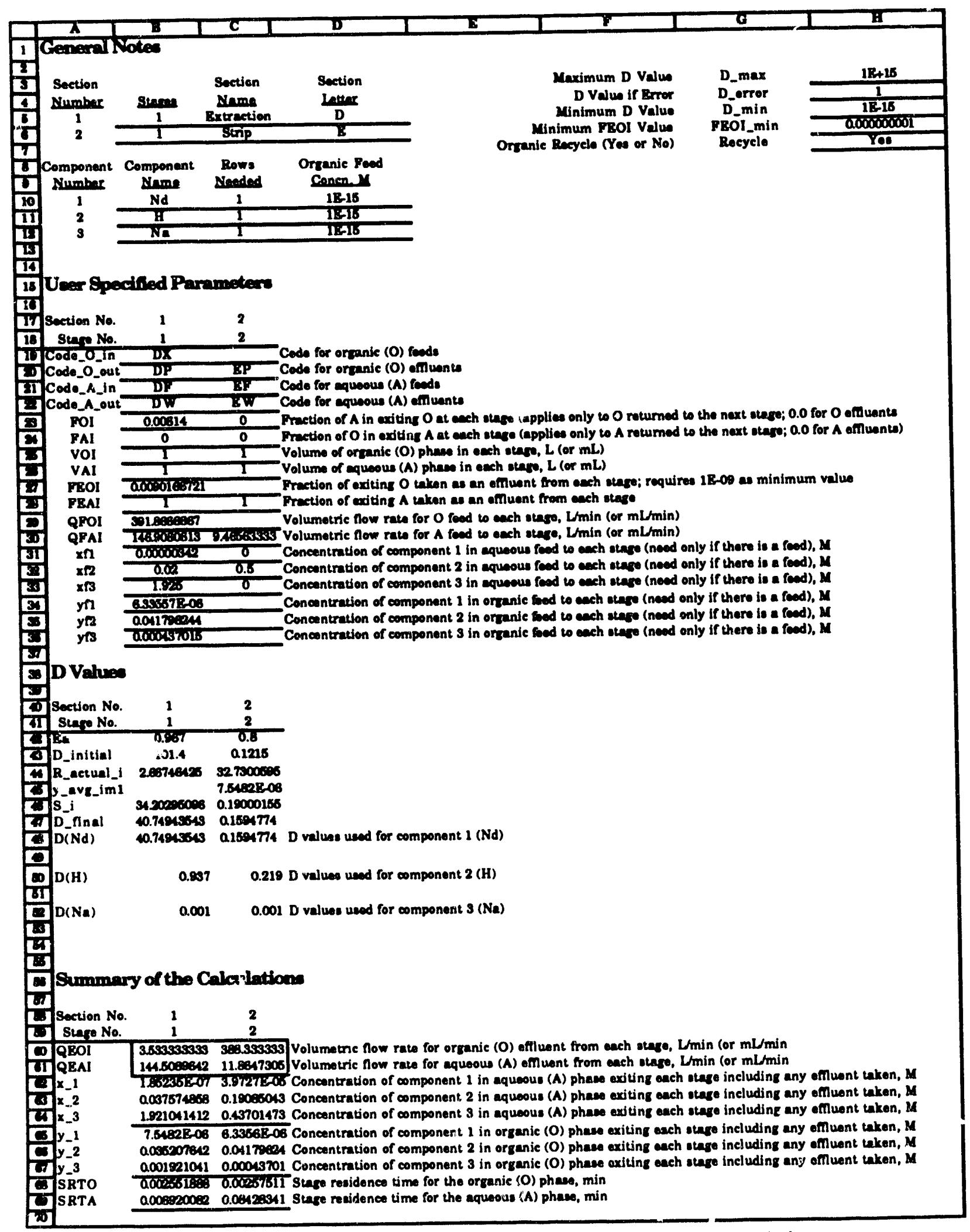

Fig. 13. Input and Summary Areas of the Two_Stage Worksheet 


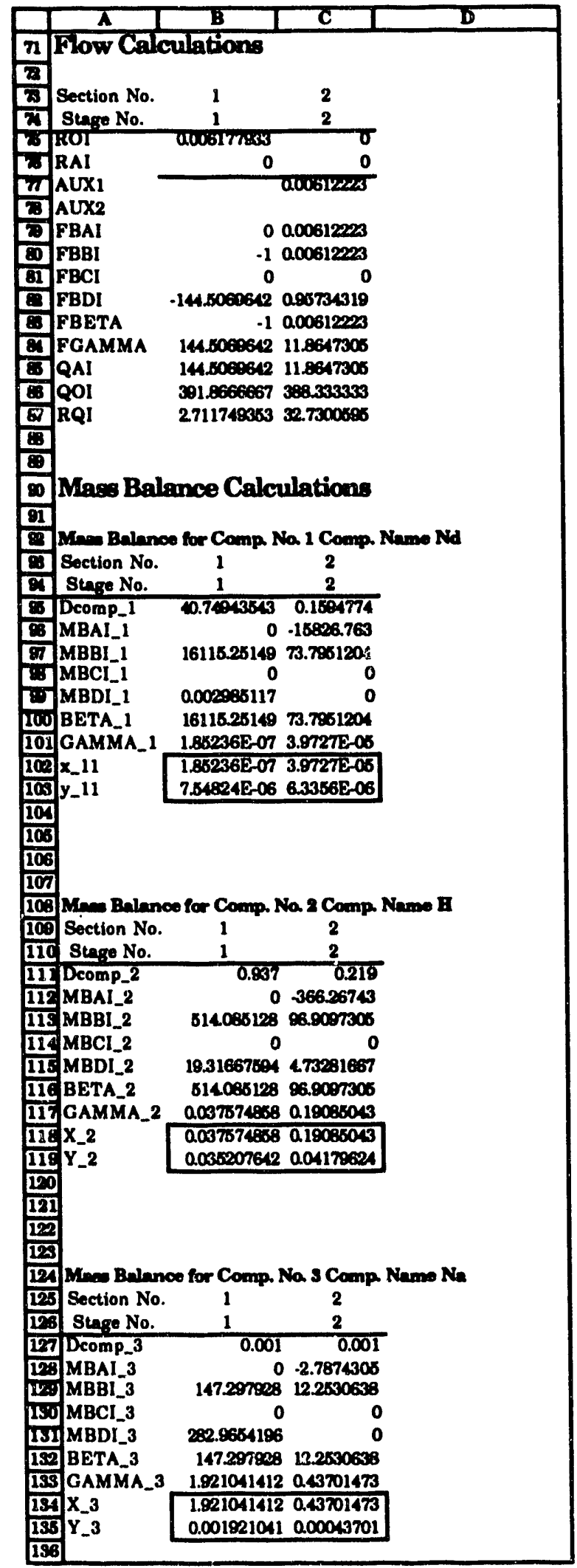

Fig. 14. Calculation Area of the Two_Stage Worksheet 


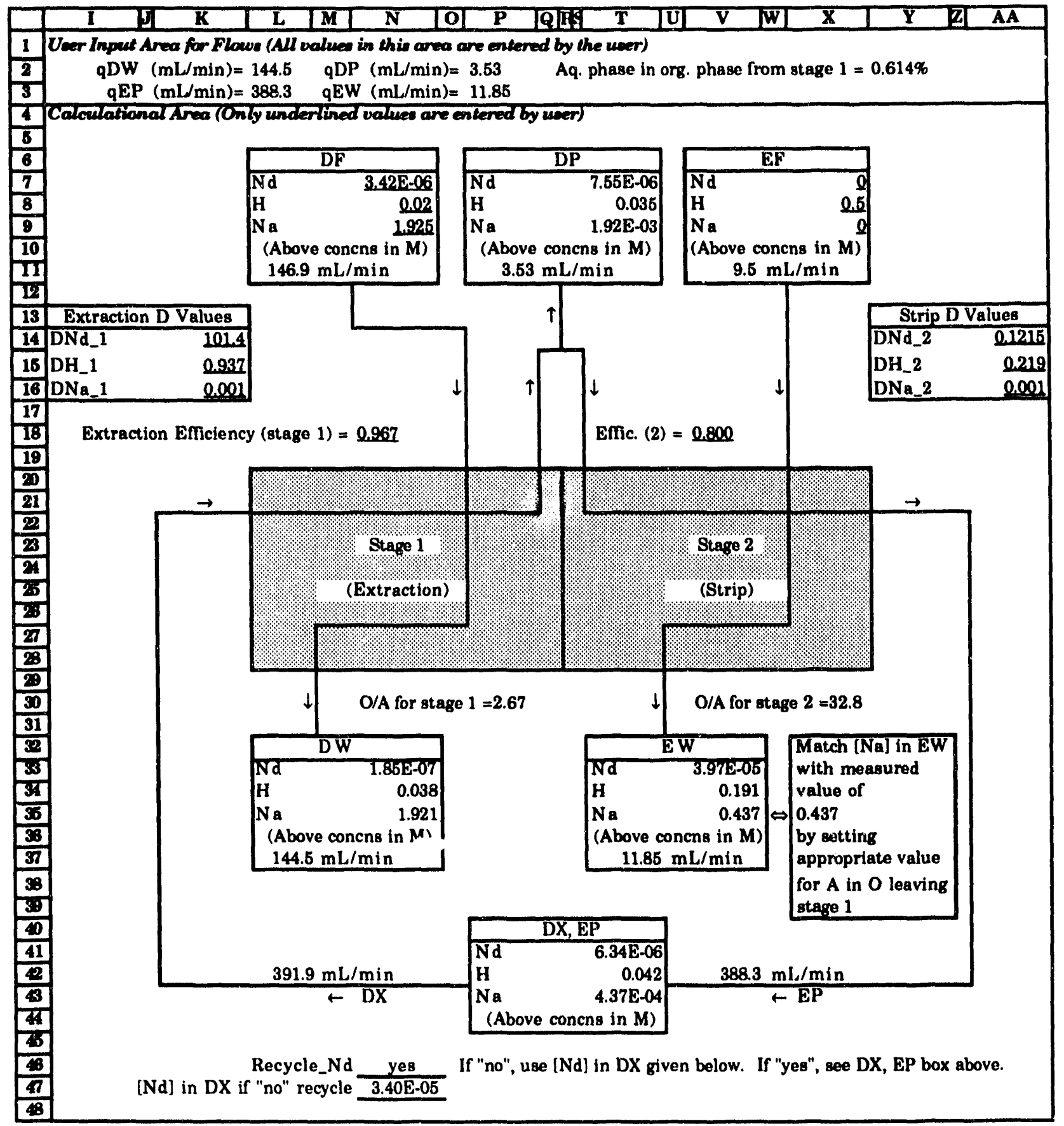

Fig. 15. Flowsheet Area of the Two_Stage Worksheet 


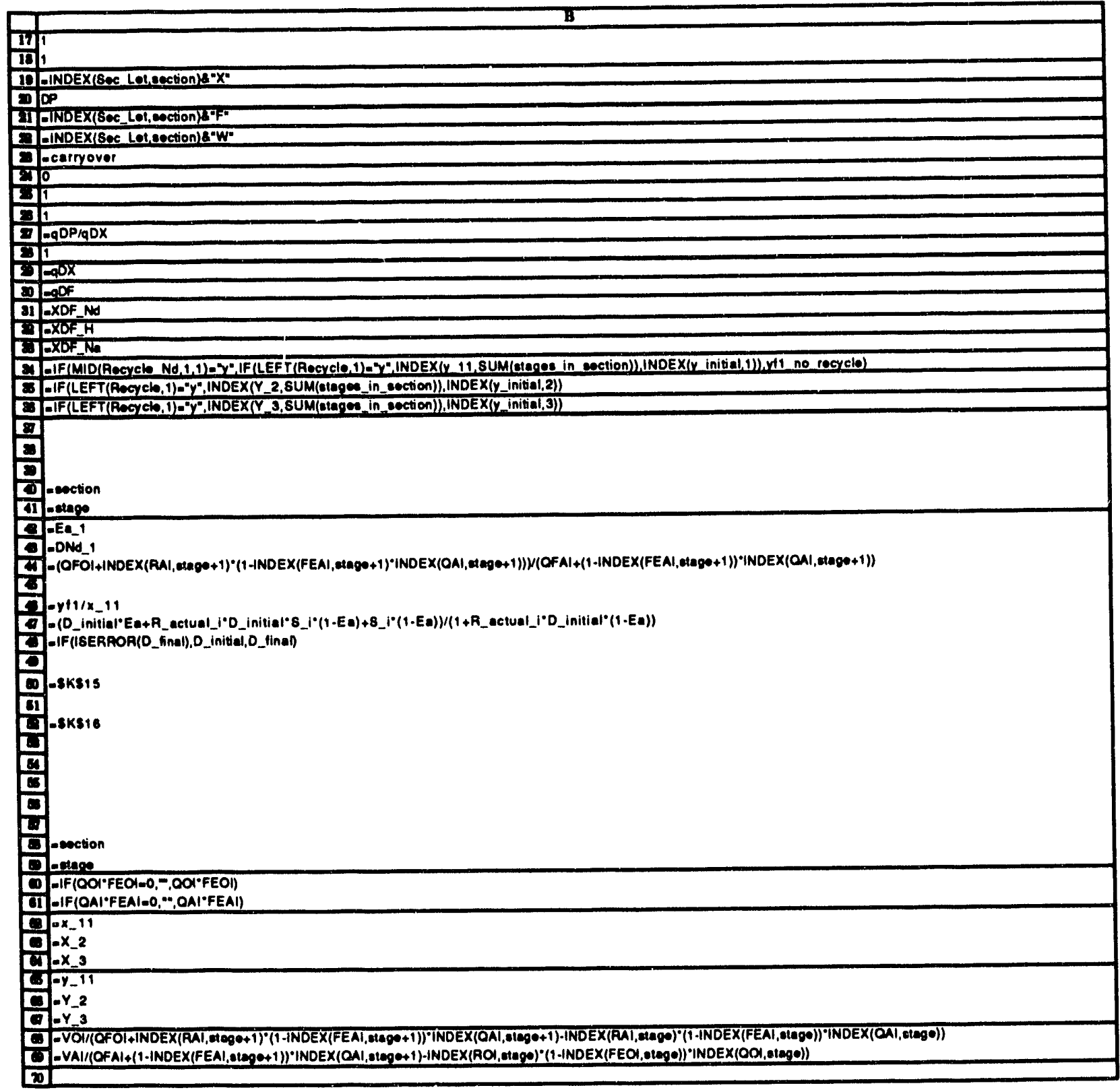

Fig. 16. Formulas for Top Part of Stage 1 in the Two_Stage Worksheet 


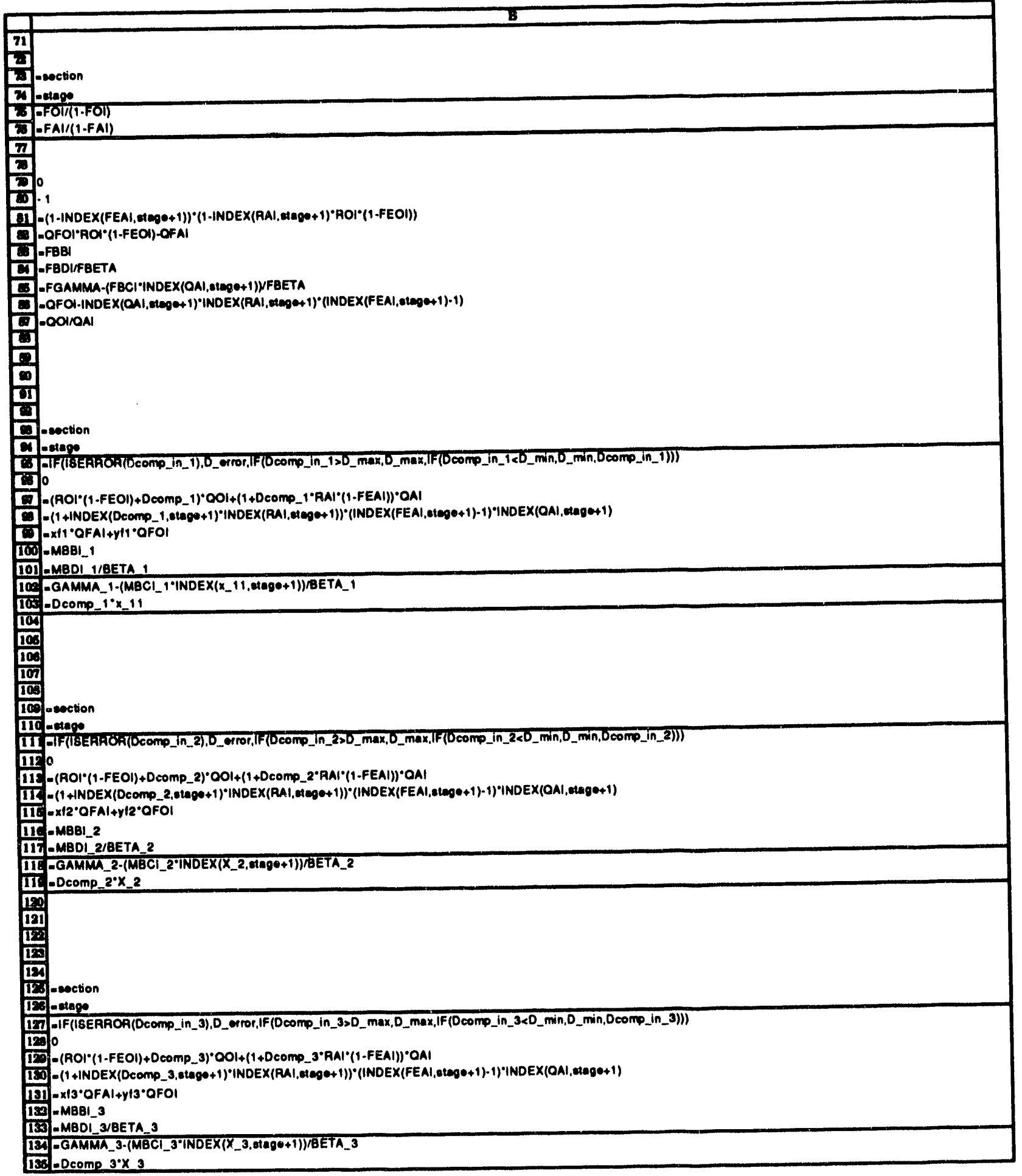

Fig. 17. Formulas for Bottom Part of Stage 1 in the Two_Stage Worksheet 


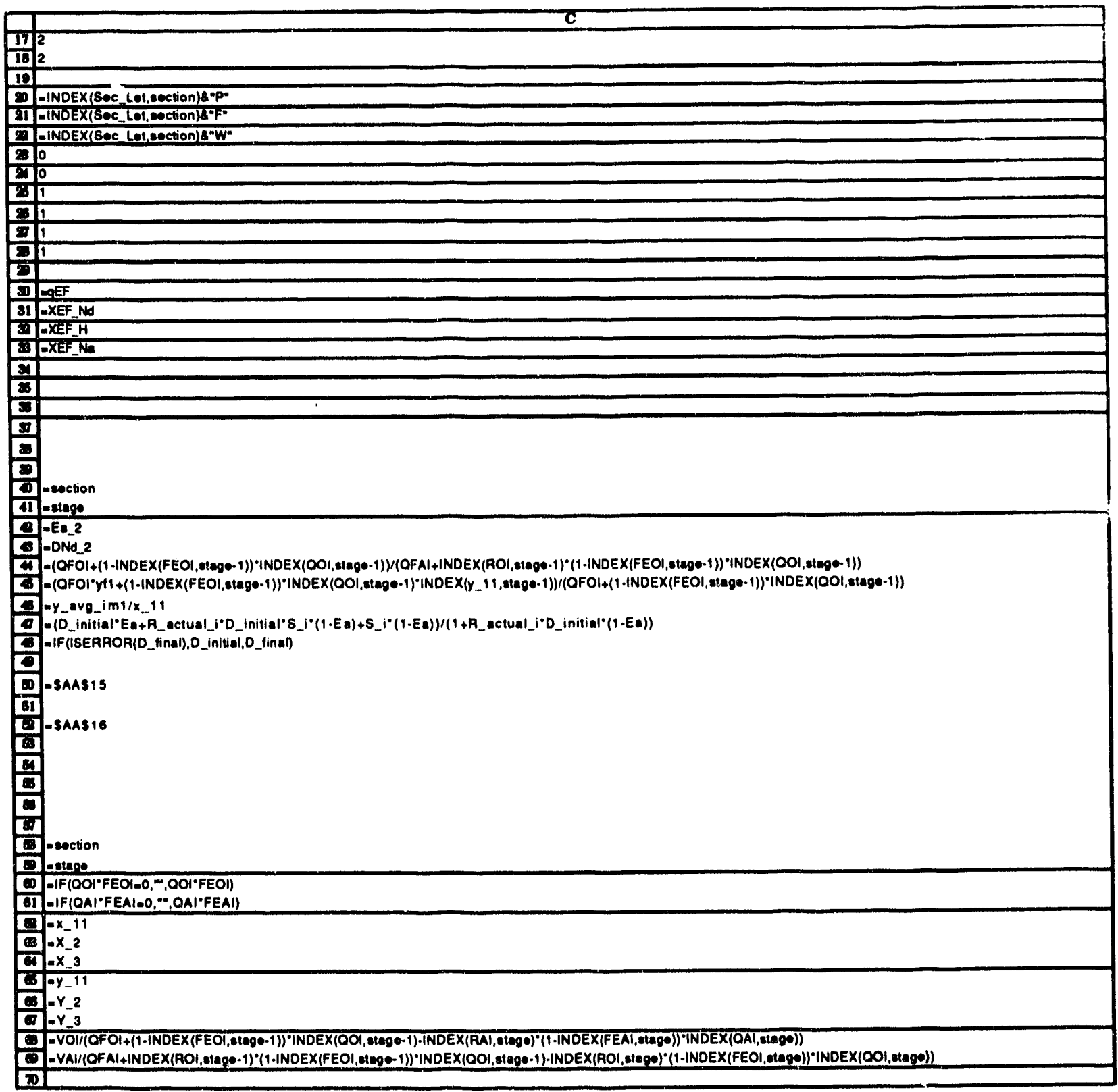

Fig. 18. Formulas for Top Part of Stage 2 in the Two_Stage Worksheet 


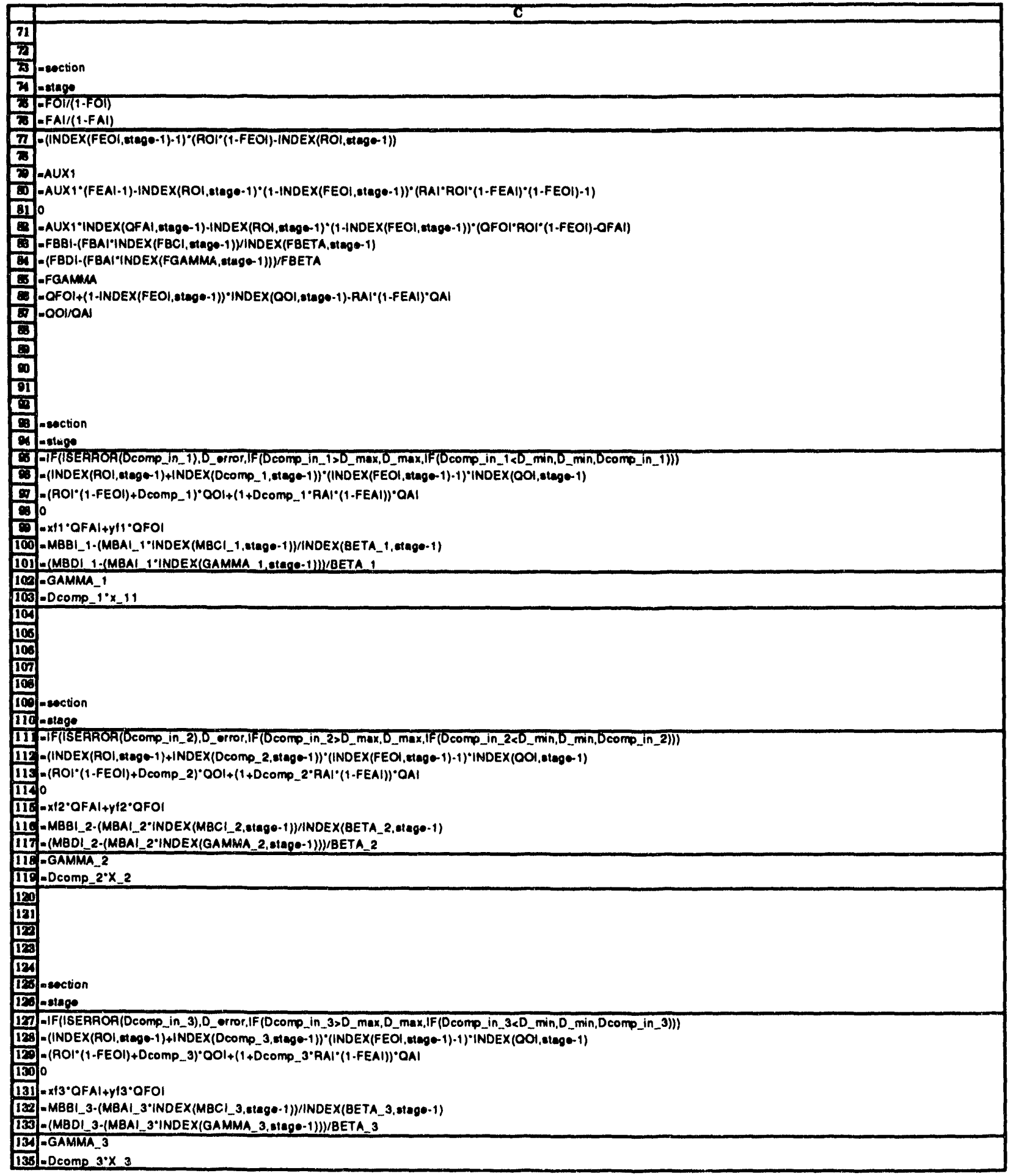

Fig. 19. Formulas for Bottom Part of Stage 2 in the Two_Stage Worksheet 


\begin{tabular}{|c|c|c|c|}
\hline & $\mathbf{F}$ & $\mathbf{G}$ & $\mathbf{H}$ \\
\hline 3 & Maximum D Value & D_max & 1000000000000000 \\
\hline 4 & $D$ Value if Error & D_error & $=$ SQRT(D_max*D_min) \\
\hline$\overline{5}$ & Minimum D Value & D_min & 0.000000000000001 \\
\hline 6 & Minimum FEOI Value & FEOOI_min & 0.000000001 \\
\hline 7 & Organic Recycle (Yes or No) & Recycle & Yes \\
\hline
\end{tabular}

Fig. 20. Formula for Limit Section of the Two_Stage Worksheet 


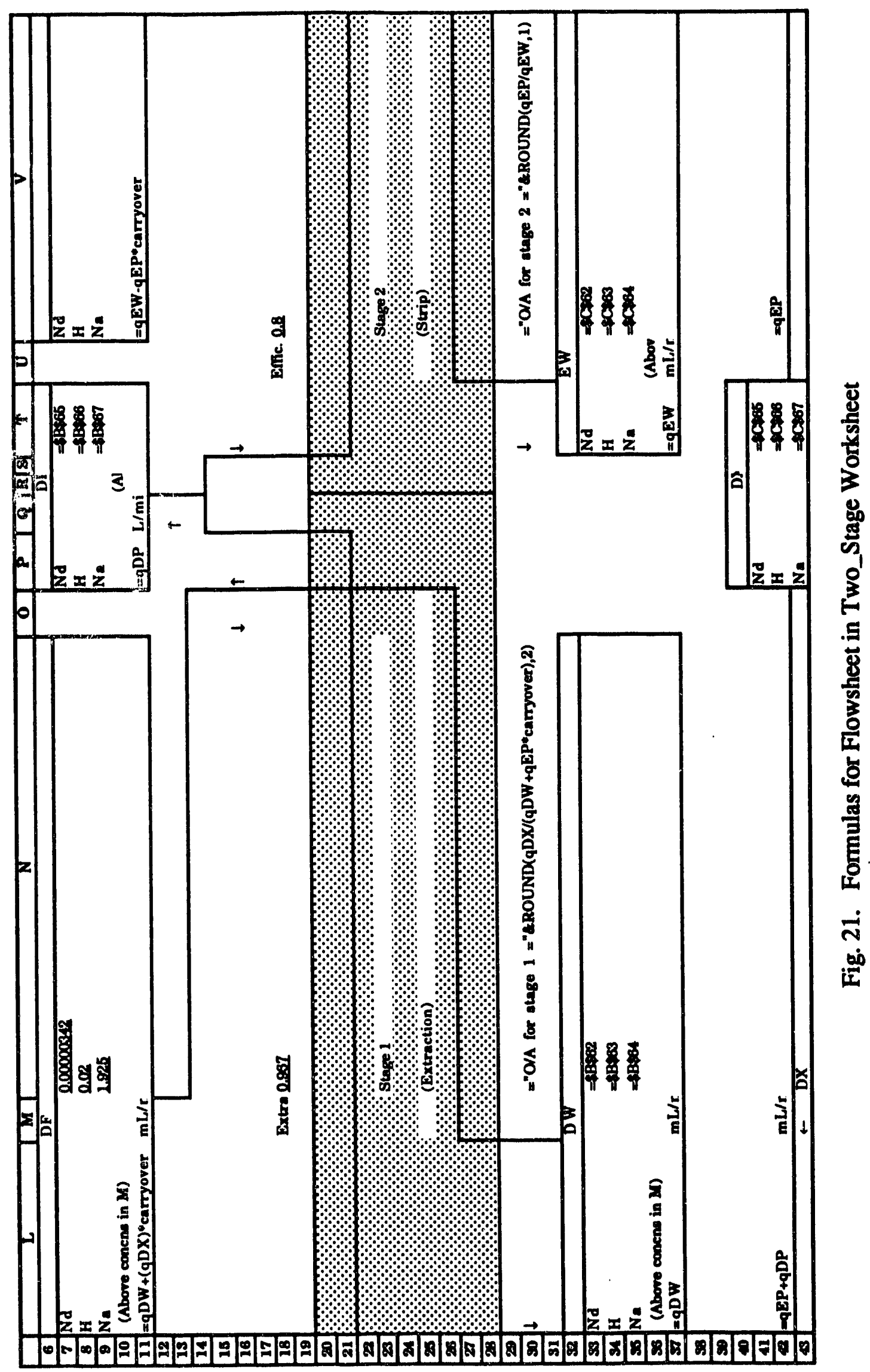



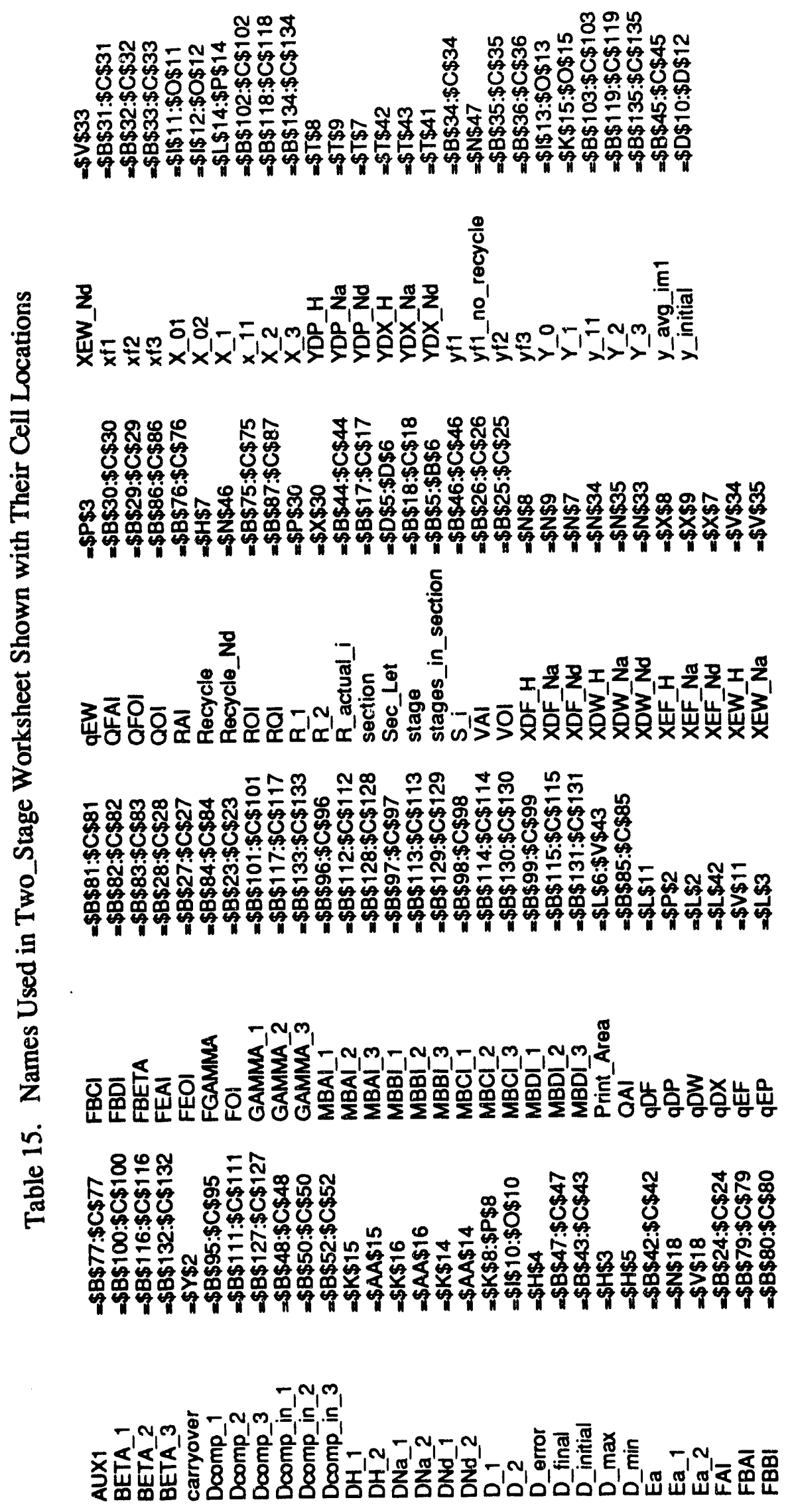
Distribution for ANL-92/26

Internal:

J. E. Battles (2)

D. B. Chamberlain

C. J. Conner

J. M. Copple

J. E. Harmon

J. C. Hutter
R. A. Leonard (10)

L. Nunez

M. C. Regalbuto

J. Sedlet

B. Srinivasan

M. J. Steindler
C. E. Till

G. F. Vandegrift (10)

D. G. Wygmans

ANL Patent Dept.

TIS Files

\section{External:}

DOE-OSTI, for distribution per UC-721 (483)

ANL-E Library (2)

ANL-W Library

Manager, Chicago Field Office, DOE

Chief, DOE-CH Patent Group

J. C. Haugen, DOE-CH

Chemical Technology Division Review Committee Members:

S. Baron, Brookhaven National Laboratory, Upton, NY

D. L. Douglas, Consultant, Bloomington, MN

N. Jarrett, Noel Jarrett Associates, Lower Burrell, PA

J. G. Kay, Drexel University, Philadelphia, PA

J. Stringer, Electric Power Research Institute, Palo Alto, CA

J. B. Wagner, Arizona State University, Tempe, AZ

R. G. Wymer, Consultant, Oak Ridge, TN

R. P. Anantatmula, Westinghouse Hanford Co., Richland, WA

J. A. Appel, Westinghouse Hanford Co., Richland, WA

M. Attrep, Jr., Los Alamos National Laboratory, Los Alamos, NM

S. Barker, Westinghouse Hanford Co., Richland, WA

G. S. Barney, Westinghouse Hanford Operations, Richland, WA

L. Beach, Rockwell International, Golden, $C O$

J. T. Bell, Oak Ridge National Laboratory, Oak Ridge, TN

C. L. Bendixsen, Westinghouse Idaho Nuclear Co., Idaho Falls, ID

J. D. Berger, Westinghouse Hanford Co., Richland, WA

B. C. Blanke, USDOE, Miamisburg, $\mathrm{OH}$

A. Bolt, Westinghouse Hanford Co., Richland, WA

W. D. Bond, Oak Ridge National Laboratory, Oak Ridge, TN

K. Boomer, Westinghouse Hanford Co., Richland, WA

D. F. Bowersox, Los Alamos National Laboratory, Los Alamos, NM

J. L. Burnett, USDOE, Office of Basic Energy Sciences, Germantown, MD

M. A. Cahill, Westinghouse Hanford Co., Richland, WA

D. Catlett, Los Aiamus National Laboratory, Los Alamos, NM 
K. A. Chacey, USDOE, Office of Waste Management, Germantown, MD

C. E. Coffey, Westinghouse Savannah River Co., Aiken, SC

E. D. Collins, Oak Ridge National Laboratory, Oak Ridge, TN

P. Colton, Battelle Pacific Northwest Laboratory, Richland, WA

C. R. Cooley, USDOE, Office of Technology Development, Germantown, MD

M. S. Coops, Lawrence Livermore National Laboratory, Livermore, CA

M. Dinehart, Los Alamos National Laboratory, Los Alamos, NM

L. P. Duffy, USDOE, Environmental Restoration \& Waste Management, Washington, DC

W. R. Dworzak, Los Alamos National Laboratory, Los Alamos, NM

G. Escobar, Westinghouse Hanford Co., Richland, WA

C. W. Frank, USDOE, Office of Technology Development, Washington, DC

W. A. Freeby, Westinghouse Idaho Nuclear Co., Idaho Falls, ID

J. C. Fulton, Westinghouse Hanford Operations, Richland, WA

T. E. Gates, Westinghouse Hanford Co., Richland, WA

R. E. Gerton, USDOE, Richland Operations Office, Richland, WA

K. A. Giese, Westinghouse Hanford Co., Richland, WA

R. Gilchrist, Westinghouse Hanford Co., Richland, WA

A. P. Gouge, Westinghouse Savannah River Co., Aiken, SC

F. R. Graham, Westinghouse Savannah River Co., Aiken, SC

K. Hain, USDOE, Office of Technology Development, Germantown, MD

H. D. Harmon, Westinghouse Savannah River Co., Aiken, SC

J. M. Hennig, USDOE, Richland Operations Office, Richland, WA

M. E. Hodges, Westinghouse Savannah River Co., Aiken, SC

G. W. Hogg, Westinghouse Idaho Nuclear Co., Inc., Idaho Falls, ID

T. M. Hohl, Westinghouse Hanford Co., Richland, WA

J. Holmes, Westinghouse Hanford Co., Richland, WA

J. O. Honeyman, Westinghouse Hanford Operations, Richland, WA

L. J. Jardine, Lawrence Livermore National Laboratory, Livermore, CA

J. J. Jicha, USDOE, New Production Department, Washington, DC

R. T. Jubin, Oak Ridge National Laboratory, Oak Ridge, TN

G. Kosiancic, Westinghouse Hanford Co., Richland, WA

D. Krenz, USDOE, Albuquerque Operations Office, Albuquerque, NM

C. M. Kronvall, Westinghouse Hanford Operations, Richland, WA

D. E. Kurath, Pacific Northwest Laboratory, Richland, WA

R. Lambert, Electric Power Research Institute, Palo Alto, CA

K. London, Rockwell International, Golden, $\mathrm{CO}$

Los Alamos National Laboratory, Director, Los Alamos, NM

R. Y. Lowrey, USDOE, Albuquerque Operations Office, Albuquerque, NM

G. J. Lumetta, Pacific Northwest Laboratory, Richland, WA

R. Maher, Westinghouse Savannah River Co., Aiken, SC

J. C. Mailen, Oak Ridge National Laboratory, Oak Ridge, TN

A. Malinauskas, Oak Ridge National Laboratory, Oak Ridge, TN

D. L. McIntosh, Westinghouse Savannah River Co., Aiken, SC

W. H. McVey, USDOE, Division of LMFBR Fuel Cycle Projects, Germantown, MD

G. A. Meyer, Westinghouse Hanford Co., Richland, WA

E. Michaels, Mound Facility, Monsanto Research Corp., Miamisburg, OH 
A. C. Muscatello, Los Alamos National Laboratory, Los Alamos, NM

M. O'Hara, Martin Marietta Energy Systems, Oak Ridge, TN

Office of Basic Energy Sciences, USDOE, Washington, DC

A. L. Olson, Westinghouse Idaho Nuclear Co., Inc., Idaho Falls, ID

R. M. Orme, Westinghouse Hanford Co., Richland, WA

M. Palmer, Los Alamos National Laboratory, Los Alamos, NM

J. H. Pashley, Oak Ridge Gaseous Diffusion Plant, Oak Ridge, TN

G. Pfennigworth, Martin Marietta Energy Systems, Oak Ridge, TN

C. R. Reichmuth, Westinghouse Hanford Co., Richland, WA

D. J. Reif, Westinghouse Savannah River Co., Aiken, SC

G. W. Rosenwald, USDOE, Richland Operations Office, Richland, WA

W. G. Ruff, Westinghouse Hanford Co., Richland, WA

W. A. Rutherford, USDCE, Richland Operations Office, Richland, WA

P. S. Schaus, Westinghouse Hanford Co., Richland, WA

M. J. Schliebe, Westinghouse Hanford Operations, Richland, WA

P. Scott, Pacific Northwest Laboratory, Richland, WA

V. Sendelweck, Rockwell International, Golden, CO

E. Slaathug, Westinghouse Hanford Co., Richland, WA

J. P. Sloughter, Westinghouse Hanford Co., Richland, WA

W. H. Smith, Los Alamos National Laboratory, Los Alamos, NM

F. D. Stevenson, USDOE, Office of Basic Energy Sciences, Germantown, MD

J. Straalsund, Pacific Northwest Laboratory, Richland, WA

J. L. Swanson, Pacific Northwest Laboratory, Richland, WA

D. W. Tedder, Georgia Institute of Technology, Atlanta, GA

M. Thompson, Westinghouse Savannah River Co., Aiken, SC

T. A. Todd, Westinghouse Idaho Nuclear Co., Inc., Idaho Falls, ID

J. C. Tseng, USDOE, Office of Waste Operations, Germantown, MD

D. A. Turner, Westinghouse Hanford Co., Richland, WA

V. C. A. Vaughn, Oak Ridge National Laboratory, Oak Ridge, TN

J. Watson, Oak Ridge National Laboratory, Oak Ridge, TN

M. E. Whatley, Oak Ridge National Laboratory, Oak Ridge, TN

B. R. Wheeler, Westinghouse Idaho Nuclear Co., Inc., Idaho Falls, ID

G. Wilson, Westinghouse Hanford Operations, Richland, WA

D. D. Wodrich, Westinghouse Hanford Co., Richland, WA

J. C. Womack, Westinghouse Hanford Co., Richland, WA

S. Yarbro, Los Alamos National Laboratory, Los Alamos, NM

D. Yearwood, Los Alamos National Laboratory, Los Alamos, NM 

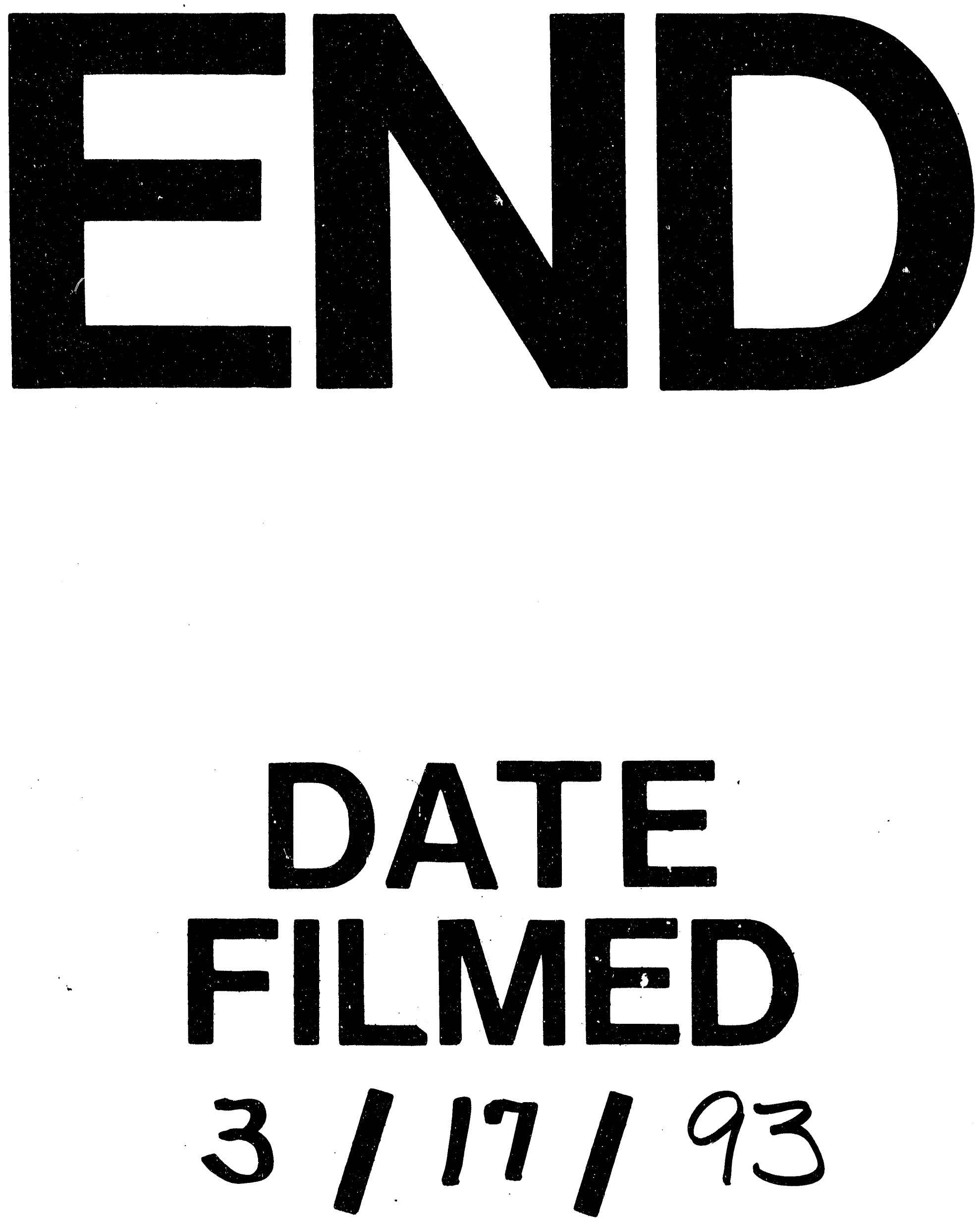